THE APPLICATION OF SINGLE

PARTICLE AEROSOL MASS

SPECTROMETRY FOR THE

DETECTION AND IDENTIFICATION OF

HIGH EXPLOSIVES AND CHEMICAL

WARFARE AGENTS

A. Martin

November 28, 2006 
This document was prepared as an account of work sponsored by an agency of the United States Government. Neither the United States Government nor the University of California nor any of their employees, makes any warranty, express or implied, or assumes any legal liability or responsibility for the accuracy, completeness, or usefulness of any information, apparatus, product, or process disclosed, or represents that its use would not infringe privately owned rights. Reference herein to any specific commercial product, process, or service by trade name, trademark, manufacturer, or otherwise, does not necessarily constitute or imply its endorsement, recommendation, or favoring by the United States Government or the University of California. The views and opinions of authors expressed herein do not necessarily state or reflect those of the United States Government or the University of California, and shall not be used for advertising or product endorsement purposes.

This work was performed under the auspices of the U.S. Department of Energy by University of California, Lawrence Livermore National Laboratory under Contract W-7405-Eng-48. 
THE APPLICATION OF SINGLE PARTICLE AEROSOL MASS SPECTROMETRY FOR THE DETECTION AND IDENTIFICATION OF HIGH EXPLOSIVES AND CHEMICAL WARFARE AGENTS

\author{
By
}

Audrey Noreen Martin

\author{
A THESIS \\ Submitted to \\ Michigan State University \\ in partial fulfillment of the requirements \\ for the degree of \\ MASTER OF SCIENCE \\ School of Criminal Justice
}

2006 


\title{
ABSTRACT \\ THE APPLICATION OF SINGLE PARTICLE AEROSOL MASS SPECTROMETRY FOR THE DETECTION AND IDENTIFICATION OF HIGH EXPLOSIVES AND CHEMICAL WARFARE AGENTS
}

By

\author{
Audrey Noreen Martin
}

Single Particle Aerosol Mass Spectrometry (SPAMS) was evaluated as a real-time detection technique for single particles of high explosives. Dual-polarity time-of-flight mass spectra were obtained for samples of 2,4,6-trinitrotoluene (TNT), 1,3,5-trinitro1,3,5-triazinane (RDX), and pentaerythritol tetranitrate (PETN); peaks indicative of each compound were identified. Composite explosives, Comp B, Semtex 1A, and Semtex 1H were also analyzed, and peaks due to the explosive components of each sample were present in each spectrum. Mass spectral variability with laser fluence is discussed. The ability of the SPAMS system to identify explosive components in a single complex explosive particle $(\sim 1 \mathrm{pg})$ without the need for consumables is demonstrated.

SPAMS was also applied to the detection of Chemical Warfare Agent (CWA) simulants in the liquid and vapor phases. Liquid simulants for sarin, cyclosarin, tabun, and VX were analyzed; peaks indicative of each simulant were identified. Vapor phase CWA simulants were adsorbed onto alumina, silica, Zeolite, activated carbon, and metal powders which were directly analyzed using SPAMS. The use of metal powders as adsorbent materials was especially useful in the analysis of triethyl phosphate (TEP), a VX stimulant, which was undetectable using SPAMS in the liquid phase. The capability of SPAMS to detect high explosives and CWA simulants using one set of operational conditions is established. 


\section{ACKNOWLEDGEMENTS}

I would like to thank Dr. George Farquar, Dr. David Fergenson, and Dr. Matthias Frank for their willingness to accept me into their lab, and their guidance and support on the project. I learned a great deal during my time at Lawrence Livermore National Laboratory (LLNL) both inside and outside the lab. I appreciate all the advice I received.

I would like to thank Dr. Ruth Waddell and Dr. Greg Swain for supporting my goals as a graduate student and my decision to spend the summer at LLNL. I appreciate the patience in allowing me to leave East Lansing for two summers.

I also graciously acknowledge the financial support and opportunity to work at LLNL that was provided me through a fellowship from the Department of Homeland Security. This work was performed while on appointment through the DHS Scholarship and Fellowship Program, administered by the Oak Ridge Institute for Science and Education (ORISE) for DHS through an interagency agreement with DOE. ORISE is managed by Oak Ridge Associated Universities under DOE contract number DE-AC0506OR23100. All opinions expressed in this work are the author's and do not necessarily reflect the policies and view of DHS, DOE, or ORISE.

I would like to acknowledge additional funding sources that made my research possible. The development of the advanced BAMS system at LLNL was funded through the LLNL LDRD Grant 02-ERD-002 and through DARPA and TSWG in the Department of Defense. This work was performed under the auspices of the United States Department of Energy (DOE) by the University of California, Lawrence Livermore National Laboratory under Contract W-7405-ENG-48. UCRL-TH-226382. 


\section{TABLE OF CONTENTS}

List of Tables ...................................................................................................................

List of Figures................................................................................................................................... vii

Chapter One: Introduction .....................................................................................................1

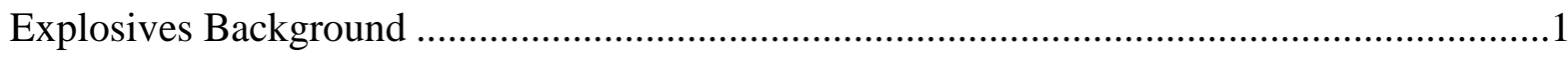

Explosives Detection Methods ..................................................................................

Bulk Explosives Detection Methods..........................................................................

Trace Explosives Detection Methods ...................................................................

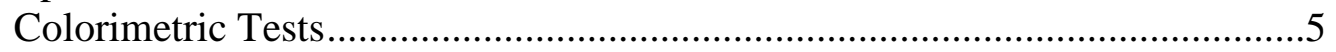

Laser Induced Fluorescence...........................................................................6

Ultraviolet Absorbance ..............................................................................

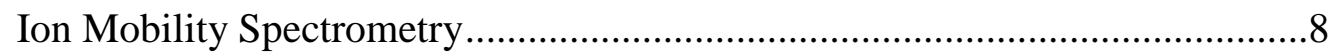

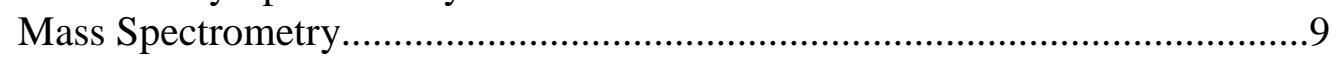

Chemical Warfare Agents Background ............................................................................12

Chemical Warfare Agents Detection Methods ...................................................................15

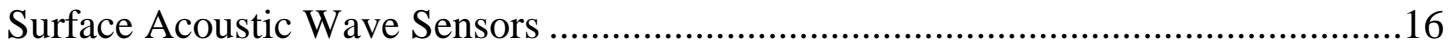

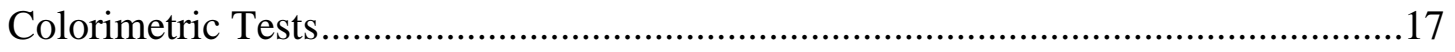

Amperometric Biosensor .................................................................................... 17

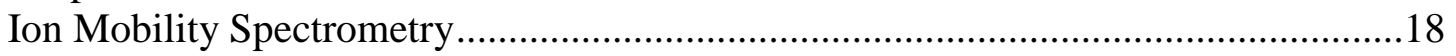

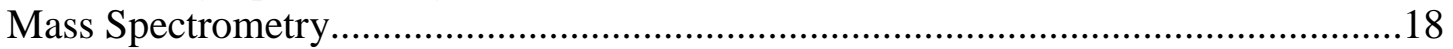

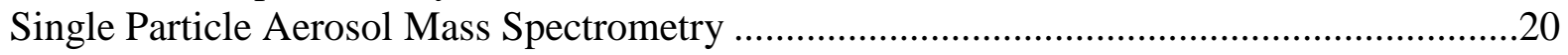

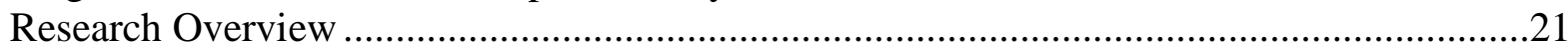

Chapter Two: Materials and Methods.............................................................................................23

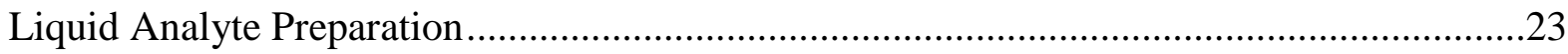

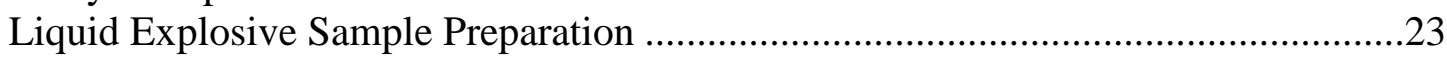

Liquid Chemical Warfare Agent Simulant Sample Preparation...................................23

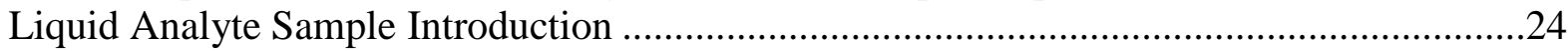

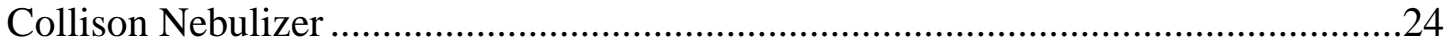

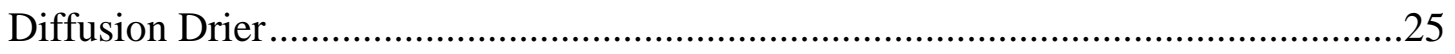

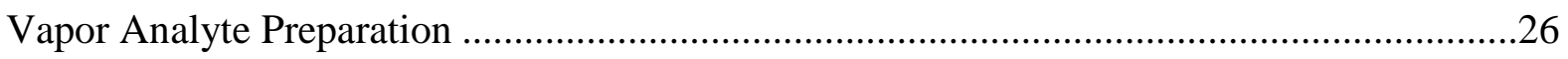

Vapor Chemical Warfare Agent Simulant Sample Preparation ...................................26

Method One: Direct Vapor Adsorption …………………..............................26

Method Two: Vapor Chamber Adsorption .......................................................28

Method Three: Wet Particle Adsorption.........................................................28

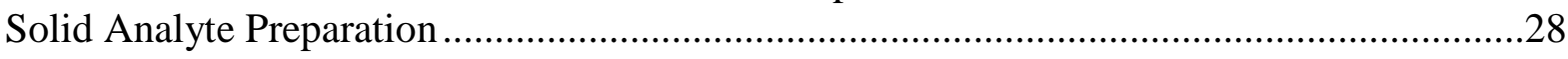

Solid Explosive Sample Preparation......................................................................28

Description of Single Particle Aerosol Mass Spectrometer....................................................29

Sample Introduction and Focusing ............................................................................29 


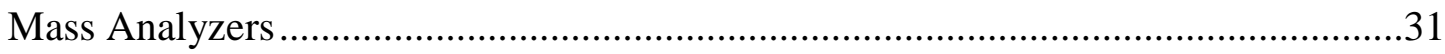

Description of Laser Optics ..............................................................................32

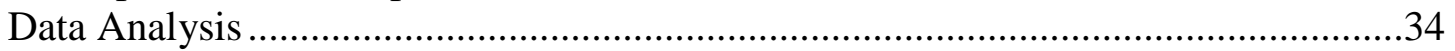

Chapter Three: Analysis of High Explosives Using SPAMS .....................................................35

This chapter is reproduced in part with permission from Analytical Chemistry, submitted for publication. Unpublished work copyright 2006 American Chemical Society.

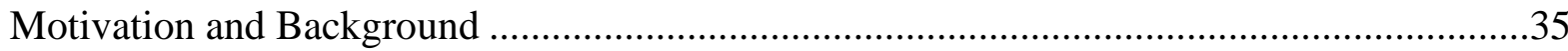

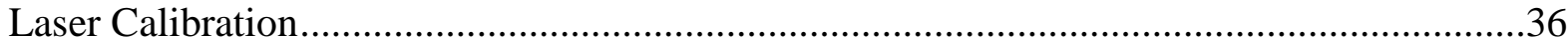

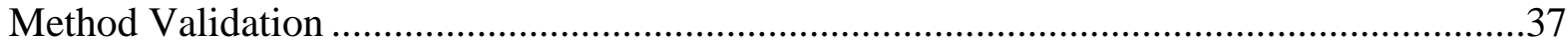

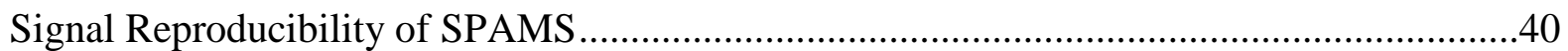

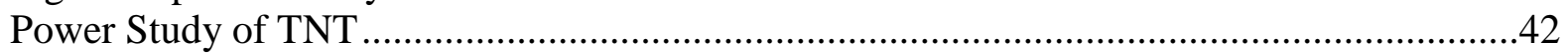

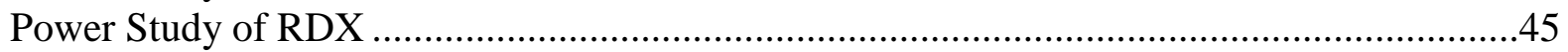

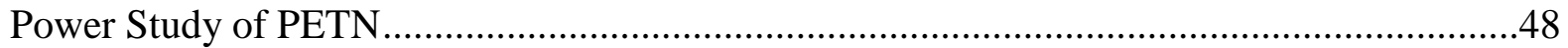

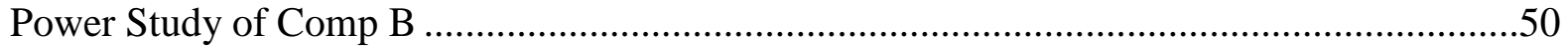

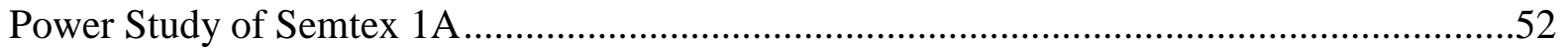

Power Study of Semtex 1H......................................................................................5

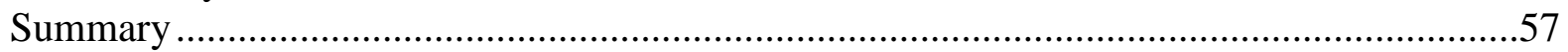

Chapter Four: Analysis of Chemical Warfare Agent Simulants Using SPAMS ...............58

This chapter is reproduced in part with permission from Analytica Chimica Acta, in preparation. Unpublished work copyright 2006 Elsevier Press.

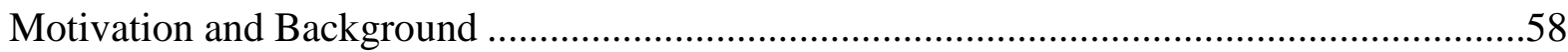

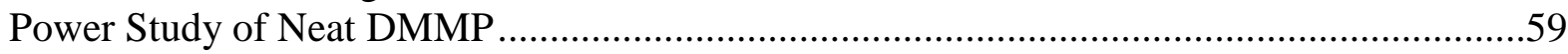

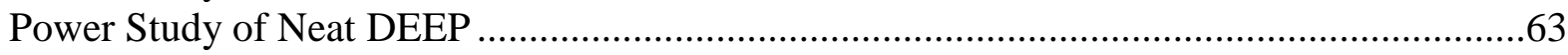

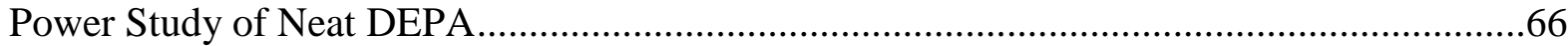

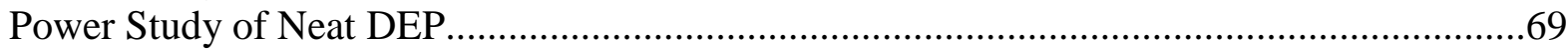

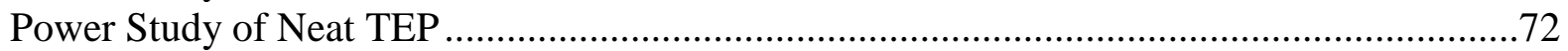

Analysis of Vapor Phase CWA Simulants..........................................................................

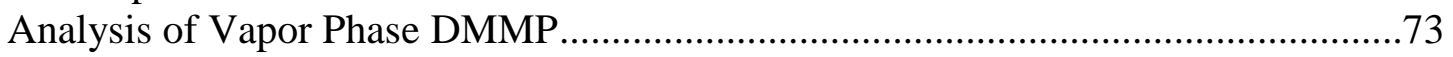

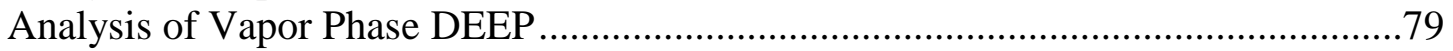

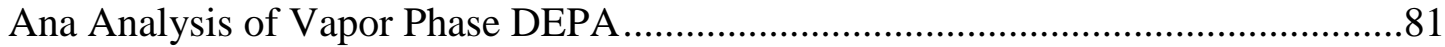

Analysis of Vapor Phase TEP .............................................................................

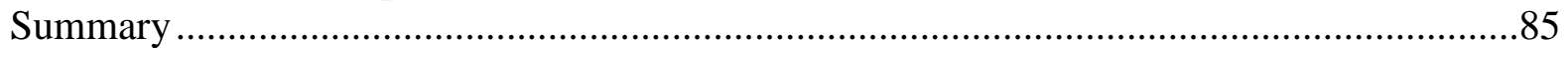

Chapter Five: Conclusions and Future Work.........................................................................87

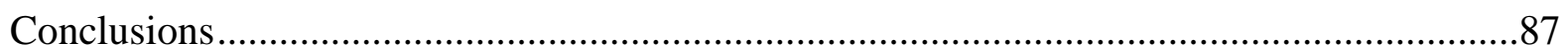

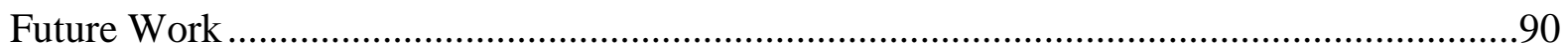

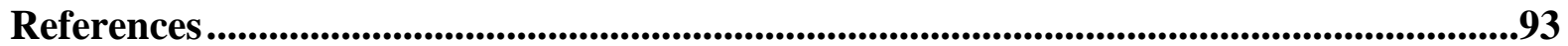




\section{LIST OF TABLES}

\section{Chapter 1: Introduction}

Table 1-1: Chemical Warfare Agent (CWA) listed by common name and chemical name. Toxicity in the vapor phase is listed as $\mathrm{LCt}_{50}$, the (L)ethal dose in (C)oncentration per ( $\mathrm{t}$ )ime in $\mathrm{mg}-\mathrm{min} / \mathrm{m}^{3}$. Toxicity in the liquid phase is listed as $\mathrm{LD}_{50}$, the dose in milligrams that is lethal to $50 \%$ of a population.

Table 1-2: Chemical name and structure of several chemical warfare agents and the simulants commonly used to study their detection.

\section{Chapter 3: Analysis of High Explosives Using SPAMS}

Table 3-1: Summary of mass spectral data from Comp B, Semtex 1A, and Semtex 1H obtained at laser fluences of $0.50,0.51$, and $0.57 \mathrm{~nJ} / \mu \mathrm{m}^{2}$, respectively. Peak position $(\mathrm{m} / \mathrm{z})$ and the suggested origin of the peak are shown.... 


\section{LIST OF FIGURES}

\section{Chapter 1: Introduction}

Figure 1-1: Chemical structures and molecular weights of a nitroaromatic, 2,4,6trinitrotoluene (TNT); a nitroamine, 1,3,5-trinitro-1,3,5-triazinane (RDX); and a nitrate ester, pentaerythritol tetranitrate (PETN).

Chapter 2: Materials and Methods

Figure 2-1: Schematic of the small-volume Collison nebulizer. Nitrogen gas is passed through the center tube and out through the six jets at the base of the cylinder. The sample aerosol forms in the nebulizer, and the particles are passed out the exit port via carbon doped conductive tubing to the diffusion drier.

Figure 2-2: Schematic of direct powder sample introduction vial. The CWAimpregnated adsorbent powder is placed in the vial along with a stainless steel nut. The vial is then hand-shaken to introduce the powder particles directly to the SPAMS via carbon doped conductive tubing.

Figure 2-3: Schematic of plastic solid sample introduction vial. The solid analyte is placed in the plastic vial along with a stainless steel nut. The vial is then hand-shaken to introduce the solid particles directly to the SPAMS via carbon doped conductive tubing.

Figure 2-4: Schematic of a Single Particle Aerosol Mass Spectrometer (SPAMS) used to obtain positive and negative ion time-of-flight mass spectra of high explosives and CWA simulants. Aerosol samples are dried and sampled into the SPAMS where they are aerodynamically focused, tracked, and characteristic molecules from the aerosol particles are desorbed and ionized by a Nd:YAG laser $(266 \mathrm{~nm})$. Positive and negative ion spectra of single particles are simultaneously collected by a dual-polarity reflectron time-of-flight mass spectrometer.

Figure 2-5: Schematic of laser optic system. Radiation from a Nd:YAG laser is passed through two frequency doublers, creating a $266 \mathrm{~nm}$ beam. The beam then passes through an aperture, an adjustable half-wave plate which is used to control the laser energy, and a vertical polarizer to isolate one polarization of light. A $10 \mathrm{~cm}$ plano-convex lens and two mirrors are used to image the beam into a $330 \mu \mathrm{m}$ spot inside the mass analyzer. .33 


\section{Chapter 3: Analysis of High Explosives Using SPAMS}

Figure 3-1: Calibration curve describing the laser power meter reading with and without the back optical window in place. Gray triangles describe the case where the optical window is removed and represents the actual energy incident on a particle in the center of the source region. Black squares describe the case when the optical window is in place and represents the energy measured during experiments. .37

Figure 3-2: (a) Single particle mass spectra of five consecutive single TNT particles (diameter $1.08 \pm 0.05 \mu \mathrm{m}$ ) obtained at a laser fluence of $0.70 \mathrm{~nJ} / \mu \mathrm{m}^{2}$. These spectra for successive particles are shown to present the typical shot-to-shot variation of the technique. (b) Single particle mass spectrum of a single TNT particle introduced into the SPAMS system from a crushed powder with no solvent, obtained at $0.75 \mathrm{~nJ} / \mu \mathrm{m}^{2}$

Figure 3-3: Single particle mass spectra of aerosolized TNT at laser fluences of 0.70, $1.51,2.51,5.21$, and $6.99 \mathrm{~nJ} / \mu \mathrm{m}^{2}$ (note differences in ion signal). Each spectrum is the average of 1000 single particle spectra. The average particle was $1.05 \pm 0.08 \mu \mathrm{m}$ in diameter. Note the $[\mathrm{TNT}-\mathrm{H}]^{-}$peak at $\mathrm{m} / \mathrm{z}-226$ is present at all laser fluences. The spectrum obtained at a laser fluence of $0.70 \mathrm{~nJ} / \mathrm{mm}^{2}$ also contained peaks at higher masses, as shown in the inset. The spectrum obtained at $6.99 \mathrm{~nJ} / \mu^{2}$ also contains an inset to show the presence of the $\mathrm{m} / \mathrm{z}-226,-212,-210$, and -197 peaks, although the signal is low......

Figure 3-4: Single particle mass spectra of aerosolized RDX at laser fluences of 0.57, $1.39,2.63,4.83$, and $7.80 \mathrm{~nJ} / \mu \mathrm{m}^{2}$ (note differences in ion signal). Each spectrum is the average of 1000 single particle spectra. The average particle was $1.00 \pm 0.03 \mu \mathrm{m}$ in diameter. Note the $\left[\mathrm{RDX}+\mathrm{NO}_{3}\right]^{-}$peak at $\mathrm{m} / \mathrm{z}-284$ is present at all laser fluences. An inset is shown for the spectra obtained at higher laser fluences to allow visualization of the peaks between $\mathrm{m} / \mathrm{z}-290$ and -250 .

Figure 3-5: Single particle mass spectra of aerosolized PETN at laser fluences of 0.57, $1.33,2.88,5.39$, and $7.95 \mathrm{~nJ} / \mu \mathrm{m}^{2}$ (note differences in ion signal). Each spectrum is the average of 1000 single particle spectra. The average particle was $1.10 \pm 0.12 \mu \mathrm{m}$ in diameter. Note the $\left[\mathrm{PETN}+\mathrm{NO}_{3}\right]^{-}$peak at $\mathrm{m} / \mathrm{z}-378$ is present at all laser fluences. Insets are included to highlight the presence of ion peaks between $\mathrm{m} / \mathrm{z}-390$ and -350 .

Figure 3-6: Single particle mass spectra of aerosolized TNT, Comp B (63\% TNT, 35\% $\mathrm{RDX}$ ), and RDX at $0.70,0.50$, and $0.57 \mathrm{~nJ} / \mu \mathrm{m}^{2}$, respectively (note differences in ion signal). Each spectrum is the average of 1000 single particle spectra. Dashed lines indicate mass peaks that are present in multiple compounds. Note the presence of peaks from TNT and RDX in the Comp B spectrum. The inset is included to allow the visualization of the high mass peaks in Comp B. 
Figure 3-7: Single particle mass spectra of aerosolized PETN and Semtex 1A at laser fluences of 0.57 and $0.51 \mathrm{~nJ} / \mu^{2}$, respectively (note differences in ion signal). Each spectrum is the average of 1000 single particle spectra. Dashed lines indicate mass peaks that are present in both compounds. Insets are included to highlight the presence of high mass peaks in both spectra.

Figure 3-8: Single particle mass spectra of aerosolized PETN, Semtex 1H, and RDX at a laser fluence of $0.57 \mathrm{~nJ} / \mu \mathrm{m}^{2}$ (note differences in ion signal). Each spectrum is the average of 1000 single particle spectra. Dashed lines indicate mass peaks that are present in multiple compounds. Insets are included to highlight the presence of high mass peaks in both

spectra .55

\section{Chapter 4: Analysis of Chemical Warfare Agent Simulants Using SPAMS}

Figure 4-1: Single particle mass spectra of aerosolized DMMP at laser fluences of 0.58, $1.11,2.57,5.05$, and $7.66 \mathrm{~nJ} / \mu^{2}$ (note differences in ion signal). Each spectrum is the average of 1000 single particle spectra. The average particle was $1.15 \pm 0.09 \mu \mathrm{m}$ in diameter. Note the $[\mathrm{DMMP}+\mathrm{H}]^{-}$peak at $\mathrm{m} / \mathrm{z}-125$ is present at all laser fluences. The structure of DMMP is included as an inset in the bottom spectrum. .60

Figure 4-2: Single particle mass spectra of aerosolized DEEP at laser fluences of 1.18, $2.77,5.13$, and $7.59 \mathrm{~nJ} / \mu^{2}{ }^{2}$ (note differences ion signal). Each spectrum is the average of 1000 single particle spectra. The average particle was $1.11 \pm 0.10 \mu \mathrm{m}$ in diameter. Note the [DEEP] peak at $\mathrm{m} / \mathrm{z}-166$ is present at all laser fluences. The structure of DEEP is included as an inset in the bottom spectrum. .64

Figure 4-3: Single particle mass spectra of aerosolized DEPA at laser fluences of 0.69, $1.17,2.78$, and $5.14 \mathrm{~nJ} / \mu^{2}{ }^{2}$ (note differences in ion signal). Each spectrum is the average of 1000 single particle spectra. The average particle was $1.16 \pm 0.03 \mu \mathrm{m}$ in diameter. Note the $[\mathrm{DEPA}+\mathrm{H}]^{+}$peak at $\mathrm{m} / \mathrm{z}+154$ is present at all laser fluences. The structure of DEPA is included as an inset in the bottom spectrum.

Figure 4-4: Single particle mass spectra of aerosolized DEP at laser fluences of 1.17, $2.77,5.10$, and $7.83 \mathrm{~nJ} / \mu^{2}$ (note differences in ion signal). Each spectrum is the average of 1000 single particle spectra. The average particle was $1.36 \pm 0.15 \mu \mathrm{m}$ in diameter. Note the $[\mathrm{DEP}+2 \mathrm{H}]^{+}$peak at $\mathrm{m} / \mathrm{z}+224$ is present at all laser fluences. The structure of DEP is included as an inset in the bottom spectrum.

Figure 4-5: Single particle mass spectra of (A) DMMP-exposed alumina and (B) unexposed alumina at a laser fluence of $3.74 \mathrm{~nJ} / \mu^{2}$ (note differences in ion signal). Each spectrum is the average of 500 single particle spectra. The structure of DMMP is included as an inset in (B). .75 
Figure 4-6: Single particle mass spectra of (A) DMMP-exposed manganese and (B) unexposed manganese at a laser fluence of $3.98 \mathrm{~nJ} / \mu^{2}$ (note differences in ion signal). Each spectrum is the average of the top 50 single particle spectra sorted by $\mathrm{m} / \mathrm{z}-125$ using computer software. The structure of DMMP is included as an inset in (B) .78

Figure 4-7: Single particle mass spectra of (A) DEEP-exposed silica and (B) unexposed silica at a laser fluence of $3.67 \mathrm{~nJ} / \mu^{2}$ (note differences in ion signal). Each spectrum is the average of the top 50 single particle spectra sorted by $\mathrm{m} / \mathrm{z}+165$, using computer software. The structure of DEEP is included as an inset in (B). .80

Figure 4-8: Single particle mass spectra of (A) DEPA-exposed titanium and (B) unexposed titanium at a laser fluence of $3.75 \mathrm{~nJ} / \mu^{2}$ (note differences in ion signal). Each spectrum is the average of the top 25 single particle spectra sorted by $\mathrm{m} / \mathrm{z}+176$ using computer software. The structure of DEPA is included as an inset in (B).

Figure 4-9: Single particle mass spectra of (A) TEP-exposed manganese and (B) unexposed manganese at a laser fluence of $3.48 \mathrm{~nJ} / \mu \mathrm{m}^{2}$. The structure of TEP is included as an inset in (B).

Figure 4-10: Single particle mass spectra of (A) TEP-exposed tungsten and (B) unexposed tungsten powder at a laser fluence of $3.46 \mathrm{~nJ} / \mu \mathrm{m}^{2}$. Each spectrum is the average of the top 50 single particle spectra sorted by $\mathrm{m} / \mathrm{z}+182$. The structure of TEP is included as an inset in (B). .85 


\section{Chapter 1: Introduction}

\subsection{Explosives Background}

There are many ways to describe and classify explosives including end use, chemical structure, and explosive potential. The end use of an explosive describes the intended application of the material. This can include military explosives, industrial explosives commonly used in demolition and construction, as well as improvised explosive devices (IEDs) that are homemade devices with no approved use. Explosives from each of these categories have been used worldwide in terrorist events. Explosives are also commonly divided into several classes based on their structure. Nitroaromatics, nitroamines, and nitrate esters are the most common types of nitrated explosives, ${ }^{1}$ and contain C-NO $\mathrm{NO}_{2}, \mathrm{~N}-\mathrm{NO}_{2}$, and C-O-NO 2 groups, respectively. Examples include 2,4,6trinitrotoluene (TNT), which is a nitroaromatic, 1,3,5-trinitro-1,3,5-triazinane (RDX), which is a nitramine, and pentaerythritol tetranitrate (PETN), which is a nitrate ester (Figure 1-1).

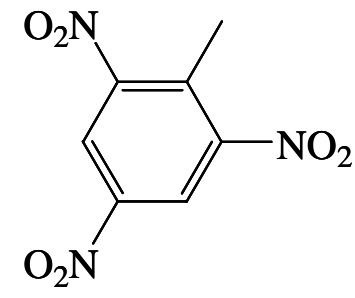

TNT

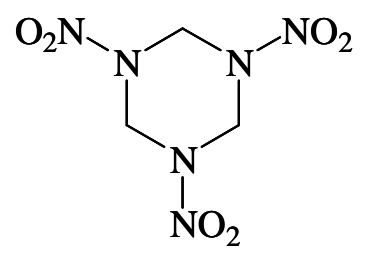

RDX

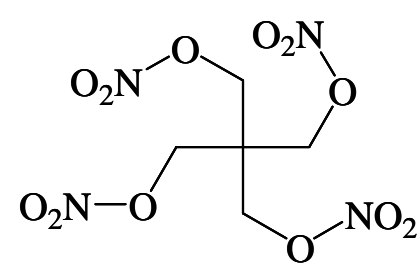

PETN

\section{2,4,6-trinitrotoluene 1,3,5-trinitro-1,3,5-triazinane Pentaerythritol tetranitrate MW 227.13 \\ MW 222.12 \\ MW 316.14}

Figure 1-1: Chemical structures and molecular weights of a nitroaromatic, 2,4,6trinitrotoluene (TNT); a nitroamine, 1,3,5-trinitro-1,3,5-triazinane (RDX); and a nitrate ester, pentaerythritol tetranitrate (PETN). 
The next classification of explosives is their explosive potential, typically described as low versus high explosives. Low explosives have low burn rates $(\mathrm{cm} / \mathrm{s})$ while high explosives exhibit detonation velocities several orders of magnitude higher $(\mathrm{km} / \mathrm{s}) .{ }^{1}$ Low explosives also deflagrate, meaning they burn with intense heat and light; whereas high explosives detonate, which is a more intense, supersonic burst of energy. High explosives are classified as primary, secondary, or tertiary explosives. Primary explosives are very sensitive to shock, friction, and are easily ignited by flame or heat. ${ }^{1}$ Though these compounds are easily ignited, they release small amounts of energy and are rarely used in terrorist events. Primary explosives are also called initiators, because their main use is in blasting caps used to initiate the detonation of a secondary explosive. ${ }^{1}$ Secondary explosives are less sensitive to shock and ignition, and are therefore commonly initiated using a primary explosive. Generally, any compound that is more sensitive than PETN is considered a primary explosive, while those less sensitive than PETN are considered secondary explosives. ${ }^{1}$ Tertiary explosives are even less sensitive to shock and ignition, and require a large shock from a secondary explosive in order to detonate. $^{1}$

Often, pure explosives are combined with other compounds in order to make a useful and safe explosive. These composite, or plastic, explosives are commonly used for both industrial and military applications. By mixing individual explosives with additives such as plasticizers, waxes, or binders, the explosive is more malleable, so it can be shaped into a device, and more stable, so it is safer to store or handle over a wider temperature range. ${ }^{2}$ Examples of common composite explosives include Composition B (Comp B), Semtex 1A, and Semtex 1H. Comp B is a mixture containing 63\% TNT, 35\% 
RDX, and $1 \%$ oil/plasticizer. Semtex 1 A contains $83.5 \%$ PETN and $16.5 \%$ oil/plasticizer. Semtex $1 \mathrm{H}$ contains $25 \%$ PETN, $60.5 \%$ RDX, and $14.4 \%$ oil/plasticizer. Semtex $1 \mathrm{H}$ caused the explosion of Pan Am Flight 103 over Scotland in 1988. ${ }^{3}$ After this event, increased pressure on the commercial explosive community lead to the inclusion of taggants in commercially produced explosives. Taggants are chemicals with high vapor pressures that are added to the explosive during production; the taggant is the target compound for detection, which indicates the presence of an explosive. 2,3-dimethyl-2,3dinitrobutane (DMNB) and ethylene glycol dinitrate (EGDN) are two taggants that are commonly used in commercial explosives produced in the United States. The vapor pressure of DMNB is $2.07 \times 10^{-3}$ Torr as compared to that of RDX (1.4 $\times 10^{-9}$ Torr $)$ or

TNT (3.0 $\times 10^{-6}$ Torr). ${ }^{4}$ Vapor-based detection methods focused on the presence of a taggant may aid in the detection or forensic attribution of an explosive device. ${ }^{5}$ Several methods have been developed and commercialized that may identify explosives based on the presence of these taggants or the explosive compound itself.

\subsection{Explosives Detection Methods}

Sensitive and specific detection of explosives is an analytical issue that is important for the prevention and attribution of terrorist activities. The ideal explosive detector would be able to identify explosive traces in the air, on clothing, materials, and the body of the terrorist with enough warning time and physical distance to minimize the damage the explosive could cause. The National Research Council Report on Opportunities to Improve Airport Passenger Screening with Mass Spectrometry describes detection of explosives in terms of stand-off detection versus point detection, and bulk detection versus trace detection. ${ }^{6}$ Stand-off detection means that the detector operates at 
a set distance from the analyzed samples. For example, a stand-off detector at an embassy would operate at the periphery of the property, and be able to detect explosives in an approaching vehicle before it was within a defined radius. This type of detection system would allow time for appropriate measures (e.g. raising a physical blockade) to be taken to avoid the destruction that would occur if the explosive were to reach its intended target. Point detection relies on the detector coming in close contact with the sample being analyzed. An example of point detection is luggage screening in an airport, where the X-ray scanner operates within a meter of the sample. For such systems, sampling must be simple, the analysis must be quick, and a low rate of false positives and false negatives in a variety of backgrounds is required. Stand-off detectors are more applicable to bulk analysis, where the explosive device as a whole is the target, while point detectors possess the sensitivity necessary for trace detection, where the explosive is targeted at the molecular level.

\subsubsection{Bulk Explosives Detection Methods}

Several bulk explosives detectors rely on imaging techniques including X-ray tomography and microwave imaging to identify quantities of explosives that pose a threat. $^{6}$ These systems focus on detecting the actual explosive device by visual characteristics such as the shape of the explosive material or detonator. ${ }^{7}$ Other bulk detection techniques rely on the chemical structure of the explosive, such as molecular bending or twisting in terahertz (THz) spectroscopy and Raman spectroscopy, ${ }^{7,8,9}$ and the

molecular electric field gradients in nuclear quadrupole resonance (NQR). ${ }^{7,} 10 \mathrm{THz}$ spectroscopy is particularly appealing because the energy of the $\mathrm{THz}$ waves is much lower than that of X-rays, and is thus safer for the personnel who operate the instrument. ${ }^{8}$ 
Raman spectroscopy has even been applied to the standoff detection of high explosives in a silica matrix from up to $50 \mathrm{~m}$ away. ${ }^{9}$ NQR detection has also been modified for standoff detection by adapting the receiving and transmitting coils and using a narrow bandwidth for detection. ${ }^{11}$ The main disadvantage of bulk detection systems is the significant amount of explosive necessary to trigger an alarm (e.g. enough explosive, wires, or detonation material present to be seen in visible images); trace detection is advantageous since trace levels of explosives (e.g. single particles) that may have been transferred to the skin or a bag of a would-be terrorist can be detected before the actual explosive device is used. ${ }^{7}$

\subsubsection{Trace Explosive Detection Methods}

Trace detection of explosive compounds has recently been reviewed by Moore and only a brief summary is included here. ${ }^{12}$ Explosives are commonly identified using colorimetry, ${ }^{13}$ UV-absorption spectroscopy, ${ }^{14}, 15$ laser-induced fluorescence (LIF), ${ }^{16,} 17$ immunoassay, ${ }^{18}$ ion mobility spectrometry (IMS), ${ }^{19-23}$ and mass spectrometry (ion trap and time-of-flight (TOF)). ${ }^{24-33}$ It should be noted that research into explosives detection is performed on gas, liquid, and/or solid phase explosives, and that the sampling methods and concepts of operation vary widely between the different techniques. The limits of detection for the various techniques are dependent on the sampling method and sample phase, and therefore prevent a direct comparison among the different techniques.

\subsubsection{Colorimetric Tests}

A common trace detection method in field applications is a colorimetric test. This involves adding a particular reagent to the suspected explosive, and observing the color of the resulting complex. Plexus Scientific markets 'Expray', a detection kit that contains 
aerosol sprays for the detection of different classes of explosives. ${ }^{34}$ The first spray detects nitroaromatics using tetrabutylammonium hydroxide, which forms a Meisenheimer complex upon reaction with a polynitroaromatic compound. ${ }^{13}$ Next, sulfanilamide, N-ethylenediamine, and sulfanilic acid are sprayed onto the suspected sample, which form an azo dye with the products from the first spray. ${ }^{13}$ This detects nitroamines and nitrate esters. Finally, a third spray containing zinc powder is applied to the sample, which detects inorganic nitrates. ${ }^{13}$ The manufacturer claims a limit of detection (LOD) of $20 \mathrm{ng}$ for RDX and $5 \mathrm{ng}$ for $\mathrm{TNT} ;{ }^{34}$ however, testing on liquid standards containing $5 \mathrm{ng}$ of TNT and $20 \mathrm{ng}$ of RDX showed no color change. ${ }^{13}$ The manufacturer also notes that some fertilizers and any compound containing nitrites may produce a false positive result using Expray; however, the spray may be advantageously used to prescreen samples for further analysis. ${ }^{34}$

\subsubsection{Laser Induced Fluorescence}

Laser induced fluorescence (LIF) is a common analytical technique that uses a laser to excite a fluorophore, allowing detection of the emitted radiation. LIF in conjunction with immunoassay is used for specific detection of explosives. Immunoassays are based on the unique bonding that occurs between an antibody and an antigen, and are commonly coupled with LIF detection. An immunoassay can be performed in several ways, one of which is a displacement assay. Anderson et al. used this technique for the detection of TNT. ${ }^{18}$ Antibodies specific for antigen/TNT were immobilized onto latex microspheres and treated with fluorescently labeled trinitrobenzene (TNB) which bound to the antibody. When TNT was introduced to the beads, it displaced the TNB, and the reduction in the fluorescence signal was quantitated. 
This technique yielded an LOD of $0.1 \mu \mathrm{g} / \mathrm{L}$ TNT and has the advantage of being multiplexed. ${ }^{18}$ However, the selectivity of immunoassay-based techniques can also be a limitation as it prevents broad application to a variety of compounds including unknown and novel explosives. Immunoassay detection schemes, as well as other detection methods, also require consumables, which limits stand-alone capabilities. Bailey and Wallenborg have also used LIF incorporated with micellar electrokinetic chromatography (MEKC) and capillary electrochromatography (CEC) for the separation and indirect detection of an Environmental Protection Agency (EPA) standard mixture of explosives (EPA 8330) containing fourteen nitroaromatic and nitramine explosives and degradation products. By monitoring the LIF of a background fluorophore $(\mathrm{Cy}-5)$ in the mobile phase, the explosive compounds were detected as negative peaks in the LIF signal. This technique provided detection limits of $1-10 \mathrm{mg} / \mathrm{L}$ for the 12 nitroaromatic compounds; whereas the nitroamines had much higher LODs due to their low quenching efficiencies. ${ }^{16}$ Bailey and Wallenborg's detection scheme was also adapted into a microchip device capable of on-site analysis. ${ }^{17}$ By performing indirect LIF with MEKC on the microchip, LODs of $1 \mathrm{ppm}(\mathrm{mg} / \mathrm{L})$ for the nitroaromatic compounds were achieved, albeit with a narrow linear dynamic range. ${ }^{17}$

\subsubsection{Ultraviolet Absorbance}

CEC can also be used to detect explosives using ultraviolet (UV) absorption. ${ }^{14,15}$ Bailey and Yan demonstrated this technique using detection at $254 \mathrm{~nm}$ for the analysis of EPA 8330. ${ }^{15}$ Complete separation of the fourteen explosives with and without the use of a surfactant to maintain electroosmotic flow was reported. Oehrle demonstrated the analysis of fourteen explosives using micellar electrokinetic capillary chromatography 
(MEKCC) with direct UV absorption detection at several wavelengths. ${ }^{14}$ The lowest detection limits (0.11-0.59 mg/L) obtained with the UV absorption technique for most explosives were achieved with a wavelength of $185 \mathrm{~nm}$, except for 1,3,5-trinitrobenzene, 1,3-dinitrobenzene, and TNT, for which limits of detection (0.23-0.34 mg/L) were optimal at $254 \mathrm{~nm}$. The differences in optimal detection wavelength may be due to the structural differences of the compounds, as those with the higher wavelength of detection are all nitroaromatic compounds. ${ }^{14}$

\subsubsection{Ion Mobility Spectrometry}

Ion mobility spectrometry (IMS) is commonly used as a detection system in airport security screening. A sample is commonly collected using a sampling cloth to wipe a surface or to adsorb vapors from a material. The sample is then ionized from the cloth, and the time it takes for the ions to migrate through an electric field inside a drift tube at atmospheric pressure is measured. Several ionization sources for IMS are common, including corona discharge, electrospray ionization, and atmospheric pressure photoionization. Ewing and Miller employed a hand-held, gas-sampling, corona discharge ionization IMS for the detection of several explosives and taggants. ${ }^{20}$ They estimated an LOD near $10 \mathrm{ppb}(\mu \mathrm{g} / \mathrm{L})$ for the taggant EGDN in nitroglycerin-dynamite. ${ }^{20}$ Tam and Hill used secondary electrospray ionization (SESI)-IMS for explosives detection. ${ }^{23}$ SESI involves ionization of the sample by reactant ions that are formed by passing a solvated sample through a charged capillary. Tam and Hill applied SESI-IMS with and without volatile and nonvolatile dopants to detect several explosives in both the liquid and vapor phases with an LOD in the low ppb $(\mu \mathrm{g} / \mathrm{L})$ range. $^{23}$ 
While IMS is frequently used, it is limited in its application by sampling requirements. The use of a sampling cloth to introduce a sample to the instrument assumes that explosive residue would have been in contact with the wiped surface, that a sufficient quantity of explosive is transferred to the wipe, and that this quantity is within the limits of operation of the IMS instrument. ${ }^{6}$ General Electric's EntryScan ${ }^{3}$ and Smiths Detection's Ionscan Sentinel II are portal-based IMS systems currently deployed in airports that sample the air around a person standing in the portal, eliminating this need for a sample wipe to contact the explosive residue. ${ }^{35,36}$ In general application, IMS has limited ability to concurrently screen for the full spectrum of explosive compounds, due to the optimization of several parameters, e.g. ionization conditions, for a particular set of compounds, and the added expense incurred for an instrument with such ability. ${ }^{6}$ IMS is also limited in its sensitivity, due to false positives, which requires the instrument to be operated at a higher detection threshold, hence introducing the potential of not detecting explosives present at levels below this threshold. ${ }^{6}$

\subsubsection{Mass Spectrometry}

Mass spectrometry (MS) is a sensitive and selective platform for the detection of explosives in the vapor phase and on surfaces. MS is most commonly coupled with another technique for sample introduction of the explosives. This provides an orthogonal detection system, as well as a simple method of sample introduction.

Perr et al. demonstrated increased selectivity and picogram detection limits for several explosives using gas chromatography (GC)-positive chemical ionization MS/MS with an ion trap mass analyzer. ${ }^{30}$ However, since the vapor pressure of many explosives is low $\left(10^{-6}-10^{-9}\right.$ Torr $){ }^{4}$ extensive heating is often required to get the sample into the gas 
phase. One limitation of such analyses is that chemicals important for forensic attribution of an explosive event can be destroyed in this heating step. An alternative analysis system is liquid chromatography-mass spectrometry (LC-MS) since LC does not rely on the explosives being vaporized and hence, does not thermally degrade the samples. Wood et al. reviewed the use of LC-MS for explosives detection, citing several studies that detected TNT, RDX, and PETN both individually and in mixed samples. ${ }^{37}$ Colorado described the use of LC-MS/MS for the analysis of TNT and RDX standards. ${ }^{38}$ The LC separation was performed with a mobile phase of water:isopropanol:methanol (60:30:10) with $0.1 \%$ chloroform added to allow for adduct formation during ionization. Atmospheric pressure chemical ionization (APCI) was used to ionize the sample with high pressure argon as it exited the LC column, and a quadrupole mass analyzer was used to achieve LODs of $1 \mathrm{ppb}(\mu \mathrm{g} / \mathrm{L})$ for both explosives. MS/MS was used to further separate and confirm the identity of the explosive analytes. By selecting a precursor ion for further ionization (m/z 227 for TNT and m/z 257 for RDX) additional fragment ions were detected that confirmed the identity of the sample. ${ }^{38}$

Recently, the Cooks group has developed desorption electrospray ionization (DESI) using an ion trap mass analyzer and has applied the technique for the sampling and detection of explosives from material surfaces. ${ }^{29,31}$ In DESI, an explosive sample on a solid is exposed to an electrospray of solvent, typically water/methanol, which creates secondary ions that are introduced into the mass analyzer. This technique has achieved LODs in the laboratory setting as low as 5 pg for RDX spiked onto a paper sample. ${ }^{31} \mathrm{~A}$ further development in DESI is the addition of a dopant to the electrospray solvent such that specific adducts of the analyte are formed during ionization. This reactive DESI was 
applied to the detection of RDX by adding $0.05 \% \mathrm{HCl}$ to the water/methanol solution; this allowed the LOD to reach $1 \mathrm{pg}$ on a spiked paper sample by detecting an $\mathrm{RDX}+\mathrm{Cl}$ adduct. Reactive DESI was also applied to composite explosives, such as Semtex $1 \mathrm{H}$ by detecting this same adduct ion. ${ }^{31}$ A significant benefit of DESI is that sampling is achieved at atmospheric pressure, which is advantageous for point detection; however, it requires consumables in the form of the electrosprayed solvents and is not capable of directly analyzing aerosolized particles.

Mass spectrometry has also recently been applied to explosives detection in novel ways. Gillen et al. analyzed explosive particles deposited on a silicon surface using secondary ion mass spectrometry. ${ }^{39}$ By using a $\mathrm{C}_{8}$ cluster primary ion beam, parent ions of TNT as well as adducts of TNT, RDX, and PETN were detected. Hankin et al. have applied femtosecond ionization to the detection of explosives using a TOF mass analyzer. $^{33}$ By desorbing a solid sample of TNT and several of its degradation products with a $5 \mathrm{~ns}, 266 \mathrm{~nm}$ laser pulse, followed by an $80 \mathrm{fs}, 800 \mathrm{~nm}$ ionization laser pulse, they were able to generate an increased amount of intact molecular ion versus nanosecond ionization schemes. The presence of the intact molecular ion is important in that it is makes identification of the analyte rapid and more facile. Mullen et al. have employed single photon ionization with $118.2 \mathrm{~nm}$ light from the frequency-tripled third harmonic output of an Nd:YAG laser for the detection of several gas-phase explosives using a TOF mass analyzer. ${ }^{28}$ Analysis of TNT yielded the parent molecular ion almost exclusively; however, the technique is limited to molecules with ionization energies below $10.49 \mathrm{eV}$ due to the limited energy produced by the laser. ${ }^{28}$ Syage et al. have collaborated with Sandia National Laboratory to combine a preconcentrating particle sampling portal 
similar to the Sentinel II described in section 1.2.2.4 with a photoionization quadrupole ion trap-TOF (QitTOF) MS for the point detection of trace explosives. ${ }^{24}$ Detection limits in the picogram range were reported when TNT, RDX, and PETN samples were introduced to the detector via a heated tube connected to the sampling inlet; however, it was noted that the LOD increased approximately two orders of magnitude when sampled directly from the portal. ${ }^{24}$

\subsection{Chemical Warfare Agents Background}

A nonconventional form of warfare or terrorism exists that involves the use of nonexplosive chemicals to cause illness or disease. Chemical warfare was outlawed by the United Nations in the Chemical Weapons Convention (CWC) of $1993 .^{40}$ The CWC, currently signed by 180 countries, declared that the production or stockpiling of Chemical Warfare Agents (CWAs) was prohibited, and existing stockpiles should be destroyed by $2007 .^{40}$ Many classes of chemicals have been used as CWAs; they are typically classified as blood agents, vesicant (blistering) agents, pulmonary agents, riotcontrol (incapacitating) agents, and nerve agents. ${ }^{41}$ Blood agents, such as cyanogen chloride, contain a cyanide group (-CN) and inhibit the body from properly using oxygen when exposed to high concentrations of the agent. Vesicant, or blistering agents, such as mustard gas, cause damage and blistering to the skin and eyes. Pulmonary agents, such as phosgene, affect the lungs and prevent the victim from breathing properly. Riotcontrol agents, for example 2-chlorobenzalmalononitrile (CS), are non-lethal agents that mainly induce lacrimation (tearing). ${ }^{42}$ Nerve agents are the final class of CWAs and are related to organophosphorus pesticides. 
Nerve agents exert their toxic effects as cholinesterase inhibitors, binding acetylcholinesterase in tissue and red blood cells, and butyrylcholinesterase in blood plasma. When the nerve agent is bound to these cholinesterases, the body is no longer able to hydrolyze acetylcholine, which results in an increased level of acetylcholine that continuously stimulates the organs. ${ }^{41}$ The nerve agent binding is permanent unless actively treated with therapeutics before the enzyme-nerve agent complex has 'aged.' Aging occurs when a small side chain of the enzyme-nerve agent complex spontaneously splits from the compound, which prevents a therapeutic oxime from degrading the agent into harmless fragments. ${ }^{43}$

Nerve agents are subdivided into G-type and V-type agents. G agents include sarin, soman, tabun, and cyclosarin and are so named due to their discovery in Germany in the 1930s and 40s. The discovery of the $\mathrm{V}$ agents followed in Great Britain with the synthesis of O-ethyl S-(2-diisopropylaminoethyl) methylphosphonothioate, commonly known as $\mathrm{VX}^{42,44}$ Both types of nerve agents are commonly liquids at standard temperature and pressures; however they can evaporate to the vapor phase. Thus there is the possibility for CWA exposure in the liquid or vapor phase, creating a challenge for detection. The V-type agents, VX in particular, are less volatile than the G-type agents and hence are described as being highly persistent. A CWA is considered persistent if it remains hazardous for over 24 hours. ${ }^{43}$

The common names, chemical names, toxicity, and volatility of several common nerve agents are shown in Table 1-1. As seen in the table, the V-type agent, VX, has an extremely low vapor pressure, and also has the highest toxicity in the liquid phase. Toxicity in the vapor phase is listed as $\mathrm{LCt}_{50}$, the (L)ethal dose in $(\mathrm{C})$ oncentration per 
(t)ime in $\mathrm{mg}-\mathrm{min} / \mathrm{m}^{3}$. Toxicity in the liquid phase is listed as $\mathrm{LD}_{50}$, the dose in milligrams that is lethal to $50 \%$ of a population. Table $1-2$ shows the chemical structure of the CWAs along with those of several CWA simulants. Simulants are used for CWA research because of the toxicity risks of working directly with CWAs. Simulants are chosen based on similarities in structure, volatility, or synthesis to the actual agent.

\begin{tabular}{|l|c|c|c|c|}
\hline \multicolumn{1}{|c|}{ CWA } & \multicolumn{2}{|c|}{ Toxicity } & \multicolumn{1}{c|}{$\begin{array}{c}\text { Vapor Pressure } \\
\left(\mathbf{m m} \mathbf{H g}, \mathbf{2 5}{ }^{\circ} \mathbf{C}\right)\end{array}$} & Aging Time \\
\cline { 2 - 5 } & $\begin{array}{c}\text { Vapor } \\
\left(\mathbf{m g - m i n} / \mathbf{m}^{\mathbf{3}}\right)\end{array}$ & $\begin{array}{c}\text { Liquid } \\
(\mathbf{m g})\end{array}$ & 2.9 & $5.2-12 \mathrm{~h}$ \\
\hline $\begin{array}{l}\text { Sarin } \\
\text { O-Isopropyl } \\
\text { methylphosphonofluoridate }\end{array}$ & $35-100$ & $100-1700$ & 0.4 & $40 \mathrm{~s}-10 \mathrm{~m}$ \\
\hline $\begin{array}{l}\text { Soman } \\
\text { O-Pinacolyl } \\
\text { methylphosphonofluoridate }\end{array}$ & $25-80$ & $50-350$ & 0.07 & $40 \mathrm{~s}-10 \mathrm{~m}$ \\
\hline $\begin{array}{l}\text { Tabun } \\
\text { Ethyl N,N-dimethyl } \\
\text { phosphoramidocyanidate }\end{array}$ & $70-400$ & $200-1500$ & 0.044 & $40 \mathrm{~s}-10 \mathrm{~m}$ \\
\hline $\begin{array}{l}\text { Cyclosarin } \\
\text { Cyclohexyl } \\
\text { methylphosphonofluoridate }\end{array}$ & $<35$ & 350 & 0.007 & \\
\hline $\begin{array}{l}\text { VX } \\
\text { O-ethyl-S-[2(diisopropylamino) } \\
\text { ethyl] methylphosphonothioate }\end{array}$ & $5-100$ & $<5-15$ & & \\
\hline
\end{tabular}

Table 1-1: Chemical Warfare Agent (CWA) listed by common name and chemical name. Toxicity in the vapor phase is listed as $\mathrm{LCt}_{50}$, the (L)ethal dose in $(\mathrm{C})$ oncentration per (t)ime in $\mathrm{mg}-\mathrm{min} / \mathrm{m}^{3}$. Toxicity in the liquid phase is listed as $\mathrm{LD}_{50}$, the dose in milligrams that is lethal to $50 \%$ of a population. ${ }^{42,44,45}$ 


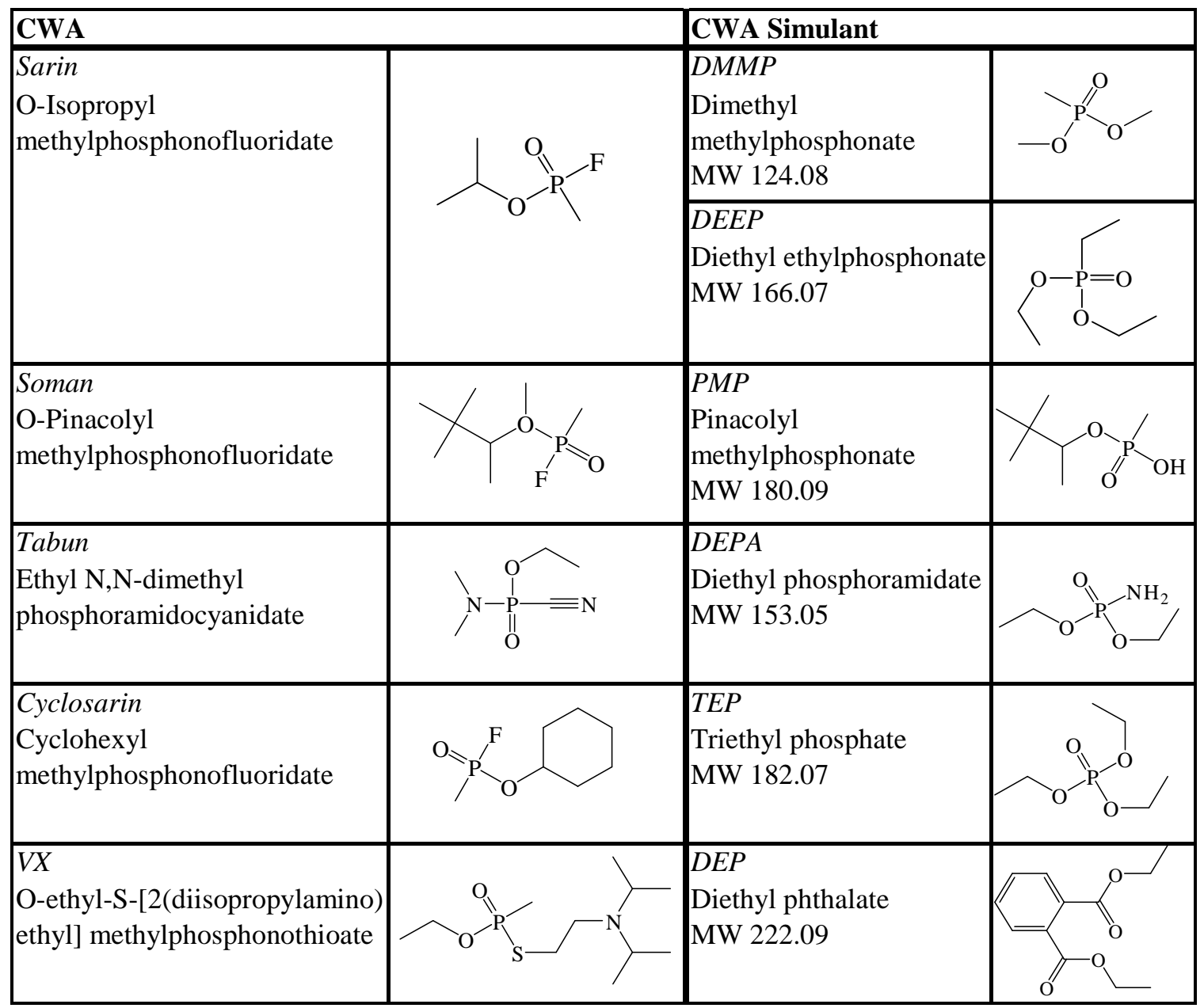

Table 1-2: Chemical name and structure of several chemical warfare agents and the simulants commonly used to study their detection.

\subsection{CWA Detection Methods}

Sensitive and specific detection of CWAs is also necessary to prevent or mitigate the casualties of a chemical attack. Ideal CWA detection would have similar qualities as an explosives detector: the capability to detect a trace amount of CWA with enough time and physical distance to minimize the number of victims exposed, and the level of exposure. To this end, a standoff trace detector would be ideal, and would operate in the same manner as the explosives detector described previously. The speed of the detection 
system for CWAs is especially important because treatment should be administered to victims of exposure before the CWA-enzyme complex has aged beyond repair. Bulk detection is not a viable option for CWAs, as only a small amount is needed to create panic or serious injury; therefore, trace methods, several of which are described below, have been the focus of detection research.

\subsubsection{Surface Acoustic Wave Sensors}

Surface Acoustic Wave (SAW) chemical sensors consist of a transducer that is functionalized with a polymer that selectively adsorbs a particular gas. A wave is propagated from one side of the SAW device to another; when a gas is adsorbed onto the transducer, the frequency of the wave is changed. Thus, by monitoring the frequency of the wave, the presence of a particular gas can be detected. McGill et al. at the Naval Research Laboratory developed the "NRL-SAWRHINO" which is an automated SAW sensor sensitive to G-type nerve agents and some mustard agents. ${ }^{46}$ They reported a detection range of $200 \mathrm{ppt}$ to $400 \mathrm{ppm}$ (200 ng/L to $400 \mathrm{mg} / \mathrm{L}$ ) for G-type agents when using a trap-and-purge gas-solid chromatographic column (TAP-GSC) to preconcentrate and separate the gases before introduction to the instrument. The MITRE Corporation has also developed a CWA sensor using SAW technology. ${ }^{47}$ The Joint Chemical Agent Detector (JCAD) is a two pound, $40 \mathrm{in}^{3}$ detector sensitive to nerve agents (G-type and Vtype), blister agents, and blood agents due to the incorporation of eight transducers. The main limitation of SAW technologies is that they are only sensitive to the gaseous forms of CWAs and are unable to detect liquid agents online. 


\subsubsection{Colorimetric Tests}

Colorimetric tests serve as the main CWA detection system for military personnel. Each United States soldier is equipped with a supply of ABC-M8 paper, which can be used to sample a suspected liquid chemical agent. The paper must be placed in contact with the liquid, and the type of agent present is indicated by the color of the paper: dark green for V-type agents, yellow for G-type agents, and red for blister agents. ${ }^{48}$ The Japanese National Defense Agency uses a similar colorimetric test where the test strips are impregnated with several pigments and a $\mathrm{pH}$ indicator. ${ }^{49}$ Depending on the agent present in the liquid sample, one of the pigments is solubilized or the $\mathrm{pH}$ changes, causing a color reaction that is sensitive to the $\mu \mathrm{g} / \mathrm{cm}^{2}$ level. Seto et al. demonstrated the use of this paper on CWAs but also found several chemicals, such as acetone, ethyl acetate, carbon tetrachloride, and aniline which gave a false positive color change. ${ }^{49}$

\subsubsection{Amperometric Biosensor}

Electrochemical methods have also been used for the detection of CWAs. ${ }^{50}$ An amperometric biosensor was used by Mulchandani et al. for the detection of several organophosphate nerve agents. ${ }^{51}$ The amperometric biosensor consisted of a thick strip of carbon coated with an organophosphorus hydrolase (OPH)-infused nafion film. When exposed to a liquid nerve agent, the OPH hydrolyzes the nerve agent to p-nitrophenol, which is electrochemically active, and oxidized by the application of an anodic potential. $^{51}$ OPH was also used to create p-nitrophenol for nerve agent detection in a flow through amperometric detector, with a short analysis time of approximately two minutes. ${ }^{52}$ 


\subsubsection{Ion Mobility Spectrometry}

IMS has also been used to detect CWAs in the same manner as IMS is used to detect explosives. A field-deployable IMS, the 'Improved Chemical Agent Monitor,' relies on a radioactive ionization source and can detect G-type and V-type CWAs after a one-minute exposure. ${ }^{50}$ Since the IMS identifies an analyte based on the time it takes to travel through an electric field at atmospheric pressure, the instrumental conditions must be tuned towards the detection of specific classes of compounds, so novel or unknown agents may be difficult to identify, as previously discussed for explosive detection.

\subsubsection{Mass Spectrometry}

Similar to the analysis of explosives using MS described previously, CWA detection with MS is often coupled to another technique for sample introduction. A variety of ionization methods and mass analyzers have been used for CWA detection. ${ }^{50}$

GC-MS is a common tool for CWA detection. GC-MS is an Organization for the Prohibition of Chemical Weapons (OPCW) approved technique for analysis of CWAs, and is used in laboratory proficiency and certification testing. ${ }^{53}$ Inficon has developed a semi-portable GC-MS called Hapsite ${ }^{\circledR}$ which is battery operated and weighs approximately 35 lbs. ${ }^{54}$ Hapsite $^{\circledR}$ has several sample introduction methods that allow for air, soil, or water sampling. After separation in the GC, the sample components are introduced to the mass spectrometer, ionized using electron impact ionization, and analyzed in a quadrupole ion trap. ${ }^{54}$ Sekiguchi et al. used the Hapsite ${ }^{\circledR}$ detection system for the analysis of vapor phase CWAs, reporting detection limits of $0.2,0.5$, and $8 \mu \mathrm{g} / \mathrm{m}^{3}$, respectively, for sarin soman, and tabun $(\mathrm{S} / \mathrm{N}=3) .{ }^{55}$ Unfortunately, CWA vapor detection requires the use of a preconcentrating step and lengthens the analysis time to 
approximately ten minutes. ${ }^{49,55}$ Another draw back of GC-MS is that samples with low volatility must be derivatized before analysis to increase their volatility and allow separation and detection.

LC-MS is also a common technique for CWA analysis, with the advantages of LC over GC described for explosive detection also being applicable to CWA detection. ${ }^{37}$ D'Agostino et al. used LC-ESI-MS for the identification of CWAs in aqueous extracts of office media (paper, carpet, drywall). ${ }^{56}$ Sarin, cyclosarin, soman, and TEP were all recovered from the materials, with efficiencies between $20-100 \%$. The wide range in recovery efficiencies was attributed to the differences in the media onto which the CWAs were deposited. Latex-painted drywall, for example, was hypothesized to absorb some of the CWAs and prevent their recovery, leading to $20 \%$ recovery for cyclosarin and soman. ${ }^{56}$ D'Agostino et al. also used DESI to analyze CWAs on office media. ${ }^{37}$ After spiking the various media with CWA, the material was placed in a sealed vial, and a solid phase microextraction (SPME) fiber was exposed to the headspace for three minutes. The SPME fiber was then used as the sample for DESI analysis, with the solvent directly electrosprayed onto the fiber. Sarin and tabun were detected at $\mu \mathrm{g}-\mathrm{CWA} / \mathrm{g}$-media in this manner. ${ }^{37}$

IMS has recently been used as a sample separation and introduction device for mass spectrometry. Hill et al. used electrospray ionization to introduce a liquid CWA sample into an IMS where the sample was separated based on ion mobility through the drift region. ${ }^{57}$ After exiting the drift region, the ions were focused into a TOF-MS for further analysis. The orthogonal nature of the data obtained from the IM(TOF)MS allowed the separation and identification of numerous CWA degradation products both 
neat and in water samples with LODs less than $100 \mathrm{ppb}(\mu \mathrm{g} / \mathrm{L})$ for most compounds. ${ }^{57}$ The analysis of $10 \mathrm{ppm}(\mathrm{mg} / \mathrm{L})$ vapor phase samples was also demonstrated using preconcentration and introduction through a heated capillary or membrane. ${ }^{58}$ Hill et al. also demonstrated the analysis of aerosolized DMMP using IM(TOF)MS. A 100 ppm (mg/L) solution of DMMP was aerosolized in water, kerosene, gasoline, and diesel, producing the same drift times and masses of ions as the DMMP sampled in the aqueous phase. $^{59}$

\subsection{Single Particle Aerosol Mass Spectrometry}

Single Particle Aerosol Mass Spectrometry (SPAMS) is an MS technique that is capable of detecting single particles of analyte in the solid or liquid phase. Samples can be directly introduced to SPAMS with little or no sample preparation. SPAMS also can be operated in on-line mode, continuously sampling the environment for contaminants. On-line SPAMS has been reviewed by Noble and Prather ${ }^{60}$ beginning with the pioneering work of Davis. ${ }^{61}$ Since its invention, SPAMS has evolved to include various components. A particle sizing region was incorporated into the front end of SPAMS, ${ }^{62}$ which determines the size of each particle that is subsequently analyzed. This adds an extra layer of selectivity to the system in that particular sizes of particles can be selectively ionized. SPAMS has also evolved to include two TOF mass analyzers, allowing the simultaneous acquisition of positive ion and negative ion spectra. ${ }^{63}$ This increases the reliability of the instrument by creating two complementary sets of mass-to-charge data in a single analysis.

The SPAMS system at Lawrence Livermore National Laboratory (LLNL) uses laser desorption/ionization to create ions that are introduced to the two TOF mass 
analyzers. SPAMS at LLNL was previously known as Bioaerosol Mass Spectrometry (BAMS) and has been applied to the detection of various species of Bacillus spores, ${ }^{64-70}$ viruses, ${ }^{64}$ toxin simulants, ${ }^{64}$ fungi, ${ }^{66}$ and Mycobacteria, ${ }^{70}$ with and without the use of a chemical matrix to aid in ionization. Matrix-free systems are ideal for real-time and online detection systems, as no sample preparation and thus very few reagents are needed for the analysis. The BAMS system has the ability to detect a small number of particles against a high background, creating the selectivity of the method. Using a matrix of 2,5,dihydroxybenzoic acid, detection limits as low as 14 zeptomol of gramicidin S per particle have been reported using the BAMS system, demonstrating the achievable sensitivity of the instrument. ${ }^{71}$

SPAMS also provides real-time detection via an automated data analysis system which could allow for early warning of a potential threat. By detecting single particles in the micrometer size range (picograms) with high throughput, these systems are capable of detecting trace quantities and allowing differentiation of signal from the background environment. As this work will show, an additional advantage of the SPAMS system is that it can be applied to the detection of chemical agents and high explosives without modification, making it a single instrument suitable for point detection and capable of continuously monitoring an environment for a wide variety of threats.

\subsection{Research Overview}

The goal of the work presented here was to determine if SPAMS was a viable detection system for high explosives and chemical agents. Single particles of several high explosives (TNT, RDX, PETN, Comp B, Semtex 1A, and Semtex 1H) were analyzed in order to determine the optimal instrumental conditions for their detection. To 
do so, the mass spectral response of these explosives was studied as a function of ionization laser energy. The composite explosives were studied to determine if the explosive components within could be detected using SPAMS. Using SPAMS for high explosive detection creates a trace point detector that is capable of on-line monitoring for these compounds, even in small (picogram) amounts.

Next, liquid CWA simulants (DMMP, DEEP, DEPA, DEP, and TEP) were studied to determine if SPAMS could also function as a detector for these compounds. The mass spectral response of the CWA simulants was studied as a function of the ionization laser energy in order to determine the best ionization conditions for analysis. Once the optimal conditions for liquid CWA simulants were determined, studies were performed to detect CWA simulants in the vapor phase. Since CWA vapors are difficult to detect, several solid support materials (activated carbon, zeolite, alumina, silica, manganese powder, tungsten powder, and titanium powder) were investigated to determine their ability to adsorb CWA simulant vapors and aid in their detection by direct sampling into the SPAMS instrument. By studying both liquid and vapor phase CWA simulants, a technique was developed that could analyze CWA samples independent of their phase. This work expands the known applications of SPAMS to include high explosives detection and chemical warfare agent detection in both the liquid and vapor phases. It also applies SPAMS to the detection of vapor-phase analytes, which is a new application of the technology. Since the SPAMS is an on-line monitoring system capable of single particle analysis, this work may offer some improvements over currently used detection techniques. 


\section{Chapter Two: Materials and Methods}

\subsection{Liquid Analyte Preparation}

\subsubsection{Liquid Explosive Sample Preparation}

TNT, RDX, PETN, Comp B, Semtex 1A, and Semtex 1H were obtained as solids from the High Explosives Applications Facility (HEAF) at LLNL. Stock solutions were made by dissolving approximately $10 \mathrm{mg}$ of explosive in $1 \mathrm{~mL}$ acetone (reagent grade, Sigma-Aldrich, St. Louis, MO). The stock solutions were made in glass vials, and stored in plastic secondary containers for the duration of the experiment. A $25 \mu \mathrm{L}$ aliquot of the explosive stock solution was diluted in $10 \mathrm{~mL}$ methanol (Burdick \& Jackson, biotechnology grade $99.9+\%$, Muskegon, MI) for analysis. A control blank solution was made by the addition of $25 \mu \mathrm{L}$ acetone (Burdick \& Jackson, HPLC grade $99.9+\%$, Muskegon, MI) to $10 \mathrm{~mL}$ methanol.

Safety Considerations - All explosives used in this study were secondary explosives and should be handled with care. No more than $10 \mathrm{mg}$ of each explosive were present in the laboratory, and whenever possible, samples were used and stored in solution. Safety glasses and nitrile gloves were worn when handling the solutions.

\subsubsection{Liquid Chemical Warfare Agent Simulant Sample Preparation}

Five chemical warfare agent (CWA) simulants, dimethyl methyl phosphonate (DMMP, a sarin simulant), diethyl ethyl phosphonate (DEEP, a sarin simulant), triethyl phosphate (TEP, a cyclosarin simulant), diethyl phosphoramidate (DEPA, a tabun simulant), and diethyl phthalate (DEP, a VX simulant) were obtained in their liquid form from Sigma-Aldrich (St. Louis, MO). A $10 \mathrm{~mL}$ aliquot of the CWA simulant was directly analyzed with no further preparation. 
Safety Considerations - While the chemicals used were simulants for chemical warfare agents, they still possess some toxicity. Safety glasses and nitrile gloves were always worn when handling the solutions, and the minimum amount of each agent was used.

\subsection{Liquid Analyte Sample Introduction}

\section{$\underline{\text { 2.2.1 Collison Nebulizer }}$}

The liquid samples were aerosolized using a six-jet low-volume glass Collison nebulizer (BGI Inc., Waltham, MA, product \# CN-25,27). The Collison nebulizer was developed by W. E. Collison as a simple and effective way to create uniform aerosols. ${ }^{72}$ The Collison nebulizer is shown in Figure 2-1. The nebulizing nozzle was a 316 stainless steel flat bottomed cylinder with six-jets evenly spaced around the lower perimeter of the

cylinder. ${ }^{73}$ The nozzle was placed into the liquid sample which filled the small well of the glass jar. A house nitrogen line was attached to the gas inlet on the "T-shaped" portion of the nebulizer, and carbon doped conductive tubing transferred the aerosolized samples from the nebulizer to the diffusion drier. 


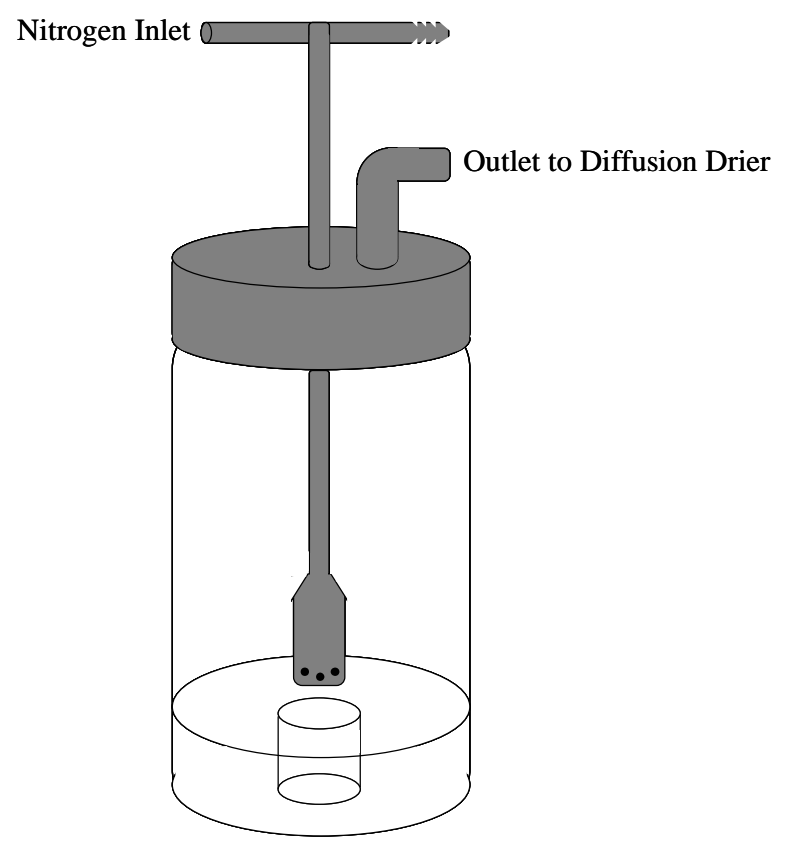

Figure 2-1: Schematic of the small-volume Collison nebulizer. Nitrogen gas is passed through the center tube and out through the six jets at the base of the cylinder. The sample aerosol forms in the nebulizer, and the particles are passed out the exit port via carbon doped conductive tubing to the diffusion drier.

\subsubsection{Diffusion Drier}

Once the sample was aerosolized it was passed through a diffusion drier to remove moisture and allow the solvent time to evaporate from the particles. The diffusion drier was built in-house at LLNL and filled with silica. The silica was replaced when the color changed from blue to pink, signifying saturation. The same diffusion drier was used for all samples in this work. Carbon doped conductive tubing transferred the aerosolized sample from the diffusion drier to the inlet of the single particle aerosol mass spectrometer. 


\subsection{Vapor Analyte Preparation}

\subsubsection{Vapor Chemical Warfare Agent Simulant Sample Preparation}

The liquid CWA simulants were also vaporized and adsorbed onto various surfaces before analysis by SPAMS. Adsorption of the CWA simulant vapors was tested on manganese powder, tungsten powder, titanium powder, zeolite, alumina, silica, and activated carbon (Sigma-Aldrich, St. Louis, MO). Several methods of adsorbing the vapors were investigated, as described below.

\subsubsection{Method One: Direct Vapor Adsorption}

A $1 \mathrm{~mL}$ aliquot of the liquid CWA simulant was placed on a small watch glass, which was in turn placed in a glass Petri dish. Approximately $300 \mathrm{mg}$ of adsorbent was placed directly into the Petri dish, which was covered, and allowed to interact for approximately two hours. The CWA-impregnated adsorbent sample was then placed in a glass vial; a clean stainless-steel nut was added to the vial to aid in aerosolization by increasing the number of particle-particle contact events. The sample was directly introduced to the SPAMS with carbon doped conductive tubing connected to either a modified vial cap made in-house, shown in Figure 2-2, or a $50 \mathrm{~mL}$ Sterile Disposable Vacuum Filtration Vial (Millipore Corp., Billerica, MA), shown in Figure 2-3. 


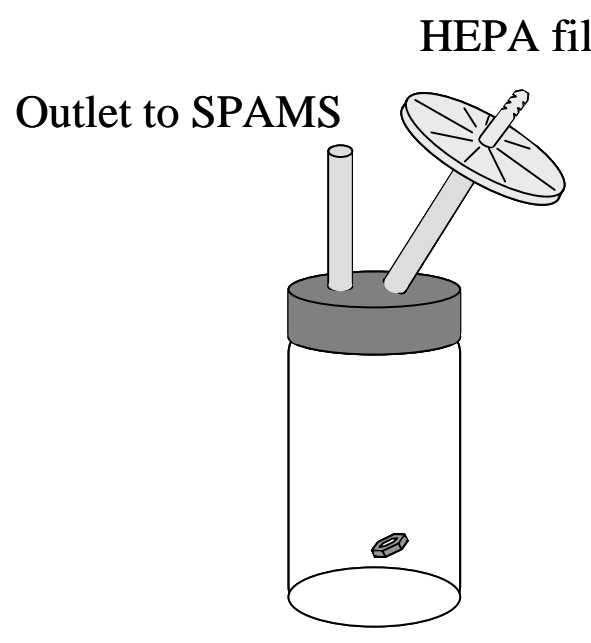

Figure 2-2: Schematic of direct powder sample introduction vial. The CWAimpregnated adsorbent powder is placed in the vial along with a stainless steel nut. The vial is then shaken to introduce the powder particles directly to the SPAMS via carbon doped conductive tubing.

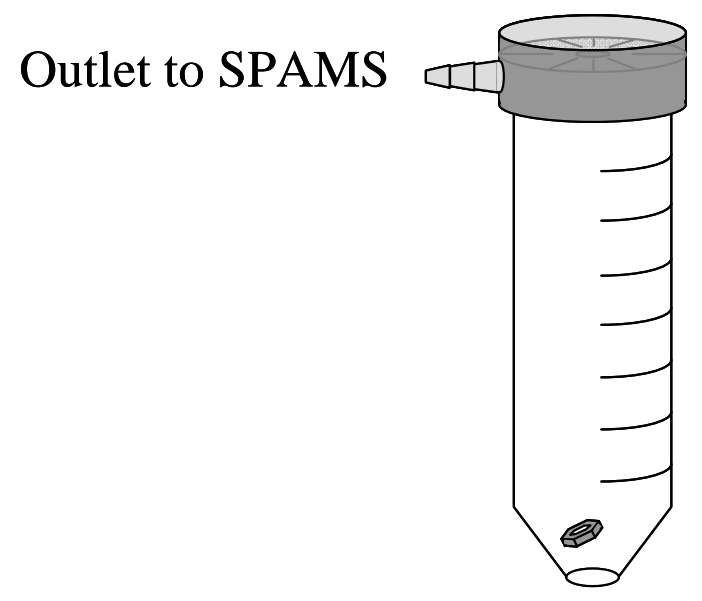

Figure 2-3: Schematic of a $50 \mathrm{~mL}$ Sterile Disposable Vacuum Filtration Vial. The solid analyte is placed in the plastic vial along with a stainless steel nut. The vial is then shaken to introduce the solid particles directly to the SPAMS via carbon doped conductive tubing. 


\subsubsection{Method Two: Vapor Chamber Adsorption}

A small piece of filter paper (Whatman Inc., Florham Park, NJ) was folded and inserted into a small sample vial ( 1.5 mL volume), soaked with approximately $250 \mu \mathrm{L}$ of CWA simulant, and placed in a large glass vial ( $\sim 20 \mathrm{~mL}$ volume). Approximately 0.5

$\mathrm{g}$ of adsorbent was placed in the large glass vial. The glass vial was then placed on a vortexer at a low setting for approximately 30 minutes. For sample introduction into the SPAMS, the small glass vial was removed, a stainless steel nut added, and the modified vial cap placed on the large vial to connect to the instrument with carbon doped conductive tubing.

\subsubsection{Method Three: Wet Particle Adsorption}

Approximately $0.25 \mathrm{~g}$ of adsorbent was placed in a small-volume plastic nebulizer (Salter Labs, Arvin, CA). A $2 \mathrm{~mL}$ aliquot of CWA simulant was added and introduced to the SPAMS through the diffusion drier in the same manner as the liquid samples described above.

\subsection{Solid Analyte Preparation}

\subsubsection{Solid Explosive Sample Preparation}

A solid sample of TNT was obtained by allowing the acetone storage solvent to evaporate. The solid sample was crushed and transferred to a $50 \mathrm{~mL}$ Sterile Disposable Vacuum Filtration Vial, and a stainless-steel nut added to aid in particle contact. The vial is shown in Figure 2-3. The vial was connected to the SPAMS via carbon-doped conductive tubing and shaken to introduce the sample to the instrument. 


\subsection{Description of Single Particle Aerosol Mass Spectrometer}

\subsubsection{Sample Introduction and Focusing}

The Single Particle Aerosol Mass Spectrometer (SPAMS) is a commercial single particle mass spectrometer (TSI, Inc., Shoreview, MN) that was highly modified in-house at $\mathrm{LLNL}^{66}$ and is shown in Figure 2-4.

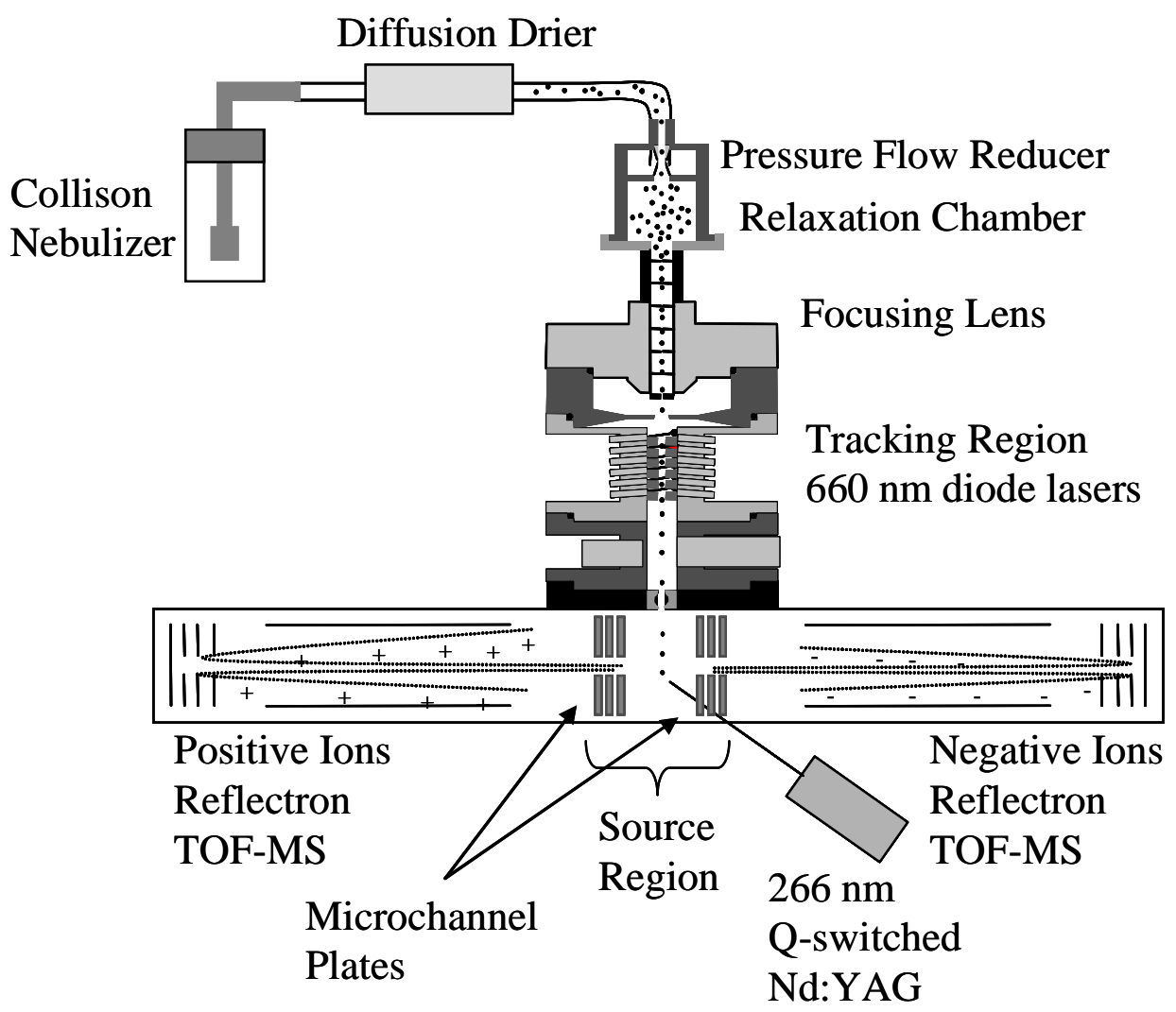

Figure 2-4: Schematic of a Single Particle Aerosol Mass Spectrometer (SPAMS) used to obtain positive and negative ion time-of-flight mass spectra of high explosives and CWA simulants. Aerosol samples are dried and sampled into the SPAMS where they are aerodynamically focused, tracked, and characteristic molecules from the aerosol particles are desorbed and ionized by a Nd:YAG laser $(266 \mathrm{~nm})$. Positive and negative ion spectra of single particles are simultaneously collected by a dual-polarity reflectron time-of-flight mass spectrometer. 
The particles from the diffusion drier enter the SPAMS through a pressure flow reducer and an aerodynamic focusing lens. The pressure flow reducer reduces the flow and pressure of the analyte stream as it enters the instrument, which must operate under vacuum. The aerosol is passed through two head-facing conical apertures which decimate the flow. The flow then reaches a relaxation chamber which removes the directionality of the particles. The particles are then introduced to the aerodynamic focusing lens which consists of nine thin lenses that center the particles traveling through the cavity, and accelerate the focused flow through the instrument. The speed of the particle through this region of the instrument is dependent on its size; smaller particles travel faster than larger particles. After leaving the aerodynamic focusing lens, the particles pass through the tracking region of the SPAMS. The tracking region contains up to six continuous wave $660 \mathrm{~nm}$ diode lasers paired with six channel photomultipliers (CPMs, part c962, Perkin Elmer Optoelectronics, Santa Clara, CA), all in series (three of each were used in these experiments). Each CPM measures a constant signal from one of the diode lasers. As a particle passes through each laser beam, it scatters the laser light, reducing the signal reaching each CPM. The time between the scattering events of each consecutive laser is used to determine the velocity of the particle with software and a field-programmable gate array. This velocity is used to calculate the particle's aerodynamic size (diameter) based on a calibration created by running a series of polymeric beads (Bangs Laboratories, Inc., Fishers, IN, and Duke Scientific Corp, Fremont, CA) of known size. Aerodynamic size is a parameter used to describe an aerosol particle, and is defined as the diameter of a unit-density spherical object that moves with an equal velocity through a fluid. ${ }^{74}$ The sized particle then passes into the 
ionization source region of the mass spectrometer. Internal electronics use the aerodynamic size and particle velocity to calculate the time when the particle reaches the center of the source region. At this time, the desorption/ionization (D/I) laser is triggered and fires at the particle, desorbing and ionizing it, creating positive and negative ions. The D/I laser was a Q-switched frequency-quadrupled Nd:YAG laser (Ultra CFR, Big Sky Laser Technologies, Inc., Bozeman, MT) operating at $266 \mathrm{~nm}$ with $7 \mathrm{~ns}$ (full width half-maximum, FWHM) pulses. The positive and negative ions generated in the source region are accelerated in opposite directions through two linear reflectron-time-of-flight mass analyzers $($ length $=536 \mathrm{~mm})$. Two spectra are therefore obtained simultaneously: one due to the ions formed with a positive charge, and one due to the ions formed with a negative charge. The dual-polarity nature of the technique generated complementary sets of information on the structure of the sample.

\subsubsection{Mass Analyzers}

A time-of-flight mass analyzer is based on the determination of the mass of an ion by measuring the time of its arrival at a detector after traveling through a field-free drift region into which it was accelerated by an electric field. ${ }^{75,76}$ This time is calculated by Equation 2-1, where $\mathrm{m}$ is the mass of the ion $(\mathrm{kg}), \mathrm{d}$ is the distance the ion travels to the detector $(\mathrm{m}), \mathrm{z}$ is the charge of the ion, $\mathrm{e}$ is the charge of an electron $(\mathrm{C})$, and $\mathrm{V}_{\mathrm{S}}$ is the accelerating voltage $(\mathrm{V})$.

$$
t^{2}=\frac{m d^{2}}{2 z e V_{S}}
$$

Equation 2-1: Transit time of an ion in a time-of-flight mass analyzer. ${ }^{75}$ 
The reflectron time-of-flight mass analyzer was developed to correct for the error in the time of arrival of ions of equal masses due to variation in their time of ionization and initial kinetic energy. ${ }^{75}$ A reflectron is added to the end of the mass analyzer; the reflectron is composed of a retarding field that deflects ions back through the flight tube. Ions with larger kinetic energies enter this decelerating region and travel deeper into it than those with lower energies. Those with lower energy are reflected quickly, and travel back towards the source region, whereas those with higher energy are slowed slightly. This results in an increased resolution for the measurement, in that the ions of equal mass will reach the detector in a shorter time packet. ${ }^{75}$ Ions were detected via ring-shaped microchannel plates (MCP, Burle Technologies, Inc., Lancaster, PA) that surround the entrance from the source region. The MCP signal was digitized (Signatec, Inc., Newport Beach, CA, PDA1000) at 8 bits with 256 arbitrary units (a.u.) on a $333 \mathrm{mV}$ scale.

\subsubsection{Description of Laser Optics}

The optical setup of the Nd:YAG laser is shown in Figure 2-5. The emitted radiation of the Nd:YAG laser passes through two frequency doublers to create the 266 $\mathrm{nm}$ beam. The beam then passes through an aperture to remove the lower energy periphery of the beam, a rotatable half-wave plate which controls beam energy, and a vertical polarizer to select only one polarized plane of light. The transmitted light is then imaged through a $10 \mathrm{~cm}$ plano-convex focusing lens onto two mirrors and into the spectrometer source region. The resulting light was an approximately $330 \mu \mathrm{m}$ diameter spot at the point of intersection with the particle beam. The cross-sectional profile of the beam was near flat-top ${ }^{64}$ with some areas of lower energy, especially near the edges of the beam. Laser pulse energy was controlled by adjustment of the rotation of the half- 
wave plate, and was measured behind the laser exit optical window at the rear of the ion source chamber with a laser power meter (Coherent, Inc., Santa Clara, CA, J25LP-MUV) with digital readout. Power measurements were determined for each experiment and are reported as an average of 50 pulses and corrected for the measured energy loss in the back window. The variation in the laser energy from pulse to pulse was determined, and was typically less than 5\%. Fluence is a measure of the laser energy per unit of the beam and was calculated by dividing the net laser energy by the cross-sectional area of the laser beam $\left(0.0855 \mathrm{~mm}^{2}\right)$. The energy incident on a particular particle was calculated by multiplying the laser fluence by the cross-sectional area of the particle, assuming a spherical geometry.

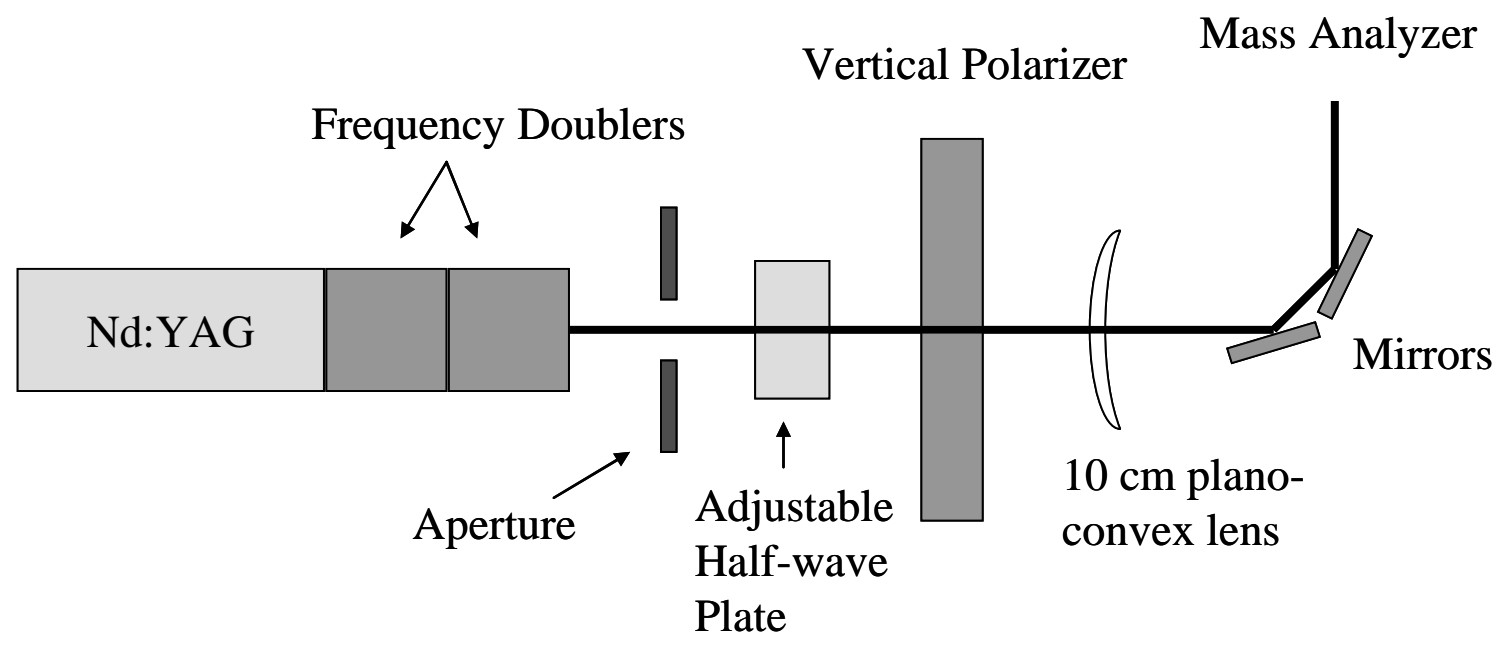

Figure 2-5: Schematic of laser optic system. Radiation from a Nd:YAG laser is passed through two frequency doublers, creating a $266 \mathrm{~nm}$ beam. The beam then passes through an aperture, an adjustable half-wave plate which is used to control the laser energy, and a vertical polarizer to isolate one polarization of light. A $10 \mathrm{~cm}$ plano-convex lens and two mirrors are used to image the beam into a $330 \mu \mathrm{m}$ spot inside the mass analyzer. 


\subsubsection{Data Analysis}

The particle size data and mass spectra were recorded using a program developed in-house using MatLAB (The Mathworks, Inc., Natick, MA). Software parameters were set to record a specific number of mass spectra per experiment; generally 1000 spectra were obtained for the liquid samples, and 500 spectra for the solid samples for statistical purposes. Spectra were saved and analyzed using 'Irene', an in-house program written in MatLAB. 'Irene' allowed spectra to be integrated, specific regions to be probed, spectral averaging, and spectral sorting by ion signal at a particular $\mathrm{m} / \mathrm{z}$ value. 


\section{Chapter 3: Analysis of High Explosives Using SPAMS}

\subsection{Motivation and Background}

This chapter describes the use of SPAMS to obtain mass spectra from high explosives. The motivation for this research is the need for a fast, sensitive, and specific detection system that is applicable to a wide number of compounds. Current technologies for explosives detection, such as IMS, are limited in that the instrument must be tuned to optimize the detection of specific classes of compounds. ${ }^{6}$ Others, such as LIF, require consumables or extensive sample preparation that reduces their viability for fast analyses and may reduce the selectivity of the measurement. ${ }^{18}$ Although other mass spectrometry techniques have been applied to the detection of explosives, ${ }^{12,} 25,28,31,33,37-39,77-83$ dualpolarity single particle detection has not been performed. SPAMS has been previously used for the detection of biological compounds, ${ }^{64-71}$ and it is shown herein that similar success was achieved for the detection of high explosives First, experiments calibrating the SPAMS D/I laser are described. Next, mass spectra of crushed 2,4,6-trinitrotoluene (TNT) particles are analyzed and compared to those of TNT particles nebulized from a methanol solution in order to validate the sampling method. Mass spectral response as a function of D/I laser fluence is then discussed for TNT, 1,3,5-trinitro-1,3,5 triazinane (RDX), and pentaerythritol tetranitrate (PETN). The analysis of several composite explosives, Composition B (Comp B), Semtex 1A, and Semtex 1H is then described. It is concluded that SPAMS is a successful technique for the detection and identification of high explosives. 


\subsection{Laser Calibration}

The power of the D/I laser was adjusted by rotation of the half-wave plate as described in Chapter Two. The laser power was then read from a laser power meter that measured the laser beam through an optical window at the back of the sample region. Error may exist in the power readings because a small amount of energy is adsorbed by the optical window; this adsorption increases as the optical window as it ages. In order to account for this energy loss, the laser power readings were calibrated by recording the laser energy for a series of half-wave plate rotations. This energy reading was the energy that was read on the meter during an experiment, and includes the energy lost in the optical window. The back optical window was then removed, and the measurements repeated. This laser energy reading was a measure of the energy inside the source region that a sample particle would experience during an experiment. The laser energy from both measurements was plotted as a function of half-plate rotation; the resulting calibration curve was used to correct the measured laser values for all measurements. The calibration procedure was repeated when a significant change in the maximum laser energy reading occurred, generally once a month. The calibration curve used for all experiments with explosives is shown in Figure 3-1A. A second calibration curve was made before the experiments involving CWA simulants which was used to correct the laser energy values in that study. 


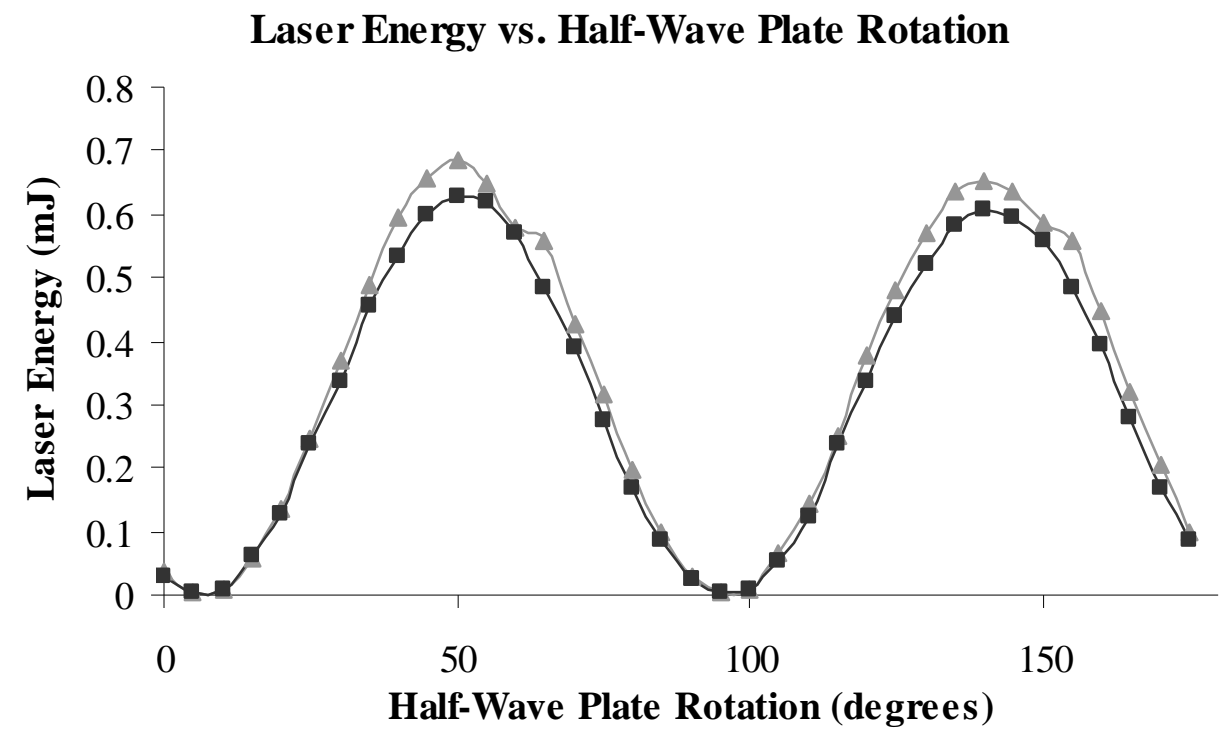

Figure 3-1: Calibration curve describing the laser power meter reading with and without the back optical window in place. Gray triangles describe the case where the optical window is removed and represents the actual energy incident on a particle in the center of the source region. Black squares describe the case when the optical window is in place and represents the energy measured during experiments.

\subsection{Method Validation}

Explosive samples are typically encountered in the solid phase. Trace explosive residues consist of small solid particles of explosive that can easily be transferred to clothing or luggage, for example. However, solid particles are difficult to directly and reproducibly produce for analysis with SPAMS; thus, the technique was developed using samples of explosives in solution. These samples were aerosolized from a methanol solution and passed through conductive tubing and a diffusion drier, so they were most likely dried particles by the time the sample reaches the SPAMS; however, it was not certain that the resulting mass spectra could be applied to direct solid samples. In order 
to validate that results obtained using liquid samples are indicative of those from solid samples, a study was performed using a small amount of solid sample for comparison.

TNT was prepared as a liquid sample in methanol as described in Chapter Two and introduced to the SPAMS via the Collison nebulizer and diffusion drier. Mass spectra and size information were recorded for 1000 particles using a laser fluence of $0.70 \mathrm{~nJ} / \mu \mathrm{m}^{2}$, which corresponds to an average energy of $0.64 \mathrm{~nJ} /$ particle. This laser fluence was chosen based on preliminary data that revealed a significant peak from the parent ion of TNT was obtained with this energy. Figure 3-2A shows the concatenated positive and negative mass spectra obtained in two seconds from five consecutively analyzed particles (diameter $1.08 \mu \mathrm{m}$, RSD 5.0\%) from the liquid TNT samples. A solid TNT sample was also analyzed using SPAMS. The solid sample was crushed and introduced directly to the instrument using a $50 \mathrm{~mL}$ Sterile Disposable Vacuum Filtration Vial as described in Chapter Two. Mass spectra and size information were recorded for ten solid particles using a laser fluence of $0.75 \mathrm{~nJ} / \mu \mathrm{m}^{2}$. Figure $3-2 \mathrm{~B}$ shows a spectrum obtained from one of these solid particles (diameter $1.28 \mu \mathrm{m}$ ). 


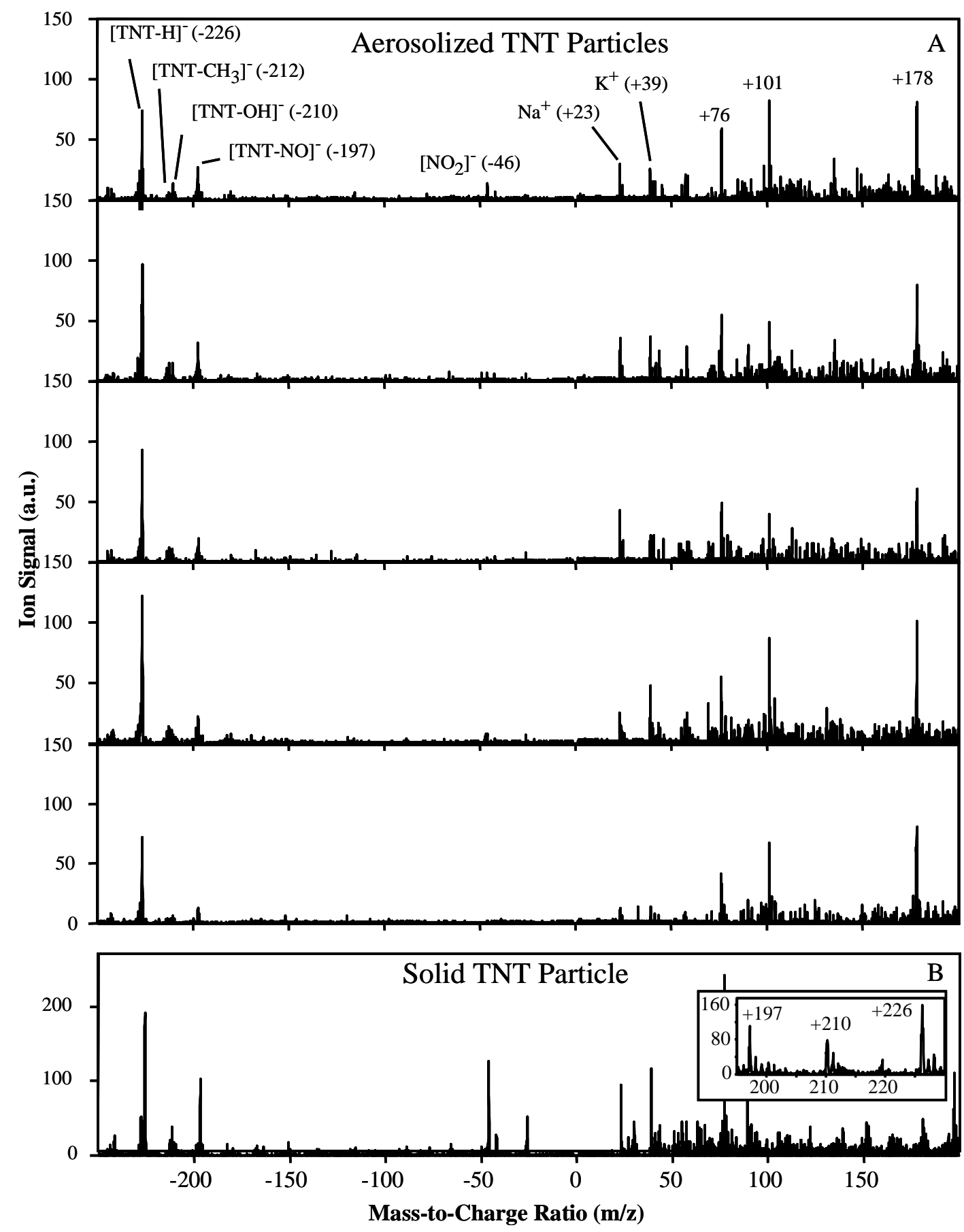

Figure 3-2: (a) Single particle mass spectra of five consecutive single TNT particles (diameter $1.08 \pm 0.05 \mu \mathrm{m}$ ) obtained at a laser fluence of $0.70 \mathrm{~nJ} / \mu \mathrm{m}^{2}$. These spectra for successive particles are shown to present the typical shot-to-shot variation of the technique. (b) Single particle mass spectrum of a single TNT particle introduced into the SPAMS system from a crushed powder with no solvent, obtained at $0.75 \mathrm{~nJ} / \mu \mathrm{m}^{2}$. 
Although the mass spectra were obtained over a large $\mathrm{m} / \mathrm{z}$ range (-500 to $500 \mathrm{amu}$ ), only the $\mathrm{m} / \mathrm{z}$ range containing observed peaks (-250 to $200 \mathrm{amu}$ ) is shown (except inset). Slight variations in peak height are present from spectrum to spectrum of the nebulized particles, but the diagnostic peaks for TNT are present in all spectra, and are discussed below. As seen in the figure, the single solid particle spectrum contains the same peaks in the negative spectrum that are used to identify TNT as the nebulized particles, as well as several peaks in the positive ion spectrum $(\mathrm{m} / \mathrm{z}+197,+210,+226)$ that are not present in the nebulized sample but are also indicative of TNT ([TNT-NO $]^{+},[\mathrm{TNT}-\mathrm{OH}]^{+}$, and $[\text { TNT-H }]^{+}$, respectively). The presence of these additional peaks could be due to the difference in sampling or there could be slight differences in the TNT sample itself, as the solid TNT sample was from a previously obtained lot than the nebulized liquid sample. Because of the similarity of the negative ion spectra and the suitability of either sample for the evaluation of high explosives detection using SPAMS, either aerosolization method could have been used for subsequent experiments. For reasons of safety, ease of aerosolization, and particle size consistency, particles from nebulized solutions were used for the remainder of the experiments.

\subsection{Signal Reproducibility of SPAMS}

The 1000 mass spectra obtained from single particles of the liquid TNT sample with a laser fluence of $0.70 \mathrm{~nJ} / \mu^{2}$ were analyzed to determine if the signal was reproducible from particle to particle. The average diameter of the 1000 detected TNT particles was $1.06 \mu \mathrm{m}$ (RSD 38.4\%). The particle size histogram was fitted to a Gaussian curve $\left(\mathrm{R}^{2}=0.960\right)$ and $\mathrm{z}$ values were used to eliminate 27 outlier particles at a $99.99 \%$ level of confidence. Removal of these particles from the size analysis yielded an average 
diameter of $1.00 \mu \mathrm{m}$ (RSD 10.8\%). In order to compare the consistency of the spectra, the peak area for the $[\mathrm{TNT}-\mathrm{H}]^{-}$peak at m/z -226 was calculated for each particle over a three $\mathrm{m} / \mathrm{z}$ window (-228 to $-225 \mathrm{amu}$ ) to include all parent ion contributions. The average peak area for the 1000 spectra was calculated to be 1468.3 arbitrary units (a.u.), RSD = $38.2 \%$, resolution $\sim 430$ (1208.9 a.u., RSD $=37.8 \%$ with outliers removed). The high peak area variation has several potential sources including: the particle size variation, the variation in particle morphology, and the difference in laser energy received by each particle. The particles were treated as spheres in the calculations; however, particles of various shapes and morphologies are a more realistic assumption. The orientation of an asymmetrical particle in the laser beam may explain some variation in the area. Variation also exists in the energy present in the laser beam. Previous research has shown that the optics used in focusing the D/I laser create a laser profile that has a roughly "flat top" distribution of energy as described in Chapter Two; ${ }^{64}$ however particles that are focused near the edges of the beam may experience a lower D/I energy. ${ }^{67}$ Also, the laser fluence of $0.70 \mathrm{~nJ} / \mu \mathrm{m}^{2}$ is an average value of 50 consecutive laser pulses, so variation exists shotto-shot, although it is typically less than $5 \%$.

In order to determine if the shot-to-shot variation could be accounted for by these sources of error, the area of the $\mathrm{m} / \mathrm{z}-226$ peak was normalized to the total area of the negative ion spectrum from $\mathrm{m} / \mathrm{z}-500$ to -1 , yielding 0.190 normalized a.u., $\mathrm{RSD}=28.8 \%$ ( 0.157 normalized a.u., RSD $=28.3 \%$ with outliers removed). While this RSD is approximately $10 \%$ lower than that of the raw data, it is still very high; thus, while some of the variance can be attributed to particle size, morphology, and laser intensity, other sources of error must be present. 


\subsection{Power Study of TNT}

The effect of laser energy on the desorption/ionization of TNT was investigated by obtaining mass spectra using laser energies that span the possible output range of the D/I laser (approximately 0 to $0.6 \mathrm{~mJ}$ for this study, corresponding to 0 to $7 \mathrm{~nJ} / \mu \mathrm{m}^{2}$ ). Laser energies near $0.05,0.1,0.2,0.4$, and $0.6 \mathrm{~mJ}$ were targeted; however, variation in laser output resulted in some variation in the actual energy measured. The laser energy for each sample, corrected using the calibration discussed previously and converted to fluence, is reported. Average mass spectra of 1000 individual TNT particles obtained with laser fluences of $0.70,1.51,2.51,5.21$, and $6.99 \mathrm{~nJ} / \mu \mathrm{m}^{2}$ are shown in Figure 3-3. 


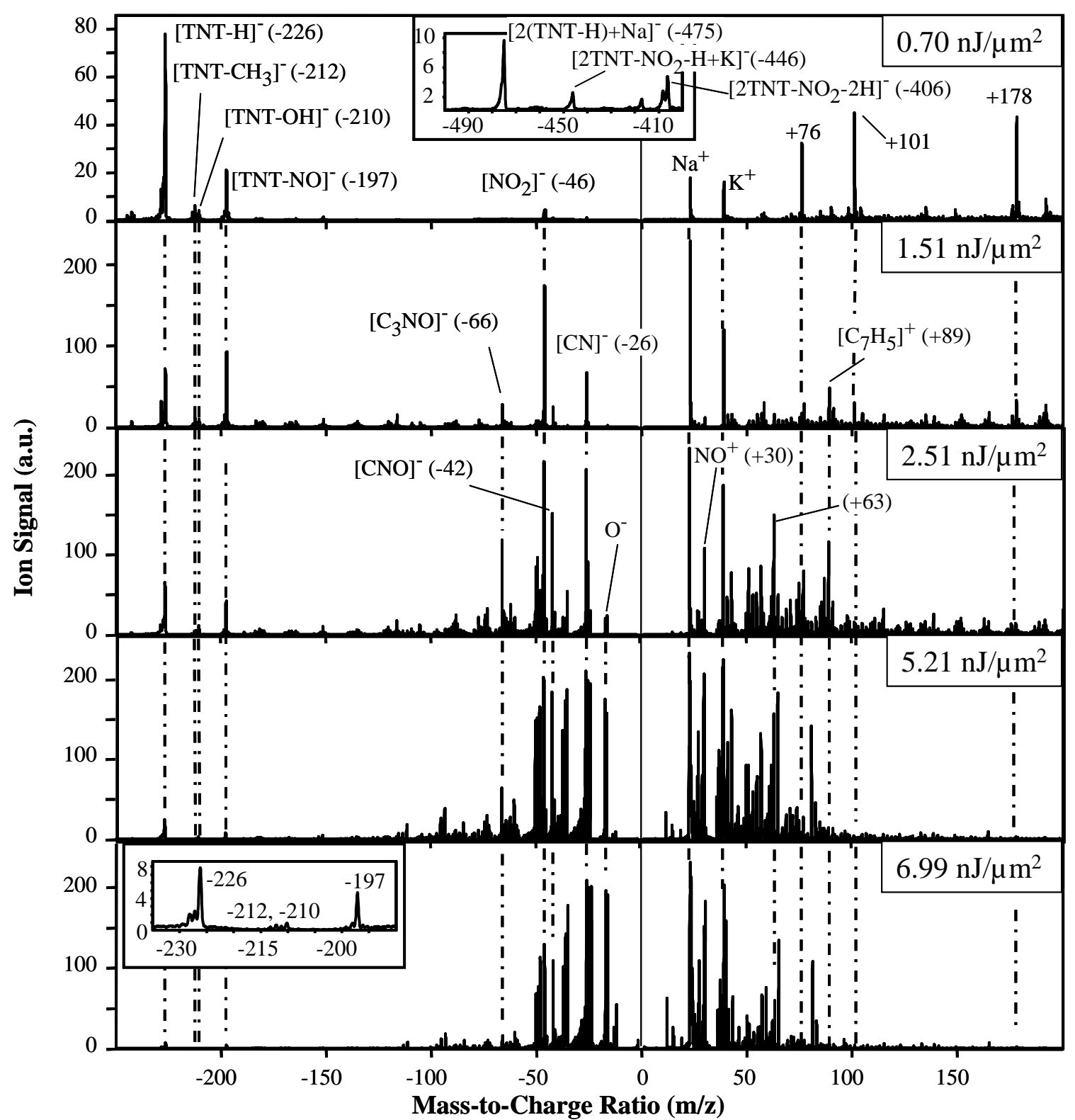

Figure 3-3: Single particle mass spectra of aerosolized TNT at laser fluences of 0.70 ,

$1.51,2.51,5.21$, and $6.99 \mathrm{~nJ} / \mu^{2}$ (note differences in ion signal). Each spectrum is the average of 1000 single particle spectra. The average particle was $1.05 \pm 0.08 \mu \mathrm{m}$ in diameter. Note the $[\mathrm{TNT}-\mathrm{H}]^{-}$peak at $\mathrm{m} / \mathrm{z}-226$ is present at all laser fluences. The spectrum obtained at a laser fluence of $0.70 \mathrm{~nJ} / \mu \mathrm{m}^{2}$ also contained peaks at higher masses, shown in the inset; the spectrum obtained at $6.99 \mathrm{~nJ} / \mu \mathrm{m}^{2}$ also contains an inset to show the presence of the $\mathrm{m} / \mathrm{z}-226,-212,-210$, and -197 peaks, although the signal is low. 
The average particle size was $1.05 \mu \mathrm{m}$ (RSD 7.2\%) for all laser powers. The molecular ion is present in the spectra, which is typical of nitroaromatic explosives that typically have peak absorbances near $254 \mathrm{~nm},{ }^{24}$ which is close to the $266 \mathrm{~nm}$ at which the laser was operated. At $0.70 \mathrm{~nJ} / \mu \mathrm{m}^{2}$, the $[\mathrm{TNT}-\mathrm{H}]^{-}$is most prevalent, which is observed at $\mathrm{m} / \mathrm{z}$ -226. As the laser power is increased, this parent ion is fragmented, resulting in a decreasing parent ion peak intensity accompanied by an increase in fragment ions. At higher fluences, the $[\mathrm{TNT}-\mathrm{H}]^{-}$ion is not the major peak in the spectrum; however, it is still apparent in the spectrum obtained, even at $6.99 \mathrm{~nJ} / \mu \mathrm{m}^{2}$. The increased fragmentation is apparent in the higher laser energy spectra, where numerous peaks appear due to loss of nitrate groups $(\mathrm{m} / \mathrm{z}-46,+30,+63,+72,+89)$ and the breaking of the aromatic ring $(\mathrm{m} / \mathrm{z}-197,-66,-42,-26,+81)$. Interestingly, the spectra taken at $0.70 \mathrm{~nJ} / \mu \mathrm{m}^{2}$ also contain peaks at $\mathrm{m} / \mathrm{z}$ well above the mass of TNT (inset, Figure 4). These peaks are possibly due to the dimerization of TNT; $[2(\mathrm{TNT}-\mathrm{H})+\mathrm{Na}]^{-}(\mathrm{m} / \mathrm{z}-475),\left[2 \mathrm{TNT}-\mathrm{NO}_{2}-\mathrm{H}+\mathrm{K}\right]^{-}(\mathrm{m} / \mathrm{z}-446)$, and $\left[2 \mathrm{TNT}-\mathrm{NO}_{2}-2 \mathrm{H}\right]^{-}(\mathrm{m} / \mathrm{z}-406)$. Peaks due to the dimerization of TNT have previously been described at $\mathrm{m} / \mathrm{z}-408$ and -447 , which are analogous to the dimers detected in this study with the addition of protons. ${ }^{84}$ Several other high mass peaks which have been previously identified, ${ }^{29,31,39}$ attributed to [TNT-CH$\left._{3}\right]^{-}$, [TNT-OH] $^{-}$, and [TNT-NO] ${ }^{-}(\mathrm{m} / \mathrm{z}$ $-212,-210-197$, respectively) that are distinct in the low energy TNT spectra are greatly reduced at high energies, presumably due to extensive fragmentation. Thus, spectra obtained with lower D/I laser fluences $\left(0.70\right.$ and $\left.1.51 \mathrm{~nJ} / \mu \mathrm{m}^{2}\right)$ allow for the more facile identification of TNT, due to the presence of the parent ion and other high mass peaks. 


\subsection{Power Study of RDX}

Average mass spectra of 1000 individual RDX particles at laser fluences of 0.57 , $1.39,2.63,4.83$, and $7.80 \mathrm{~nJ} / \mu \mathrm{m}^{2}$ are shown in Figure 3-4. 


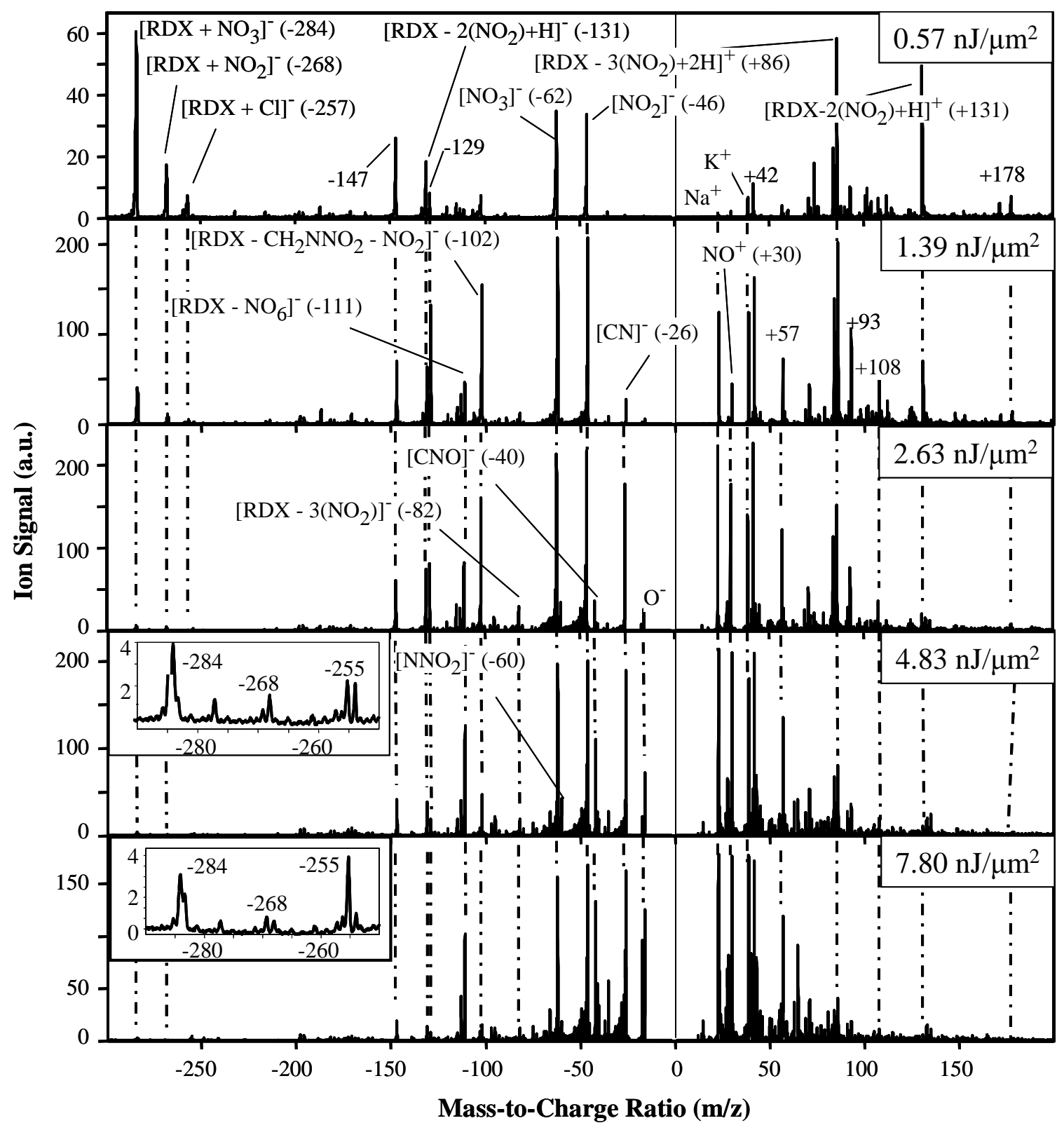

Figure 3-4: Single particle mass spectra of aerosolized RDX at laser fluences of 0.57, $1.39,2.63,4.83$, and $7.80 \mathrm{~nJ} / \mu \mathrm{m}^{2}$ (note differences in ion signal). Each spectrum is the average of 1000 single particle spectra. The average particle was $1.00 \pm 0.03 \mu \mathrm{m}$ in diameter. Note the $\left[\mathrm{RDX}+\mathrm{NO}_{3}\right]^{-}$peak at $\mathrm{m} / \mathrm{z}-284$ is present at all laser fluences. An inset is shown for the spectra obtained at higher laser fluences to allow visualization of the peaks between $\mathrm{m} / \mathrm{z}-290$ and -250 . 
The average particle size was $1.00 \mu \mathrm{m}$ (RSD 2.7\%) for all laser powers. The parent ion is present in neither the positive nor the negative spectrum; this has been previously documented and it has been suggested that this is due to the low bond energy of $\mathrm{N}$ $\mathrm{NO}_{2}{ }^{24,31}$ However, several peaks are present that can be used to identify RDX. The $\left[\mathrm{RDX}+\mathrm{NO}_{3}\right]^{-}$ion is the most prominent in the $0.57 \mathrm{~nJ} / \mu \mathrm{m}^{2}$ spectrum $(\mathrm{m} / \mathrm{z}-284),{ }^{39}$ but its intensity decreases as the D/I laser energy increases. The same trend is seen for [RDX + $\left.\mathrm{NO}_{2}\right]^{-}$and $[\mathrm{RDX}+\mathrm{Cl}]^{-}\left(\mathrm{m} / \mathrm{z}-268,-257\right.$, respectively). ${ }^{25,31,39}$ Possibly, as the laser energy increases, less RDX remains intact to react and form these RDX adducts. At a laser fluence of $7.80 \mathrm{~nJ} / \mu^{2}$ the peak at $\mathrm{m} / \mathrm{z}-257$ is not present; however a new peak at $\mathrm{m} / \mathrm{z}-255$ is seen. The source of this peak is unknown although it is not likely to be due to a chlorine adduct since no isotopic pattern is present. The peak at $\mathrm{m} / \mathrm{z}-102$, due to $\left[\mathrm{RDX}-\mathrm{CH}_{2} \mathrm{NNO}_{2}-\mathrm{NO}_{2}\right]^{-}$, is typically seen in the mass spectra of nitramines, ${ }^{24,31}$ and is present in the RDX spectra obtained with all laser fluences. The most prominent peak in the positive ion spectra is attributed to $\left[\mathrm{RDX}-3\left(\mathrm{NO}_{2}\right)\right]^{+}(\mathrm{m} / \mathrm{z}+86)$. The intensity of this peak increases almost a factor of four from laser fluence $0.57 \mathrm{~nJ} / \mu \mathrm{m}^{2}$ to $1.39 \mathrm{~nJ} / \mu \mathrm{m}^{2}$, and then decreases as the D/I laser energy is increased further. It is possible that there is insufficient energy at the lowest laser fluence to completely remove all the nitro groups from the RDX. This hypothesis is supported by the increase in intensity of the $\left[\mathrm{NO}_{3}\right]^{-}$ and $\left[\mathrm{NO}_{2}\right]^{-}$ions as laser fluence is increased above $1.39 \mathrm{~nJ} / \mu \mathrm{m}^{2}$. The decrease in intensity of the $\mathrm{m} / \mathrm{z}+86$ peak as the laser power is further increased may be due to more extensive fragmentation. Several other peaks show the same trend, such as [RDX$\left.2\left(\mathrm{NO}_{2}\right)+\mathrm{H}\right]^{-}(\mathrm{m} / \mathrm{z}-131)$. A peak at $\mathrm{m} / \mathrm{z}-46$ due to the characteristic $\mathrm{NO}_{2}{ }^{-}$of explosives is present in the negative spectrum of RDX, as well as in the negative spectrum of TNT. 


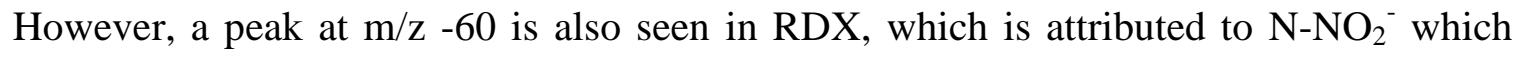
could aid in distinguishing a nitramine from a nitroaromatic explosive. Since more high mass peaks were identified in the spectrum obtained with a laser fluence of $0.57 \mathrm{~nJ} / \mu \mathrm{m}^{2}$, this was chosen as the optimal detection energy for RDX.

\subsection{Power Study of PETN}

Average mass spectra of 1000 individual PETN particles at laser fluences of 0.57 , $1.33,2.88,5.39$, and $7.95 \mathrm{~nJ} / \mu \mathrm{m}^{2}$ are shown in Figure 3-5. 


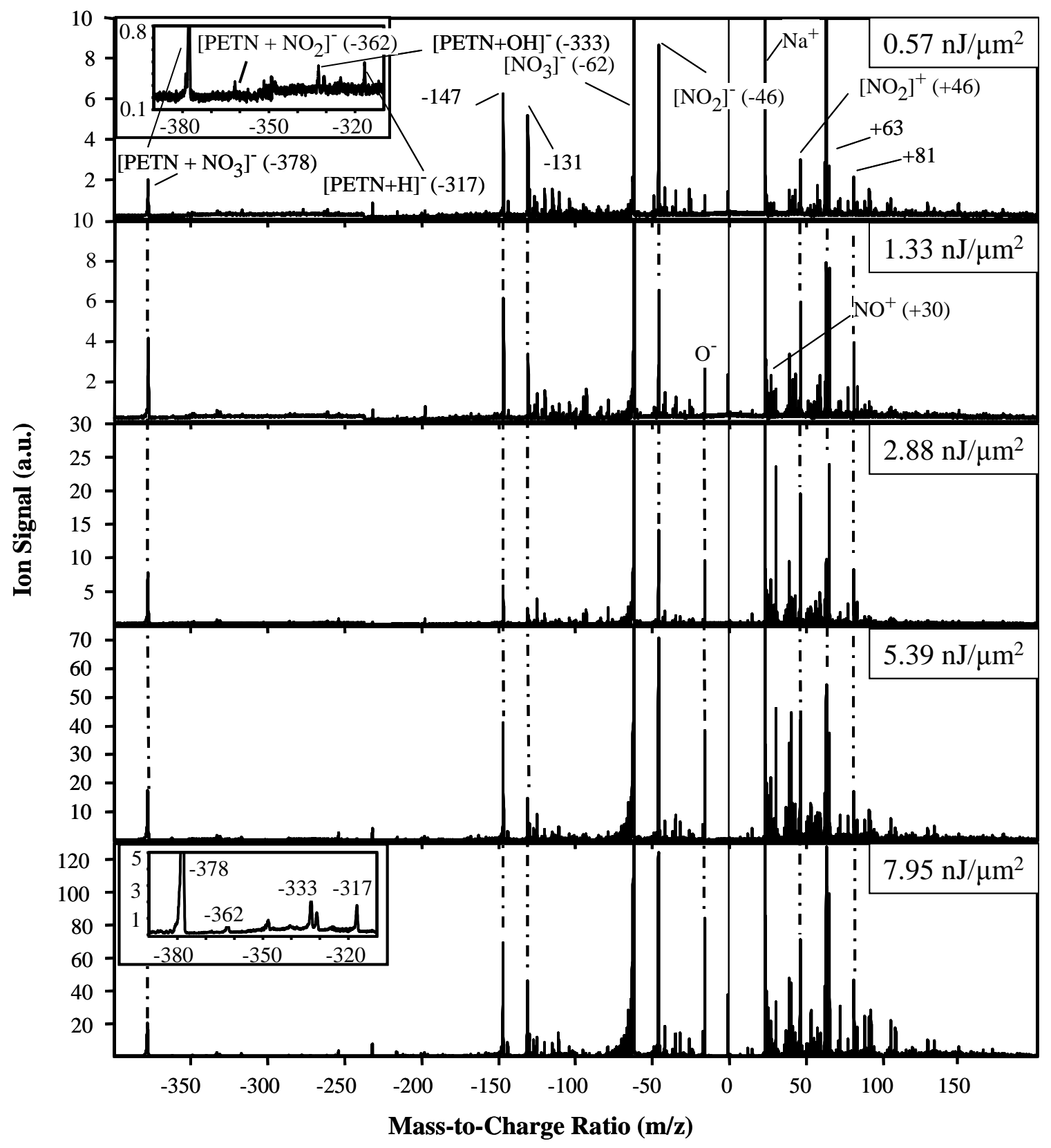

Figure 3-5: Single particle mass spectra of aerosolized PETN at laser fluences of 0.57, $1.33,2.88,5.39$, and $7.95 \mathrm{~nJ} / \mu \mathrm{m}^{2}$ (note differences in ion signal). Each spectrum is the average of 1000 single particle spectra. The average particle was $1.10 \pm 0.12 \mu \mathrm{m}$ in diameter. Note the $\left[\mathrm{PETN}+\mathrm{NO}_{3}\right]^{-}$peak at $\mathrm{m} / \mathrm{z}-378$ is present at all laser fluences. Insets are included to highlight the presence of ion peaks between $\mathrm{m} / \mathrm{z}-390$ and -310 . 
The average particle size was $1.10 \mu \mathrm{m}$ (RSD 10.6\%) for all laser powers. A small but significant signal from the parent ion is seen at $\mathrm{m} / \mathrm{z}-317$ at a fluence of $0.57,5.39$, and $7.95 \mathrm{~nJ} / \mu \mathrm{m}^{2}$. It is unclear why this peak is not seen with fluences of 1.33 and 2.88 $\mathrm{nJ} / \mu \mathrm{m}^{2}$. The most prominent peak at all laser fluences is attributed to $\left[\mathrm{NO}_{3}\right]^{-}$at $\mathrm{m} / \mathrm{z}-62$, due to the presence of nitrate esters in PETN. ${ }^{24}$ The $\left[\mathrm{PETN}+\mathrm{NO}_{3}\right]^{-}$complex can be seen at $\mathrm{m} / \mathrm{z}-378$ and its intensity increases with laser energy, ${ }^{39}$ allowing more facile identification of PETN when using higher D/I laser energies. A [PETN+NO $\left.]_{2}\right]^{-}$complex is also seen at $\mathrm{m} / \mathrm{z}-362$, as well as $[\mathrm{PETN}+\mathrm{OH}]^{-}(\mathrm{m} / \mathrm{z}-333)$, both of which follow the same trend towards higher laser fluences. ${ }^{39}$ Few fragments appear in the spectrum due to the symmetry of the molecule, and fragments that are observed are more prevalent at higher laser fluences. The main fragments characteristic of PETN may be $\left[\mathrm{C}_{3} \mathrm{H}_{3} \mathrm{~N}_{2} \mathrm{O}_{5}\right]^{-}$ and $\left[\mathrm{C}_{3} \mathrm{H}_{3} \mathrm{~N}_{2} \mathrm{O}_{4}\right]^{-}$occurring at $\mathrm{m} / \mathrm{z}-147$ and -131 , respectively. A laser fluence of 0.57 $\mathrm{nJ} / \mu \mathrm{m}^{2}$ was also chosen as the optimal detection fluence for PETN.

\subsection{Power Study of Comp B}

Several plastic explosive compositions were also analyzed by SPAMS to test the ability of the instrument to identify individual explosives within a particle of mixed composition. Comp B is approximately $63 \% \mathrm{RDX}, 35 \% \mathrm{TNT}$, and $1 \%$ wax or binder to make the mixture safer to handle by preventing friction detonation. ${ }^{2}$ Mass spectra were obtained at $0.50,1.47,2.77,5.34$, and $8.01 \mathrm{~nJ} / \mu \mathrm{m}^{2}$. The average particle size was 1.00 $\mu \mathrm{m}(\mathrm{RSD} 5.0 \%)$ for all laser powers. Figure 3-6 shows the average spectra of Comp B taken at a laser fluence of $0.50 \mathrm{~nJ} / \mu \mathrm{m}^{2}$ compared to the average spectra of TNT at 0.70 $\mathrm{nJ} / \mu \mathrm{m}^{2}$ and $\mathrm{RDX}$ at $0.57 \mathrm{~nJ} / \mu \mathrm{m}^{2}$, the optimal fluences determined for these two explosives. 


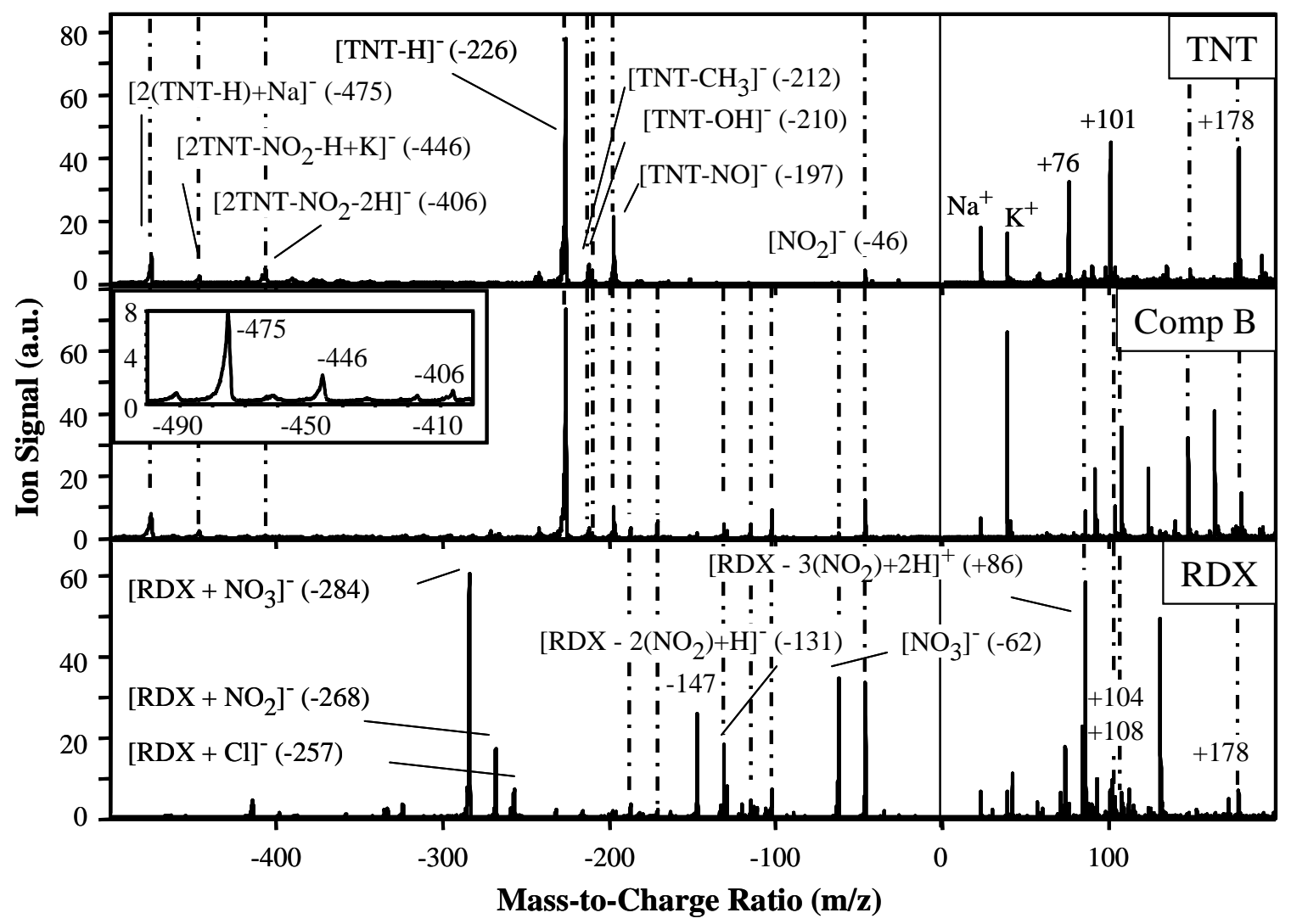

Figure 3-6: Single particle mass spectra of aerosolized TNT, Comp B (63\% TNT, 35\% $\mathrm{RDX}$ ), and $\mathrm{RDX}$ at $0.70,0.50$, and $0.57 \mathrm{~nJ} / \mu \mathrm{m}^{2}$, respectively (note differences in ion signal). Each spectrum is the average of 1000 single particle spectra. Dashed lines indicate mass peaks that are present in multiple compounds. Note the presence of peaks from TNT and RDX in the Comp B spectrum. The inset is included to allow the visualization of the high mass peaks in Comp B.

Dashed lines identify mass peaks present in the Comp B spectrum that are attributed to each component (TNT or RDX). Multiple peaks in the Comp B spectrum match peaks present in TNT; in fact, the $[\mathrm{TNT}-\mathrm{H}]^{-}$ion is the most prevalent peak in the Comp B spectrum. The TNT dimer compounds, $[2(\mathrm{TNT}-\mathrm{H})+\mathrm{Na}]^{-}(\mathrm{m} / \mathrm{z}-475)$, and $\left[2 \mathrm{TNT}^{-\mathrm{NO}_{2}-}\right.$ 
$\mathrm{H}+\mathrm{K}]^{-}(\mathrm{m} / \mathrm{z}-446)$ are also visible in the Comp B spectrum. Many other peaks in the Comp B spectrum match those in RDX: $\left[\mathrm{RDX}-2\left(\mathrm{NO}_{2}\right)+\mathrm{H}\right]^{-}(\mathrm{m} / \mathrm{z}-131),\left[\mathrm{RDX}-3\left(\mathrm{NO}_{2}\right)\right]^{+}$ (+86) as well as peaks at $\mathrm{m} / \mathrm{z}-115$ and +178 . There are several peaks in the Comp B spectrum that cannot be identified as either TNT or RDX, such as m/z $+92,+124,+164$, and +180 . These peaks may be due to an unknown complex between TNT and RDX fragments or the plasticizers present in the compound. The identification of these fragments was beyond the scope of this work.

\subsection{Power Study of Semtex 1A}

Semtex 1A is a common plastic explosive developed in the 1960s in the former Czechoslovakia that is made from a combination of PETN (83.5\%) and plasticizers (16.5\%). Mass spectra were obtained at fluences of $0.51,1.46,2.70,5.19$, and 7.78 $\mathrm{nJ} / \mu \mathrm{m}^{2}$. The average particle size was $1.07 \mu \mathrm{m}(\mathrm{RSD} 4.7 \%)$ for all laser fluences. Figure 3-7 displays an average mass spectrum of Semtex $1 \mathrm{~A}$ taken with $0.51 \mathrm{~nJ} / \mu \mathrm{m}^{2}$ laser fluence compared with the average mass spectra of PETN obtained with a laser fluence of $0.57 \mathrm{~nJ} / \mu \mathrm{m}^{2}$, the optimum fluence determined for PETN. 


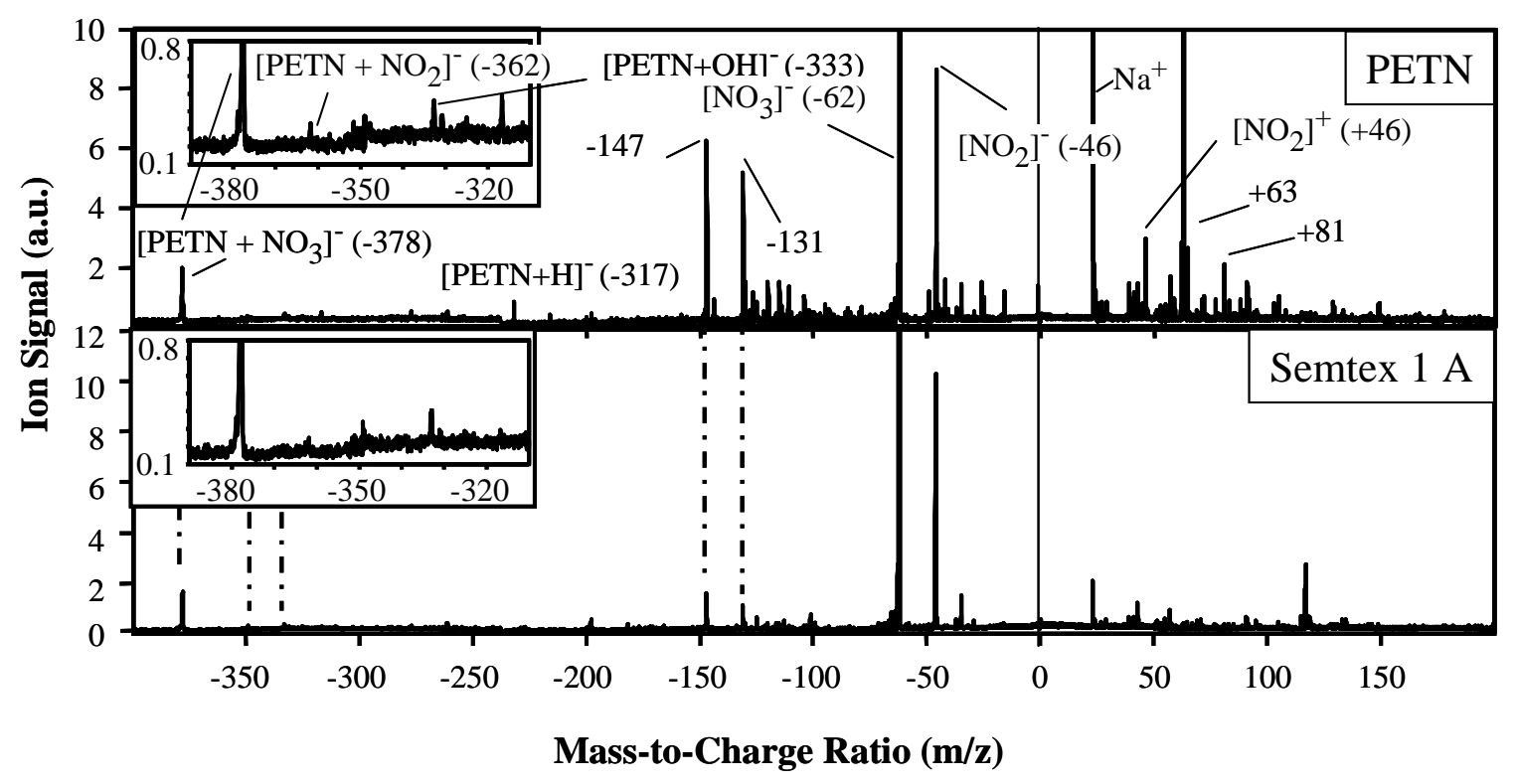

Figure 3-7: Single particle mass spectra of aerosolized PETN and Semtex 1A at laser fluences of 0.57 and $0.51 \mathrm{~nJ} / \mu \mathrm{m}^{2}$, respectively (note differences in ion signal). Each spectrum is the average of 1000 single particle spectra. Dashed lines indicate mass peaks that are present in both compounds. Insets are included to highlight the presence of high mass peaks in both spectra.

Dashed lines in Figure 3-7 indicate mass peaks present in the Semtex 1A sample and the pure PETN sample. The $\left[\mathrm{PETN}+\mathrm{NO}_{3}\right]^{-}$and $[\mathrm{PETN}+\mathrm{OH}]^{-}$peaks at $\mathrm{m} / \mathrm{z}-378$ and -333 , respectively, are present in the Semtex 1A sample as well as peaks at -147 and -131. The peak in the Semtex 1A spectrum at $\mathrm{m} / \mathrm{z}+117$ is not present in the pure PETN sample. This peak could be due to the presence of various plasticizers in the Semtex 1A sample which may cause additional fragmentation of the PETN, or may fragment themselves. However, further investigation was beyond the scope of this work. 


\subsection{Power Study of Semtex $1 \mathrm{H}$}

An additional composition of Semtex, Semtex 1H, was also analyzed with the SPAMS instrument. Semtex 1H contains PETN (25\%) and RDX (60.5\%), along with oil and plasticizers $(14.4 \%)$ for stability. Mass spectra were obtained at 0.57, 1.43, 2.66, 5.34, and $7.83 \mathrm{~nJ} / \mu \mathrm{m}^{2}$. The average particle size was $1.08 \mu \mathrm{m}$ (RSD 12.8\%) for all laser fluences. The average mass spectrum of Semtex $1 \mathrm{H}$ obtained with a laser fluence of 0.57 $\mathrm{nJ} / \mu \mathrm{m}^{2}$ is shown in Figure 3-8 compared to the spectra of PETN and RDX obtained at $0.57 \mathrm{~nJ} / \mu \mathrm{m}^{2}$ (the optimal fluence for the detection of the individual explosives). 


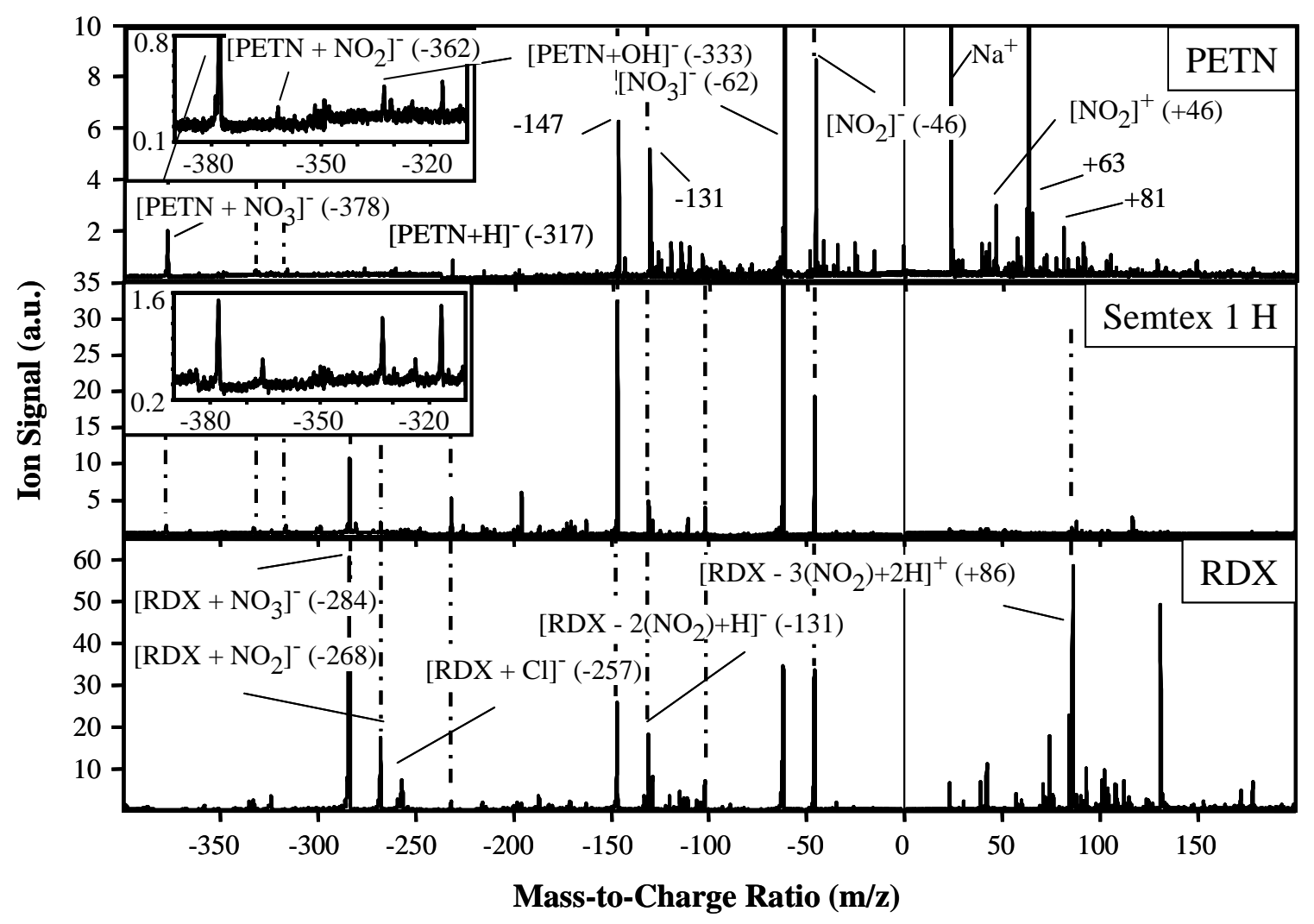

Figure 3-8: Single particle mass spectra of aerosolized PETN, Semtex 1H, and RDX at a laser fluence of $0.57 \mathrm{~nJ} / \mu \mathrm{m}^{2}$ (note differences in ion signal). Each spectrum is the average of 1000 single particle spectra. Dashed lines indicate mass peaks that are present in multiple compounds. Insets are included to highlight the presence of high mass peaks in both spectra.

Again, the dashed lines identify mass peaks present in multiple spectra. The spectrum of Semtex $1 \mathrm{H}$ is very similar to that of Semtex $1 \mathrm{~A}$, but contains more peaks due to the addition of RDX. In addition to the peaks discussed previously in Semtex 1A, peaks at $\mathrm{m} / \mathrm{z}-284\left(\left[\mathrm{RDX}+\mathrm{NO}_{3}\right]^{-}\right),-268\left(\left[\mathrm{RDX}+\mathrm{NO}_{2}\right]^{-}\right),-147$ (unknown fragment), -131 ([RDX $\left.\left.2\left(\mathrm{NO}_{2}\right)+\mathrm{H}\right]^{-}\right),-102\left(\left[\mathrm{RDX}-\mathrm{CH}_{2} \mathrm{NNO}_{2}-\mathrm{NO}_{2}\right]^{-}\right)$, and $+86\left(\left[\mathrm{RDX}-3\left(\mathrm{NO}_{2}\right)\right]^{+}\right)$are present. The 
presence of many of these peaks due to PETN and RDX in Semtex 1H was previously reported. ${ }^{39}$ The data from the composite explosives are summarized in Table 3-1.

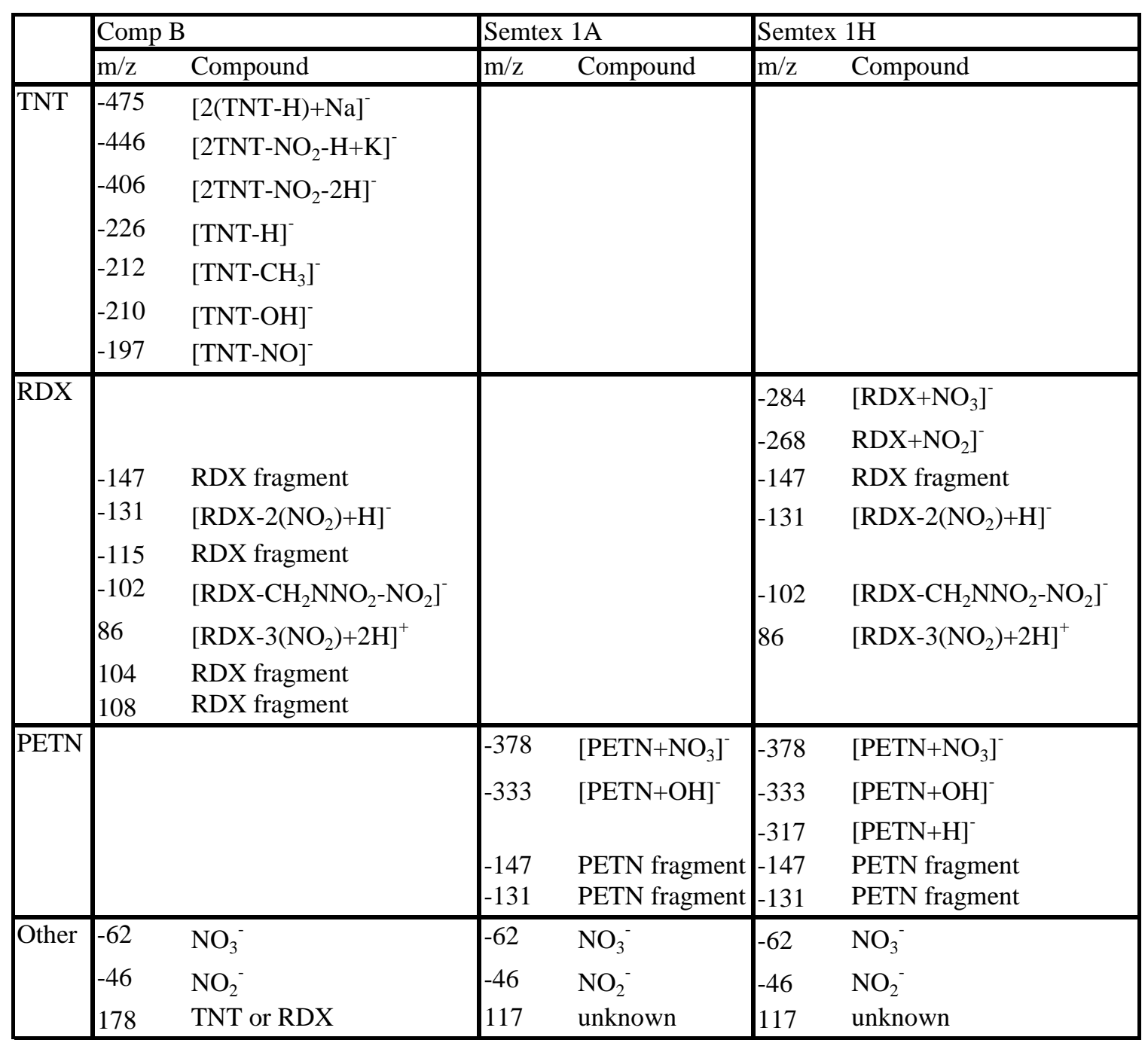

Table 3-1: Summary of mass spectral data from Comp B, Semtex 1A, and Semtex 1H obtained at laser fluences of $0.50,0.51$, and $0.57 \mathrm{~nJ} / \mu \mathrm{m}^{2}$, respectively. Peak position $(\mathrm{m} / \mathrm{z})$ and the suggested origin of the peak are shown. 


\subsection{Summary}

The SPAMS system was shown to be capable of the detection of explosive samples introduced to the system in the liquid phase (dissolved in methanol). TNT was used to demonstrate that this sample introduction method provided similar particle size and mass spectral information to direct solid sample introduction. TNT was also used to determine the particle to particle reproducibility of the method, which was $5.5 \%$ when peak area was normalized for each mass spectrum. Samples of pure RDX and PETN were successfully analyzed to demonstrate the applicability of SPAMS to a variety of classes of explosives (i.e. nitramines and nitrate esters as well as nitroaromatics).

The analysis of composite explosive samples highlighted a benefit of the SPAMS single particle analysis system, since information on the specific components of an individual particle can be obtained. TNT and RDX were identified in the spectra of Comp B. The contribution from the individual explosive components confirms their presence in a composite mixture. In comparing the spectra from Semtex 1A and Semtex $1 \mathrm{H}$, the presence of the peaks due to RDX corroborates the information that the $1 \mathrm{H}$ variety also contains a percentage of RDX while the $1 \mathrm{~A}$ does not. As composite explosives such as Semtex are commonly used in terrorist activities, the ability to determine the composition of these materials holds the potential to identify their synthetic origin, which may provide information to aid in the investigation and attribution of terrorist attacks. 


\section{Chapter 4: Analysis of Chemical Warfare Agent Simulants Using SPAMS}

\subsection{Motivation and Background}

This chapter illustrates the application of SPAMS to obtain mass spectral data from Chemical Warfare Agents (CWA), specifically nerve agent simulants. This research is driven by the need for a sensitive and selective instrument that can detect small quantities of CWAs in the liquid and vapor phases. Currently, no system exists that has such capabilities without extensive sampling requirements. The research is focused on detection of CWA simulants in both phases because CWAs are toxic in both phases and can be found in either form, depending on the volatility of the particular agent. Several technologies have been used to detect CWAs and their simulants. Colorimetric tests are the military standard presumptive test for possible CWAs, but they suffer from a wide range of false positives. ${ }^{48,49}$ Surface acoustic wave sensors have been used to successfully detect vapor-phase $\mathrm{CWAs}^{46,47}$ but the technique is not capable of liquid agent detection. IMS is perhaps the most commonly deployed detection system, but the need for specific operating conditions limits the range of agents which it can detect in a given experiment. ${ }^{6,50}$ Mass spectrometric techniques have also been applied to CWA detection; ${ }^{37,}$ 50, 54-56 however, no dual-polarity single particle data has been published. Because of the success of SPAMS for the detection of biological samples and high explosives, the technique was tested for the analysis of liquid CWA simulants. CWA simulants were chosen to represent a variety of G-type nerve agents, as well as one Vtype agent, VX. The chosen CWAs represented a wide range of volatilities spanning four orders of magnitude $(0.007-2.9 \mathrm{~mm} \mathrm{Hg})$, which controls the phase in which the agents would likely persist and their duration. Initially, two liquid sarin simulants, dimethyl 
methyl phosphonate (DMMP) and diethyl ethyl phosphonate (DEEP), were analyzed with SPAMS to determine the mass spectral response as a function of D/I laser fluence. Diethyl phosphoramidate (DEPA), a tabun simulant, and triethyl phosphate (TEP), a cyclosarin simulant, were then analyzed in the liquid form, although analysis of TEP was unsuccessful. Next, diethyl phthalate (DEP), serving as a VX simulant, was studied under various laser fluences. Once the ability of SPAMS to detect most liquid CWA simulants was established, vapor phase detection was investigated. Using activated carbon, alumina, silica, zeolite, and tungsten, titanium, and manganese powders, each vapor-phase CWA simulant was adsorbed onto particles which were analyzed using SPAMS. Successful detection of each vapor-phase agent was achieved, including TEP. It is concluded that SPAMS is capable of detecting and differentiating several chemical agents in the liquid and vapor phases under the same operating conditions.

\subsection{Power Study of Neat DMMP}

Liquid samples of CWA simulants were prepared as described in Chapter Two and introduced to the SPAMS. The effect of laser energy on the desorption/ionization of neat DMMP was investigated. Laser fluences were selected to cover the output range of the D/I laser as discussed previously. Average mass spectra of 1000 individual DMMP particles obtained with laser fluences of $0.58,1.11,2.57,5.05$, and $7.66 \mathrm{~nJ} / \mu \mathrm{m}^{2}$ are shown in Figure 4-1. 


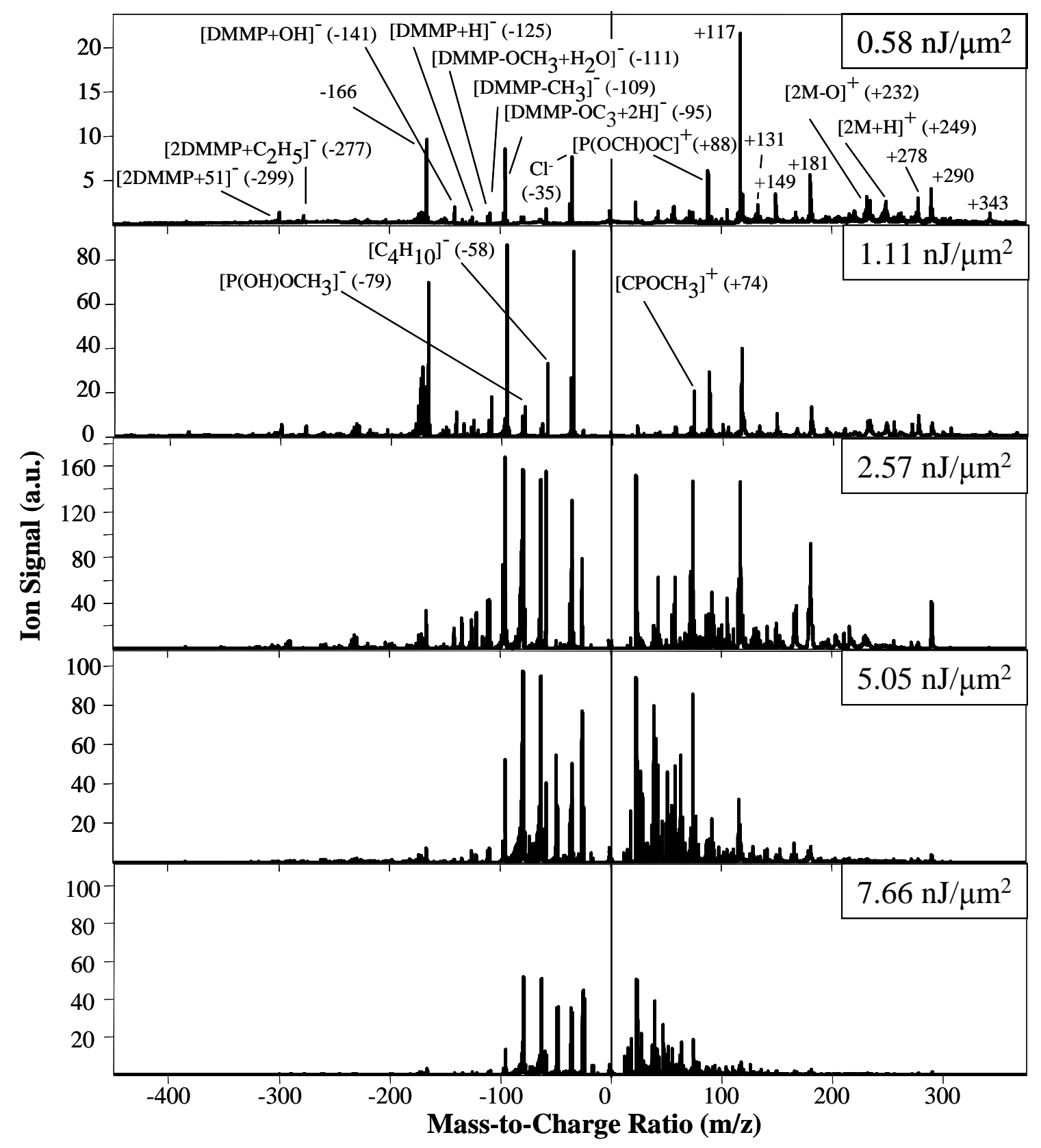

Figure 4-1: Single particle mass spectra of aerosolized DMMP at laser fluences of 0.58, $1.11,2.57,5.05$, and $7.66 \mathrm{~nJ} / \mu \mathrm{m}^{2}$ (note differences in ion signal). Each spectrum is the average of 1000 single particle spectra. The average particle was $1.15 \pm 0.09 \mu \mathrm{m}$ in diameter. Note the $[\mathrm{DMMP}+\mathrm{H}]^{-}$peak at $\mathrm{m} / \mathrm{z}-125$ is present at all laser fluences. The structure of DMMP is included as an inset in the bottom spectrum. 
The average particle size was $1.15 \mu \mathrm{m}(\operatorname{RSD} 7.8 \%, \mathrm{n}=1000)$ for all laser powers. The RSD for the liquid CWA simulants is often higher than that determined for the nebulized explosive samples. Although the explosive samples were nebulized in solution, the diffusion drier removes moisture and solvent, so the particles analyzed in the SPAMS are most likely crystallized solid particles with a narrow size range. Since the CWA simulants are liquids at room temperature, some variation may exist in the droplet size introduced to the SPAMS.

The negative molecular ion $[\mathrm{DMMP}+\mathrm{H}]^{-}$was present in all the spectra, and is most prevalent when a D/I laser energy of $2.57 \mathrm{~nJ} / \mu \mathrm{m}^{2}$ was used. As the laser energy was increased, increased fragmentation occurred and less molecular ion and other characteristic negative peaks (e.g. m/z -277, -141) were present. At the lower D/I laser energies $\left(2.57 \mathrm{~nJ} / \mu \mathrm{m}^{2}\right.$ and below) several fragments of DMMP were identified including $\left[\mathrm{C}_{4} \mathrm{H}_{10}\right]^{-}, \quad\left[\mathrm{P}(\mathrm{OH}) \mathrm{OCH}_{3}\right]^{-}, \quad\left[\mathrm{DMMP}_{-} \mathrm{OC}_{3}+2 \mathrm{H}\right]^{-}, \quad\left[\mathrm{DMMP}^{-\mathrm{CH}_{3}}\right]^{-}, \quad$ and $\quad[\mathrm{DMMP}-$ $\left.\mathrm{OCH}_{3}+\mathrm{H}_{2} \mathrm{O}\right]^{-}$at $\mathrm{m} / \mathrm{z}-58,-79,-95,-109$, and -111 , respectively, many of which have been seen in previous studies involving DMMP..$^{56,80,85,86}$ The maximum signal from each of these peaks was also seen using a laser energy of $2.57 \mathrm{~nJ} / \mu \mathrm{m}^{2}$. The negative ion spectra also contain several peaks above the mass of the parent ion. The hydroxyl adduct of DMMP is seen at $\mathrm{m} / \mathrm{z}-141$, and again showed the highest signal when obtained using the $2.57 \mathrm{~nJ} / \mu \mathrm{m}^{2}$ laser energy. The peak at $\mathrm{m} / \mathrm{z}-166$, is one of the most prominent peaks in the spectra obtained at low laser fluences, with its maximum signal at $1.11 \mathrm{~nJ} / \mu \mathrm{m}^{2}$. Since this peak is above the mass of DMMP, it is not surprising that its maximum signal occurs at a lower laser fluence than the fragments described above; at fluences above $1.11 \mathrm{~nJ} / \mu \mathrm{m}^{2}$, this compound may itself be fragmented. This peak could be due to an 
unknown adduct of DMMP, or fragmention of a DMMP dimer. Several other peaks related to DMMP dimers are also seen at the low laser energies: [2DMMP $\left.+\mathrm{C}_{2} \mathrm{H}_{5}\right]^{-}$and

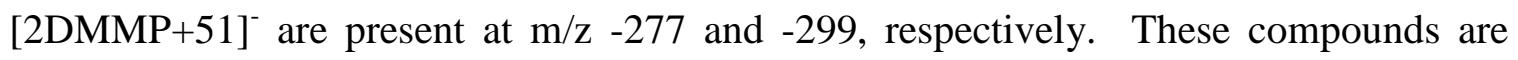
only present when the sample is ionized at 0.58 and $1.11 \mathrm{~nJ} / \mu \mathrm{m}^{2}$; at higher fluences the energy incident on the particles may be too great to allow dimer formation.

The positive ion spectra also contain identifiable peaks due to DMMP fragments and dimers. The most prominent peak in the spectrum obtained at $0.58 \mathrm{~nJ} / \mu \mathrm{m}^{2}$ is at $\mathrm{m} / \mathrm{z}$ +117 and is seen in the spectra obtained at all laser energies. The origin of this peak is unknown, but it is hypothesized that it is due to a fragment of a DMMP dimer. $[\mathrm{P}(\mathrm{OCH}) \mathrm{OC}]^{+}$is seen at $\mathrm{m} / \mathrm{z}+88$; this peak is present in the spectra obtained at lower laser energies, but is absent at $7.66 \mathrm{~nJ} / \mu^{2}$. The parent dimer may not form or greater fragmentation could occur at this high laser fluence to prevent this fragment from being seen. Other peaks due to the dimerization of DMMP are also seen in the positive ion spectra: $[2 \mathrm{DMMP}-\mathrm{O}]^{+}$and $[2 \mathrm{DMMP}+\mathrm{H}]^{+}$, at $\mathrm{m} / \mathrm{z}+232$ and +249 , respectively; the $[2 \mathrm{DMMP}+\mathrm{H}]^{+}$peak has been previously reported. ${ }^{87}$ Several unknown peaks at $\mathrm{m} / \mathrm{z}+278$, +290 , and +343 are seen at low laser fluences $\left(<2.57 \mathrm{~nJ} / \mu \mathrm{m}^{2}\right)$, but are not present in the higher energy spectra. These unidentified peaks are thought to be due to adducts of the DMMP dimer, but have not yet been confirmed. Definitive identification of these peaks could be determined by tandem mass spectrometry experiments (MS/MS) to isolate and fragment these compounds, but was outside the scope of this study. The absence of these peaks at higher laser fluences may be a result of the increased energy preventing stable dimerization. The presence of the identifiable positive ion peaks, combined with the information from the negative ion spectra, especially the presence of the molecular ion, 
allow the identification of DMMP. As with many of the explosives, the low laser fluence $\left(0.58 \mathrm{~nJ} / \mu \mathrm{m}^{2}\right)$ appears to be the optimal fluence for detection of DMMP.

\subsection{Power Study of Neat DEEP}

Liquid samples of the CWA simulant DEEP were prepared as described in Chapter Two and introduced to the SPAMS. The effect of laser energy on the desorption/ionization of neat DEEP was investigated using four laser fluences. Average mass spectra of 1000 individual DEEP particles obtained with laser fluences of 1.18, 2.77, 5.13, and $7.59 \mathrm{~nJ} / \mu^{2}$ are shown in Figure 4-2. 


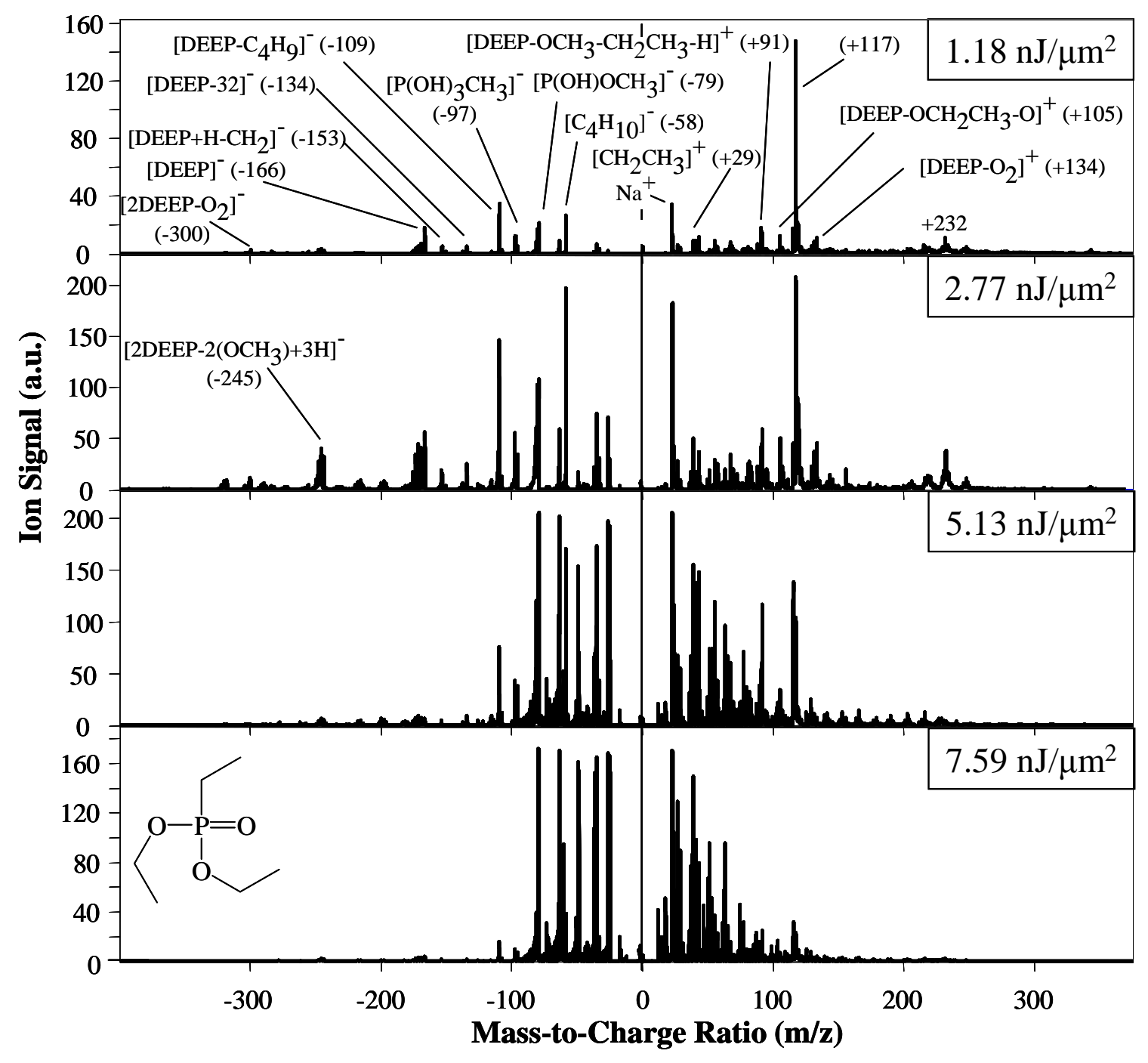

Figure 4-2: Single particle mass spectra of aerosolized DEEP at laser fluences of 1.18, 2.77, 5.13, and $7.59 \mathrm{~nJ} / \mu^{2}$ (note differences ion signal). Each spectrum is the average of 1000 single particle spectra. The average particle was $1.11 \pm 0.10 \mu \mathrm{m}$ in diameter. Note the $[\mathrm{DEEP}]^{-}$peak at $\mathrm{m} / \mathrm{z}-166$ is present at all laser fluences. The structure of DEEP is included as an inset in the bottom spectrum.

The average particle size was $1.11 \mu \mathrm{m}(\mathrm{RSD} 8.9 \%, \mathrm{n}=1000)$ for all laser powers. The negative molecular ion [DEEP] $]^{-}$was present in all the spectra, with the greatest signal 
when a D/I laser fluence of $2.77 \mathrm{~nJ} / \mu^{2}$ was used. At the highest laser power (7.59 $\mathrm{nJ} / \mu \mathrm{m}^{2}$ ) the parent ion was still distinguishable from the background. However, at these high laser energies, few other identifying peaks are seen in the spectra, as increased fragmentation broke the particles into smaller and more common fragments, making definitive identification more difficult. Peaks at -134 and -153 , due to the loss of $\mathrm{O}_{2}$ from DEEP and [DEEP+H-CH$]^{-}$, are present at the low energies $\left(5.15 \mathrm{~nJ} / \mu \mathrm{m}^{2}\right.$ and below $)$, again with a maximum signal when a laser fluence of $2.77 \mathrm{~nJ} / \mu \mathrm{m}^{2}$ is used. The spectra at lower D/I laser energies show several fragments that match those seen in the spectra of DMMP; m/z -109, -79, -58, corresponding to [DEEP-C $\left.{ }_{4} \mathrm{H}_{9}\right]^{-},\left[\mathrm{P}(\mathrm{OH}) \mathrm{OCH}_{3}\right]^{-},\left[\mathrm{C}_{4} \mathrm{H}_{10}\right]^{-}$, respectively. ${ }^{56,80,86}$ Fragments common to both DMMP and DEEP are not unexpected, due to the similarity in structures of the two simulants. The low energy spectra also contain some high mass peaks including $\left[2 \mathrm{DEEP}^{-\mathrm{O}_{2}}\right]^{-}$and $\left[2 \mathrm{DEEP}-2\left(\mathrm{OCH}_{3}\right)+3 \mathrm{H}\right]^{-}$, at $\mathrm{m} / \mathrm{z}-300$ and -245 , respectively, again due to the dimerization of the parent ion. Thus, these mass peaks are not seen at high energies because the increase in laser fluence either prevents their formation, or fragments the dimers completely.

The positive ion spectra of DEEP contain several unique peaks. $\left[\mathrm{CH}_{2} \mathrm{CH}_{3}\right]^{+}$, due to fragmentation of the ethyl group from DEEP, is seen at $\mathrm{m} / \mathrm{z}+29$ at all laser fluences, with increased signal as the energy and hence, degree of fragmentation, increase. Peaks at $\mathrm{m} / \mathrm{z}+91$ and +105 , due to $\left[\mathrm{DEEP}-\mathrm{OCH}_{3}-\mathrm{CH}_{2} \mathrm{CH}_{3}-\mathrm{H}\right]^{+}$and $\left[\mathrm{DEEP}-\mathrm{OCH}_{2} \mathrm{CH}_{3}-\mathrm{O}\right]^{+}$ respectively, are also the result of fragmentation of DEEP. Loss of $\mathrm{O}_{2}$ from DEEP is present in the mass peak at $\mathrm{m} / \mathrm{z}+134$.

A peak at $\mathrm{m} / \mathrm{z}+117$ is the most prominent peak in the mass spectra at the laser fluences of $2.77 \mathrm{~nJ} / \mu \mathrm{m}^{2}$ and below, as was also the case for DMMP. In addition, a peak at 
$\mathrm{m} / \mathrm{z}+232$ was observed in the DEEP spectra; again, this peak was also present in DMMP spectra. However, neither the peak at $\mathrm{m} / \mathrm{z}+117$ nor the peak at $\mathrm{m} / \mathrm{z}+232$ have been identified. While several peaks in the DEEP spectra are similar those obtained in the DMMP spectra, several peaks $(\mathrm{m} / \mathrm{z}-245,-153,-132,+91,+105,+134)$ are present that can distinguish the two compounds. A laser fluence of $1.18 \mathrm{~nJ} / \mu \mathrm{m}^{2}$ appears to be the optimal laser energy for the detection and differentiation of DEEP.

\subsection{Power Study of Neat DEPA}

Liquid samples of DEPA were prepared as described in Chapter Two and introduced to the SPAMS. The effect of laser energy on the desorption/ionization of neat DEPA was investigated. Laser fluences above $5.14 \mathrm{~nJ} / \mu \mathrm{m}^{2}$ were not tested due to the lack of significant spectral differences between data obtained at fluences of 2.78 and 5.14 $\mathrm{nJ} / \mu \mathrm{m}^{2}$. Average mass spectra of 1000 individual DEPA particles obtained with laser fluences of 0.69, 1.17, 2.78, and $5.14 \mathrm{~nJ} / \mu^{2}$ are shown in Figure 4-3. 


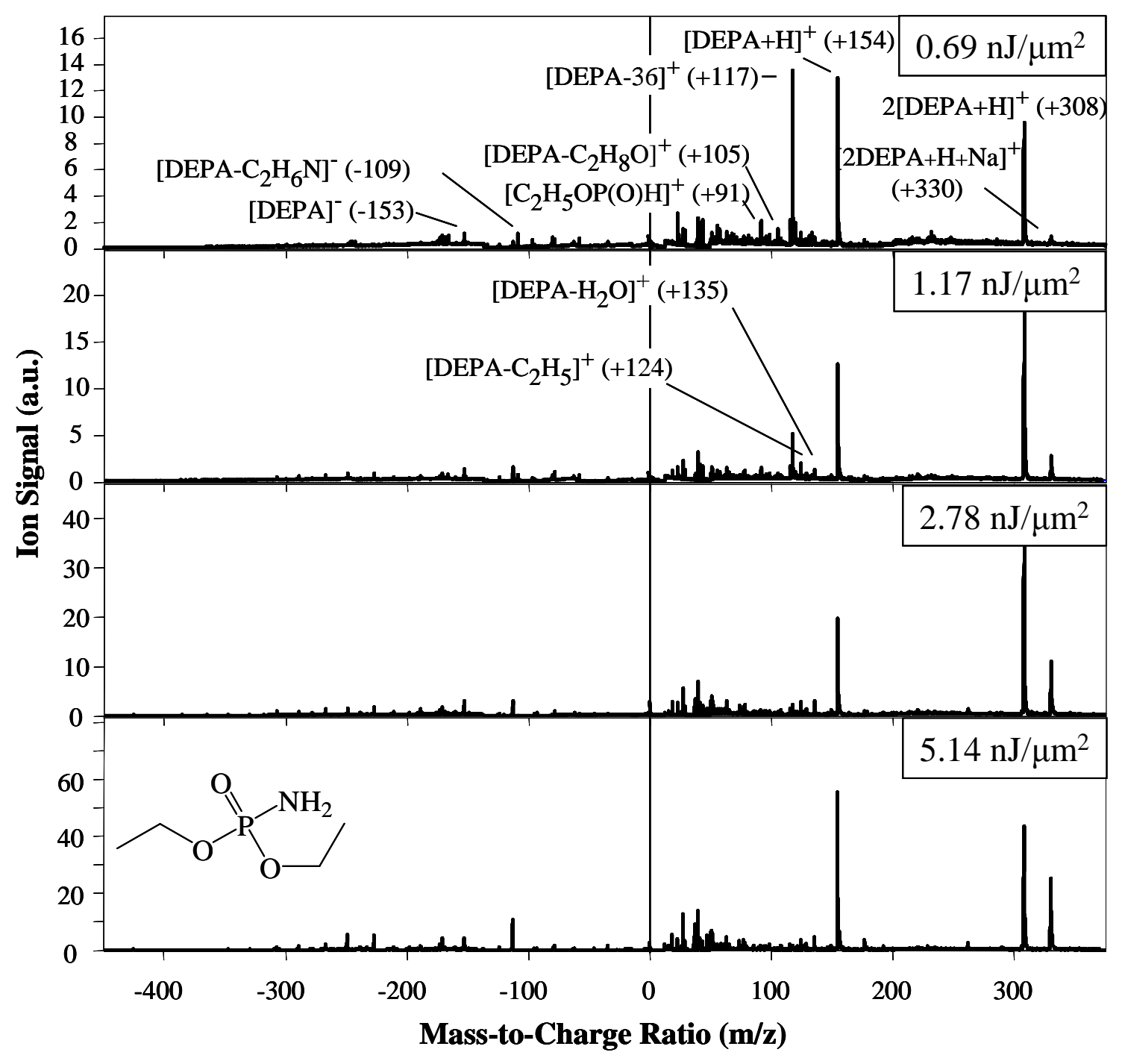

Figure 4-3: Single particle mass spectra of aerosolized DEPA at laser fluences of 0.69, $1.17,2.78$, and $5.14 \mathrm{~nJ} / \mu \mathrm{m}^{2}$ (note differences in ion signal). Each spectrum is the average of 1000 single particle spectra. The average particle was $1.16 \pm 0.03 \mu \mathrm{m}$ in diameter. Note the $[\mathrm{DEPA}+\mathrm{H}]^{+}$peak at $\mathrm{m} / \mathrm{z}+154$ is present at all laser fluences. The structure of DEPA is included as an inset in the bottom spectrum. 
The average particle size was $1.16 \mu \mathrm{m}(\operatorname{RSD} 2.5 \%, \mathrm{n}=1000)$ for all laser powers. The mass spectra of DEPA are much simpler than those of DMMP or DEEP due to the identical side chains $\left(\mathrm{OCH}_{2} \mathrm{CH}_{3}\right)$ and the similar weights of the $\mathrm{NH}_{2}$ and $\mathrm{O}$ groups (16.023 versus $15.999 \mathrm{amu})$. The negative ion spectra contains a peak due to the molecular ion [DEPA] $]^{-}$at $\mathrm{m} / \mathrm{z}-153$. A peak at $\mathrm{m} / \mathrm{z}-109$, a peak which was also present in spectra for DMMP and DEEP, is due to [DEPA- $\left.\mathrm{C}_{2} \mathrm{H}_{6} \mathrm{~N}\right]^{-}$and was present at all laser energies, with the highest signal obtained with a fluence of $5.14 \mathrm{~nJ} / \mu \mathrm{m}^{2}$. No evidence of dimer formation was seen in the negative spectra, most likely due to the small number of negative ions that was detected.

The positive ion spectra of DEPA also show similarities to DMMP and DEEP. Peaks at $\mathrm{m} / \mathrm{z}+91$ and +105 are seen in the DEPA and DEEP spectra, and peaks at $\mathrm{m} / \mathrm{z}$ +117 and +232 are seen in the DEPA, DEEP and DMMP spectra. The recurrence of these peaks in the spectra of DMMP, DEEP, and DEPA is expected, as the structural similarities of the molecules would lead to the same fragments being formed. Peaks at $\mathrm{m} / \mathrm{z}+124$ and +135 are more abundant as the laser energy increases, and are attributed to $\left[\text { DEPA- } \mathrm{C}_{2} \mathrm{H}_{5}\right]^{+}$and $\left[\text {DEPA- } \mathrm{H}_{2} \mathrm{O}\right]^{+}$. A large peak due to $[\mathrm{DEPA}+\mathrm{H}]^{+}$at $\mathrm{m} / \mathrm{z}+154$ is also present in the spectra; in fact, it is the second most abundant ion in the spectra. This is expected due to the high proton affinity of the terminal amine in DEPA. ${ }^{58}$ Although no peaks due to dimers were seen in the negative spectra, the positive spectra contain two peaks due to the formation of dimers: $2[\mathrm{DEPA}+\mathrm{H}]^{+}$and $[2 \mathrm{DEPA}+\mathrm{H}+\mathrm{Na}]^{+}$, at $\mathrm{m} / \mathrm{z}+308$ and +330 , respectively. Again, the large signal from these dimer peaks is expected due to the ease with which DEPA can accept a proton, which also explains the lack of dimers in the negative spectra. Even though many of the peaks in the DEPA spectra match those of 
DMMP and DEEP, the presence of the molecular ion, especially the protonated molecular ion at $\mathrm{m} / \mathrm{z}+154$, allows the definitive identification of DEPA. For DEPA detection, a laser fluence of $1.17 \mathrm{~nJ} / \mu \mathrm{m}^{2}$ would be optimal, as this fluence allows the detection of the fragment peaks in addition to significant signal from the dimers.

\subsection{Power Study of Neat DEP}

Liquid samples of the CWA simulant DEP were prepared as described in Chapter Two and introduced to the SPAMS. The effect of laser energy on the desorption/ionization of neat DEP was investigated. Average mass spectra of 1000 individual DEP particles obtained with laser fluences of 1.17, 2.77, 5.10, and $7.83 \mathrm{~nJ} / \mu \mathrm{m}^{2}$ are shown in Figure 4-4. 


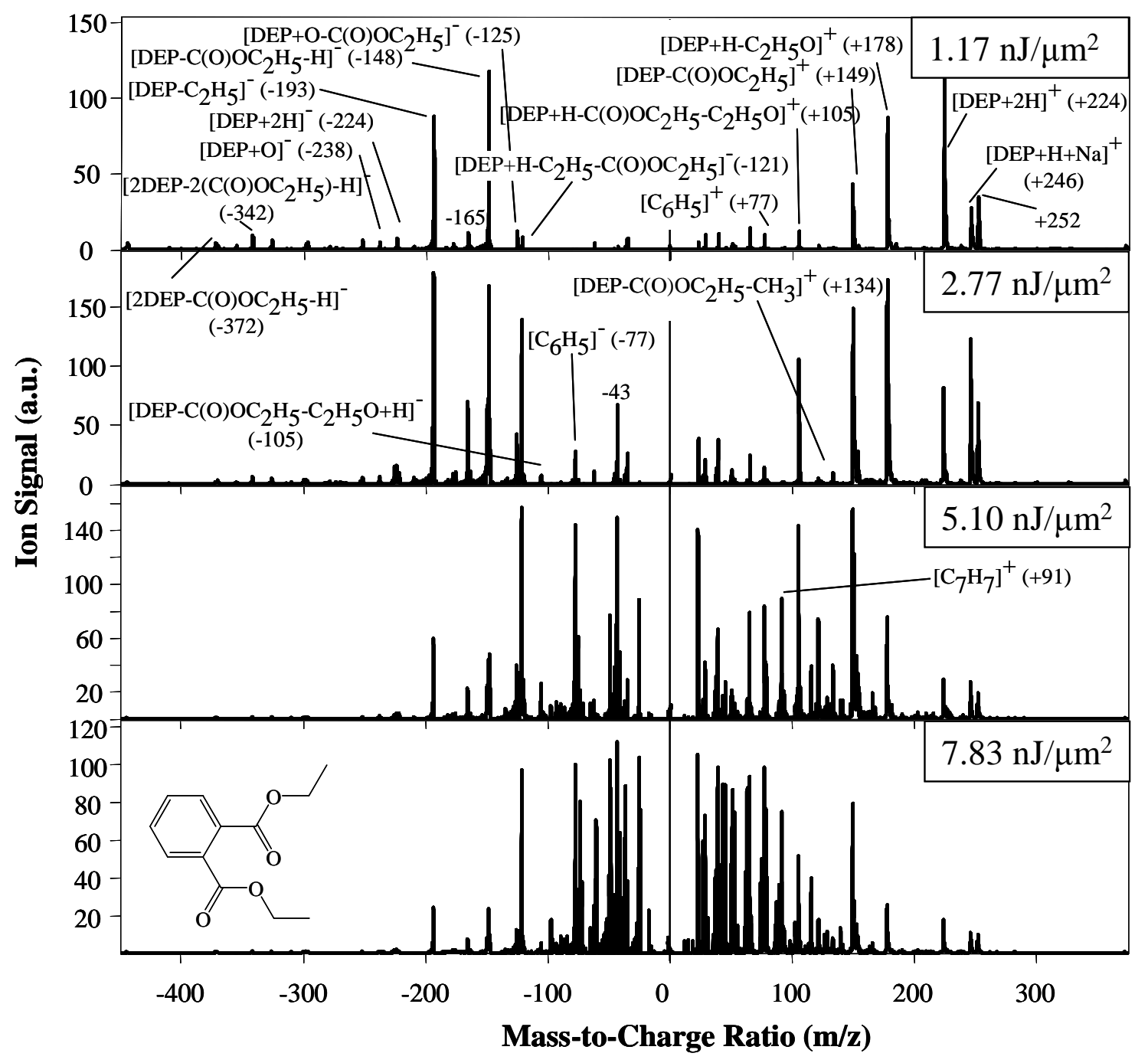

Figure 4-4: Single particle mass spectra of aerosolized DEP at laser fluences of 1.17, $2.77,5.10$, and $7.83 \mathrm{~nJ} / \mu^{2}$ (note differences in ion signal). Each spectrum is the average of 1000 single particle spectra. The average particle was $1.36 \pm 0.15 \mu \mathrm{m}$ in diameter. Note the $[\mathrm{DEP}+2 \mathrm{H}]^{+}$peak at $\mathrm{m} / \mathrm{z}+224$ is present at all laser fluences. The structure of DEP is included as an inset in the bottom spectrum.

The average particle size was $1.36 \mu \mathrm{m}$ (RSD 10.9\%, $\mathrm{n}=1000)$ for all laser powers. The spectra obtained with DEP are quite different than those of the organophosphate 
simulants described above. The most abundant peak in the negative ion spectra obtained at $1.17 \mathrm{~nJ} / \mu \mathrm{m}^{2}$ occurs at $\mathrm{m} / \mathrm{z}-148$ and is attributed to a fragment of DEP, [DEP$\left.\mathrm{C}(\mathrm{O}) \mathrm{OC}_{2} \mathrm{H}_{5}-\mathrm{H}\right]^{-}$. The next most abundant peak is $\left[D E P-\mathrm{C}_{2} \mathrm{H}_{5}\right]^{-}$at $\mathrm{m} / \mathrm{z}-193$. These two fragments are seen at all laser energies, although their relative abundance changes; the $\mathrm{m} / \mathrm{z}-193$ has a higher ion signal in the spectra obtained with laser fluences of $2.77-5.10$ $\mathrm{nJ} / \mu^{2}$, and the signal intensity is approximately equal at a fluence of $7.83 \mathrm{~nJ} / \mu \mathrm{m}^{2}$. These peaks are formed as the side chains are fragmented from DEP. Several other peaks, due to similar losses, are seen at $\mathrm{m} / \mathrm{z}-125,-121,-105$, and -77 . A peak due to $[\mathrm{DEP}+2 \mathrm{H}]^{-}$is seen at $\mathrm{m} / \mathrm{z}-224$, with the greatest intensity at $2.77 \mathrm{~nJ} / \mu \mathrm{m}^{2}$. The oxygen adduct of the parent ion is also present at $\mathrm{m} / \mathrm{z}-238$. Several high mass peaks are observed, for example at $\mathrm{m} / \mathrm{z}-342$ and -372 , which are due to the fragmentation of the DEP dimer, via loss of the side chains from the DEP dimer.

The positive ion spectra of DEP also contain peaks due to the loss of DEP side chains. Peaks at $+105,+134,+149$, and +178 are due to such fragments. The low energy spectra have significant contributions from high mass ions also. The $[\mathrm{DEP}+2 \mathrm{H}]^{+}$ion is observed and can be used to identify the presence of DEP. Adducts at $m / z+246$, identified as $[\mathrm{DEP}+\mathrm{H}+\mathrm{Na}]^{+}$, and +252 , which was not identified, are also present in all the spectra. The formation of these high mass ions could be aided by the fragmentation of the side chains which creates fragment ions that can in turn react with other compounds in the plume. At laser powers of $5.10 \mathrm{~nJ} / \mu \mathrm{m}^{2}$ and above, ions at +77 and +91 become more prevalent. These ions are due to the ring structure of DEP, indicating $\left[\mathrm{C}_{6} \mathrm{H}_{5}\right]^{+}$and the tropyllium ion, $\left[\mathrm{C}_{7} \mathrm{H}_{7}\right]^{+}$, respectively. At these laser fluences, the fragmentation in DEP is extensive, but identifying peaks, for example $\mathrm{m} / \mathrm{z}-224,-193$, - 
$121,+224$ and +246 , are still present. As the spectrum obtained with a laser fluence of $1.17 \mathrm{~nJ} / \mu^{2} \mathrm{~m}^{2}$ contained significant identifiable peaks, this was chosen as the optimal detection fluence of DEP.

\subsection{Power Study of Neat TEP}

Liquid samples of the CWA simulant TEP were prepared as described in Chapter Two and introduced to the SPAMS. No particles were detected in the tracking region of the instrument, although aerosolized droplets could be seen in the nebulizer. The reason for the lack of transport is unclear; the vapor pressure of TEP is similar to that of DMMP (4.81 x $10^{-2} \mathrm{~mm} \mathrm{Hg}$ at $25.2{ }^{\circ} \mathrm{C}^{88}$ versus $<0.1 \mathrm{mmHg}$ at $20{ }^{\circ} \mathrm{C},{ }^{89}$ respectively), and the viscosity and specific gravity of TEP are within the bounds of the rest of the chemical agents studied. ${ }^{89-92}$ The analysis of neat TEP was not pursued further.

\subsection{Analysis of Vapor Phase CWA Simulants}

Vapor phase CWA simulants were studied by exposing a support material to the simulant vapors for various amounts of time. Several support materials were tested, including zeolite, silica, alumina, and activated carbon. Several metal powders, titanium, tungsten, and manganese, were also investigated due to the low spectral background of the metals. It was hypothesized that the simple background spectra of the metal supports would allow for easy identification of new peaks that could be due to adsorbed species. A variety of methods, described in Chapter Two, were tested to determine if the vapor phase agents could be detected. However, not all methods were investigated for all simulant vapors due to the success of certain methods. All samples were analyzed using

SPAMS with a laser fluence near $3 \mathrm{~nJ} / \mu \mathrm{m}^{2}$. This laser fluence was chosen as a median 
output of the laser, and because peaks were seen in the neat samples at this power. For each experiment, 500 spectra of the support material with absorbed agent were obtained, as well as 500 spectra of each unexposed support material to serve as background spectra.

\subsubsection{Analysis of Vapor Phase DMMP}

Zeolite is an alumino-silicate substance with a structure that stores cations inside its pores. Zeolite is commonly used as a desiccant or adsorbent, as the cations in the pores can be replaced by water or a cation of interest. Zeolite was used to determine if DMMP could adsorb into its pores. Zeolite was placed in a Petri dish and exposed to DMMP for three hours as described in Method One of Chapter Two (section 2.3.1.1). The zeolite sample was then introduced directly to the SPAMS using a $50 \mathrm{~mL}$ Sterile Disposable Vacuum Filtration Vial. The average spectrum of 500 particles of zeolite exposed to DMMP analyzed with a laser fluence of $3.64 \mathrm{~nJ} / \mu \mathrm{m}^{2}$ did not show any additional significant peaks other than the zeolite background. The in-house software analysis program, 'Irene,' allowed for individual particle mass spectra to be sorted based on the ion signal at an $\mathrm{m} / \mathrm{z}$ defined by the user. This was useful when analyzing the adsorbed CWA simulants on the supports, as it is possible that the CWA simulant did not adsorb onto every solid particle. The presence of these pure particles with no adsorbed simulant may skew the average spectra and prevent any simulant from being seen in the average. In order to determine if this was the case, the DMMP-exposed zeolite single particle spectra were sorted based on the ion intensity at $\mathrm{m} / \mathrm{z}-123\left([\mathrm{DMMP}-\mathrm{H}]^{-}\right)$. By viewing the individual spectra, individual particles can be investigated for DMMP adsorption. After this sorting, a small peak was observed at $\mathrm{m} / \mathrm{z}+125,[\mathrm{DMMP}+\mathrm{H}]^{+}$ (10.9 a.u., $\mathrm{S} / \mathrm{N}>3$ ) in the average of the top 27 single particle spectra. Although this peak 
indicates the presence of DMMP on several of the zeolite particles, the lack of reproducibility prevented this technique from being further pursued.

Silica $\left(\mathrm{SiO}_{2}\right)$, commonly used in separations or filtrations, was also tested for its ability to adsorb DMMP for subsequent SPAMS analysis. Silica was exposed to DMMP vapors for three hours using a Petri dish as described in Method One of Chapter Two. The particles were then introduced to the SPAMS using a $50 \mathrm{~mL}$ Sterile Disposable Vacuum Filtration Vial, analyzed with a laser fluence of $3.79 \mathrm{~nJ} / \mu \mathrm{m}^{2}$, and the data analyzed using 'Irene'. Even when sorted by m/z -125 ([DMMP+H]'), the mass spectra did not show any significant difference over the average background spectrum; thus, the use of Silica for DMMP detection was not pursued further.

Alumina was also tested for DMMP analysis using the procedure described in Method One of Chapter Two. After exposure for three hours, 500 particles were analyzed at a laser fluence of $3.74 \mathrm{~nJ} / \mu \mathrm{m}^{2}$. The average spectrum obtained as compared to the background spectrum is shown in Figure 4-5. 


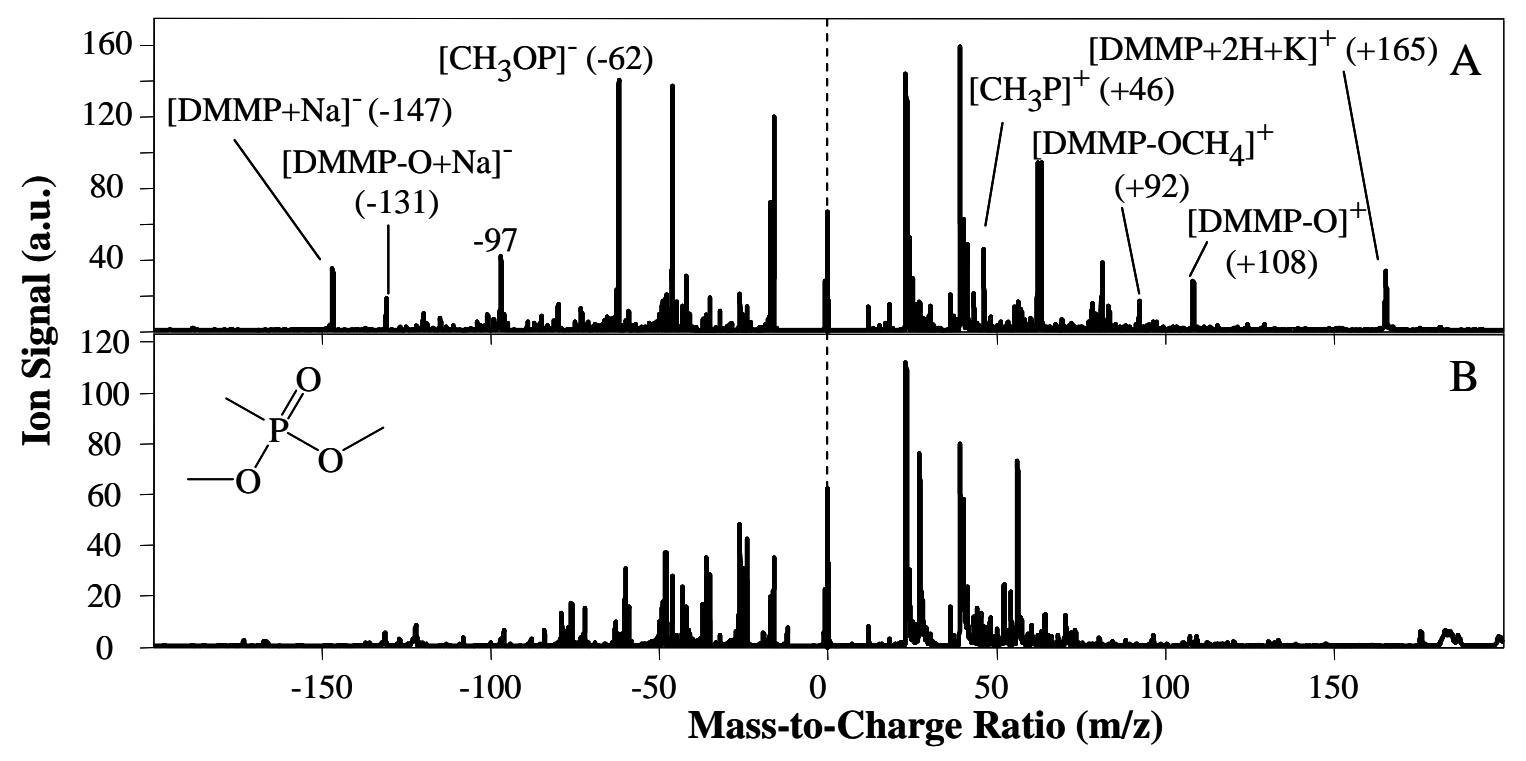

Figure 4-5: Single particle mass spectra of (A) DMMP-exposed alumina and (B) unexposed alumina at a laser fluence of $3.74 \mathrm{~nJ} / \mu \mathrm{m}^{2}$ (note differences in ion signal). Each spectrum is the average of 500 single particle spectra. The structure of DMMP is included as an inset in (B).

Several peaks were present in the DMMP-exposed alumina that were not seen in the alumina background. Peaks at $\mathrm{m} / \mathrm{z}-147,-130,-97$, and -62 , due to [DMMP+Na]', $[\mathrm{DMMP}+\mathrm{Na}-\mathrm{O}]^{-},\left[\mathrm{P}(\mathrm{OH})_{3} \mathrm{CH}_{3}\right]^{-}$, and $\left[\mathrm{CH}_{3} \mathrm{OP}\right]^{-}$, as well as $\mathrm{m} / \mathrm{z}+46,+78,+92,+108$, and +165 , due to $\left[\mathrm{CH}_{3} \mathrm{P}\right]^{+},\left[\mathrm{PO}_{2} \mathrm{CH}_{3}\right]^{+},\left[\mathrm{DMMP}-\mathrm{OCH}_{4}\right]^{+},[\mathrm{DMMP}-\mathrm{O}]^{+}$, and $[\mathrm{DMMP}+\mathrm{K}+2 \mathrm{H}]^{+}$ are significantly greater than the background signal. The peaks attributed to DMMP and its fragments in the vapor phase were different than those seen in the liquid phase analysis. This is due to the difference in ionization conditions the DMMP experiences due to the addition of the adsorbent support material. In liquid analysis, solution phase reactions may occur during laser desorption/ionization that cause new compounds to be formed. In the vapor analysis these solution phase reactions may not occur, and the 
presence of the support material may provide a softer ionization process since the support can absorb the laser energy and in turn transfer the energy to the simulant molecules. With a soft ionization technique, less fragmentation would be expected since the energy ionizing the analyte is lower due to the transfer to and from the support. However, the peaks indicative of DMMP and its fragments can be used to identify DMMP in either phase. DMMP adsorption on alumina was also tested using the Method Two as described in Chapter Two (section 2.3.1.2). Alumina was exposed to DMMP vapors using this configuration for 1.25 hours and then introduced to the SPAMS using a glass vial and modified plastic vial cap described in Figure 2-2. Using this method, no signal above background was seen from the DMMP on alumina in the average spectrum obtained at a laser fluence of $3.68 \mathrm{~nJ} / \mu^{2}$. DMMP was only identified when 'Irene' was used to sort the spectra by $\mathrm{m} / \mathrm{z}+125$, [DMMP+H] $]^{+}$. This method was not further pursued due to the successful and superior detection of DMMP adsorbed onto alumina in the first method described previously.

The utility of activated carbon as a possible adsorbent for DMMP was tested using SPAMS. Method One was used to expose the activated carbon to the DMMP vapors with an exposure time of three hours. The powdered sample was then introduced to the SPAMS as a solid using a $50 \mathrm{~mL}$ Sterile Disposable Vacuum Filtration Vial attached to the instrument with conductive tubing. In the average of 500 spectra obtained with a laser fluence of $3.66 \mathrm{~nJ} / \mu \mathrm{m}^{2}$ no peaks above background were detected for DMMP. To determine if the lack of DMMP was due to an insufficient time of exposure to the solids, the experiment was repeated using exposure times of six hours, and overnight. The mass spectra were obtained using laser fluences of 3.92 , and $2.44 \mathrm{~nJ} / \mu^{2}$, 
respectively. Upon spectral sorting by $\mathrm{m} / \mathrm{z}-147$ using 'Irene', ten or fewer spectra were identified containing any signal above background. For this reason, activated carbon was not pursued as an adsorbent for DMMP, and Method One was not used for any other CWA simulants.

Several metal powders were also tested as possible adsorbents for DMMP vapors. Titanium powder was exposed to DMMP vapor using Method Two as described in Chapter Two. After two hours of exposure, the DMMP-exposed titanium was introduced to the SPAMS via the glass vial with modified plastic cap. No signal above background was seen in the average spectrum obtained with a laser fluence of $3.86 \mathrm{~nJ} / \mu \mathrm{m}^{2}$; however, when sorted for $\mathrm{m} / \mathrm{z}-123[\mathrm{DMMP}-\mathrm{H}]^{-}$using the software, a small peak was present in several of the top spectra [DMMP-H] ${ }^{-}$(26.1 a.u., $\mathrm{S} / \mathrm{N}>8$, for average of top ten). Since the technique was not reproducible for DMMP detection in the 500 spectra collected, titanium was not pursued as an adsorbent material.

Tungsten powder was used for DMMP adsorption according the procedure described in Method Three of Chapter Two (section 2.3.1.3). The liquid sample was introduced to the system via conductive tubing. Spectra were obtained with a laser fluence of $3.44 \mathrm{~nJ} / \mathrm{mm}^{2}$; however, the background tungsten peaks were not present, so it was concluded that the particles being analyzed were neat DMMP, with no signal from DMMP adsorbed on tungsten. This method of DMMP exposure was not pursued further.

The final metal powder tested for DMMP vapor analysis was manganese powder. Manganese was exposed to DMMP vapor using Method Two as described in Chapter Two. The metal powder was exposed to the vapors for 2.25 hours and subsequently introduced to the SPAMS using the glass vial with modified plastic cap. 500 particles 
were obtained with a laser fluence of $3.98 \mathrm{~nJ} / \mu \mathrm{m}^{2}$. A small peak at $\mathrm{m} / \mathrm{z}-125$ $[\mathrm{DMMP}+\mathrm{H}]^{-}$was present in the average spectrum of the 500 particles $(6.8$ a.u., $\mathrm{S} / \mathrm{N}>4)$. When the spectra were sorted by $\mathrm{m} / \mathrm{z}-125$ the peak was more pronounced. Figure 4-6 shows the average of the top 50 mass spectra with a peak at m/z -125 for DMMP-exposed manganese. The manganese background spectra were also sorted by peak intensity at $\mathrm{m} / \mathrm{z}-125$ and the average of the top 500 spectra is also shown.

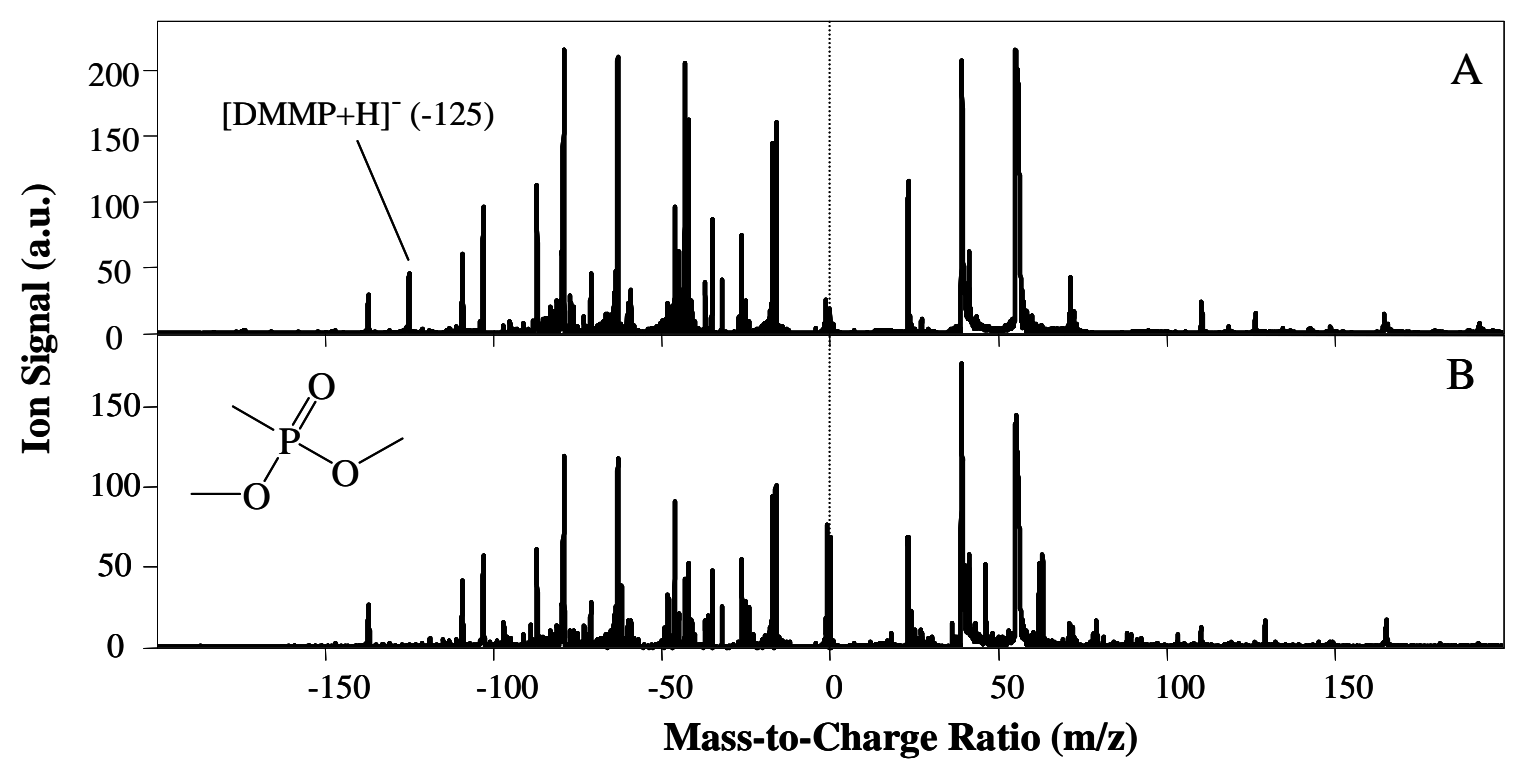

Figure 4-6: Single particle mass spectra of (A) DMMP-exposed manganese and (B) unexposed manganese at a laser fluence of $3.98 \mathrm{~nJ} / \mu \mathrm{m}^{2}$ (note differences in ion signal). Each spectrum is the average of the top 50 single particle spectra sorted by $\mathrm{m} / \mathrm{z}-125$ using computer software. The structure of DMMP is included as an inset in (B).

Although the spectra contain many peaks, the DMMP-exposed manganese shows a significant peak at $\mathrm{m} / \mathrm{z}-125\left([\mathrm{DMMP}+\mathrm{H}]^{-}\right)$that is not present in the background $(45.4$ a.u., $\mathrm{S} / \mathrm{N}>12$ ). This method of vapor analysis showed a molecular ion peak that can be 
easily distinguished from the background. Thus, DMMP vapor can be analyzed with SPAMS when adsorbed onto a manganese powder support surface.

\subsubsection{Analysis of Vapor Phase DEEP}

Vapor phase DEEP was studied in the same manner as described above for DMMP, investigating zeolite, silica, alumina, titanium powder, and manganese powder as support materials. DEEP vapors were exposed to the solid supports using Method Two as described in Chapter Two, and introduced to the SPAMS using a glass vial with the modified plastic cap.

Zeolite was exposed to DEEP vapors for 30 minutes as described above. Mass spectra were obtained using a laser fluence of $3.67 \mathrm{~nJ} / \mu^{2}$ for 500 particles of DEEPexposed zeolite. The average DEEP-exposed zeolite spectrum showed a slight peak at $\mathrm{m} / \mathrm{z}-137$ [DEEP- $\left.\mathrm{CH}_{2} \mathrm{CH}_{3}\right]^{-}$that was not present in the background, but the intensity was very small and no other identifying peaks were seen. This limited signal resulted in the exclusion of zeolite as a means of analysis for DEEP vapors.

Silica was also exposed to DEEP vapors for 45 minutes as previously described. 500 mass spectra were collected with a laser fluence of $3.67 \mathrm{~nJ} / \mu \mathrm{m}^{2}$. The average spectrum of DEEP-exposed silica showed a peak at -97 (15.3 a.u., S/N >5), which could be due to $\left[\mathrm{P}(\mathrm{OH})_{3} \mathrm{CH}_{3}\right]^{-}$or $\left[\mathrm{PO}_{3}+\mathrm{H}_{2} \mathrm{O}\right]^{-}$, that was not present in the silica background. A slight peak at $\mathrm{m} / \mathrm{z}+165$, due to $[\mathrm{DEEP}-\mathrm{H}]^{+}$, was also seen in this average spectrum. Upon sorting by $\mathrm{m} / \mathrm{z}+165$ this signal was significantly increased. The average of the top 50 spectra in this sorted condition for the DEEP-exposed silica and a similarly sorted background are shown in Figure 4-7. 


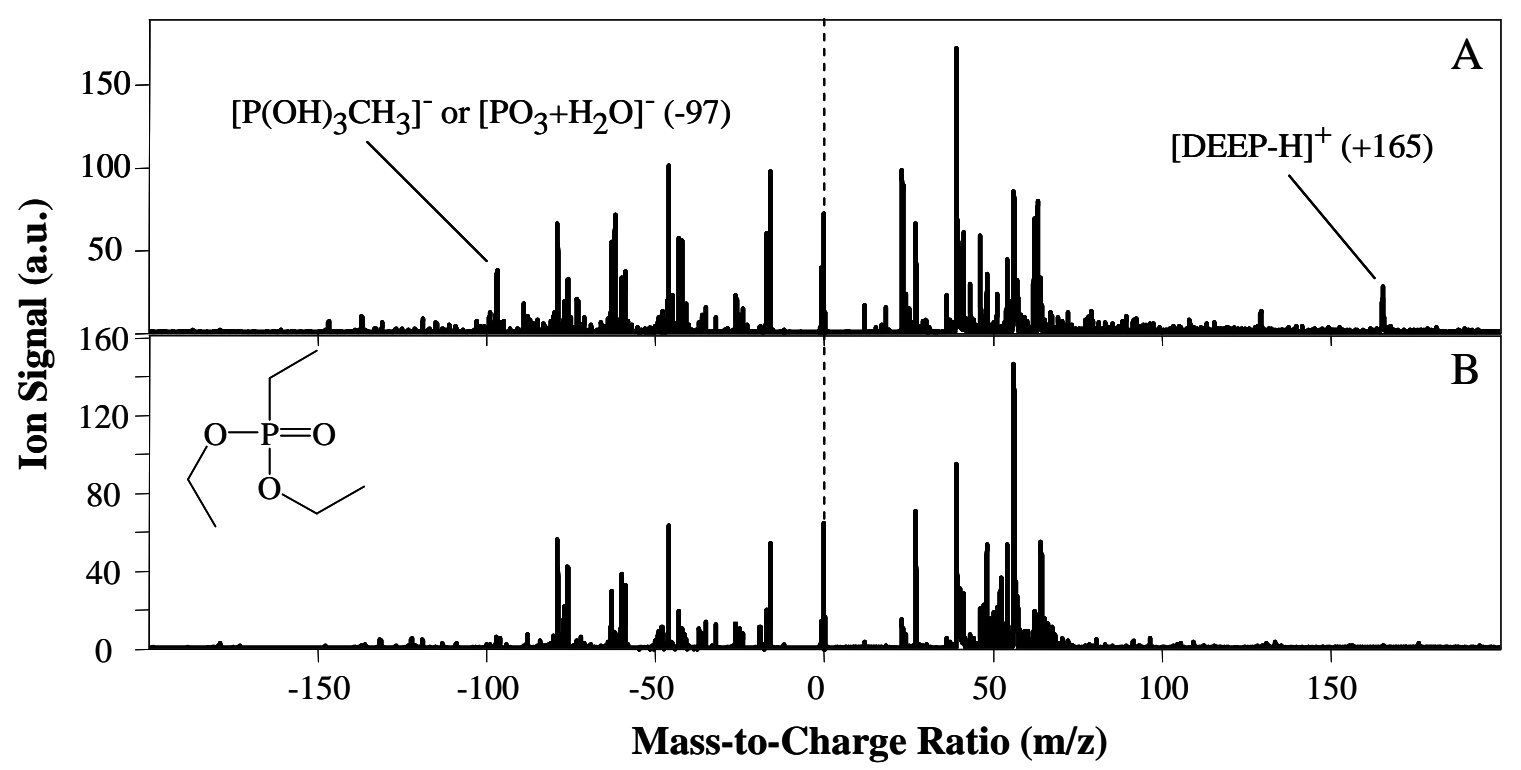

Figure 4-7: Single particle mass spectra of (A) DEEP-exposed silica and (B) unexposed silica at a laser fluence of $3.67 \mathrm{~nJ} / \mu^{2}$ (note differences in ion signal). Each spectrum is the average of the top 50 single particle spectra sorted by $\mathrm{m} / \mathrm{z}+165$, using computer software. The structure of DEEP is included as an inset in (B).

The peak at $\mathrm{m} / \mathrm{z}-97\left(\left[\mathrm{P}(\mathrm{OH})_{3} \mathrm{CH}_{3}\right]^{-}\right.$or $\left.\left[\mathrm{PO}_{3}+\mathrm{H}_{2} \mathrm{O}\right]^{-}\right)$is very apparent in the sorted average (38.1 a.u., $\mathrm{S} / \mathrm{N}>3)$, as is the $\mathrm{m} / \mathrm{z}+165$ peak $[\mathrm{DEEP}-\mathrm{H}]^{+}(28.1$ a.u., $\mathrm{S} / \mathrm{N}>7)$. This allows the DEEP vapors to be detected when silica is used as an adsorbent.

Analysis of DEEP vapor using alumina after exposure for 40 minutes yielded an average spectrum (500 particles, laser fluence of $3.50 \mathrm{~nJ} / \mu \mathrm{m}^{2}$ ) with a small peak at $\mathrm{m} / \mathrm{z}$ +166 that was greater than the alumina background signal at $\mathrm{m} / \mathrm{z}+166$. Upon sorting by this mass, the $\mathrm{m} / \mathrm{z}+166$ peak $[\mathrm{DMMP}]^{+}$was larger; however due to a slight background signal in unexposed alumina at the mass, this adsorbent was not pursued.

DEEP vapor was also analyzed using titanium and manganese powder. The metal powder was exposed to DEEP vapor for 120 minutes and 30 minutes, respectively. 500 
particles were analyzed for each sample with laser fluences of 3.92 and $4.00 \mathrm{~nJ} / \mu \mathrm{m}^{2}$. No difference was seen between the pure titanium and DEEP-exposed titanium mass spectra, or the pure manganese and DEEP-exposed manganese spectra. These methods of DEEP vapor analysis were not pursued further.

\subsubsection{Analysis of Vapor Phase DEPA}

Vapor phase DEPA was only studied using titanium powder as a support material due to time constraints. The titanium powder was exposed to the vapor-phase agent for 50 minutes using Method Two as previously described, and introduced to the SPAMS using a glass vial with modified plastic cap. 500 mass spectra were obtained with a laser fluence of $3.75 \mathrm{~nJ} / \mu^{2}$. The average mass spectrum of the DEPA-exposed particles did not show any significant signal over the background. However, when sorted by $\mathrm{m} / \mathrm{z}$ +176 , an average of the top 25 mass spectra showed peaks at m/z $-109\left[\right.$ DEPA- $\mathrm{C}_{2} \mathrm{H}_{5^{-}}$ $\left.\mathrm{CH}_{3}\right]^{-}$and $\mathrm{m} / \mathrm{z}+176[\mathrm{DEPA}+\mathrm{Na}]^{+}$which were not present in a similarly sorted background. An unidentified peak is also seen at $\mathrm{m} / \mathrm{z}+115$. These spectra are shown in Figure 4-8. 


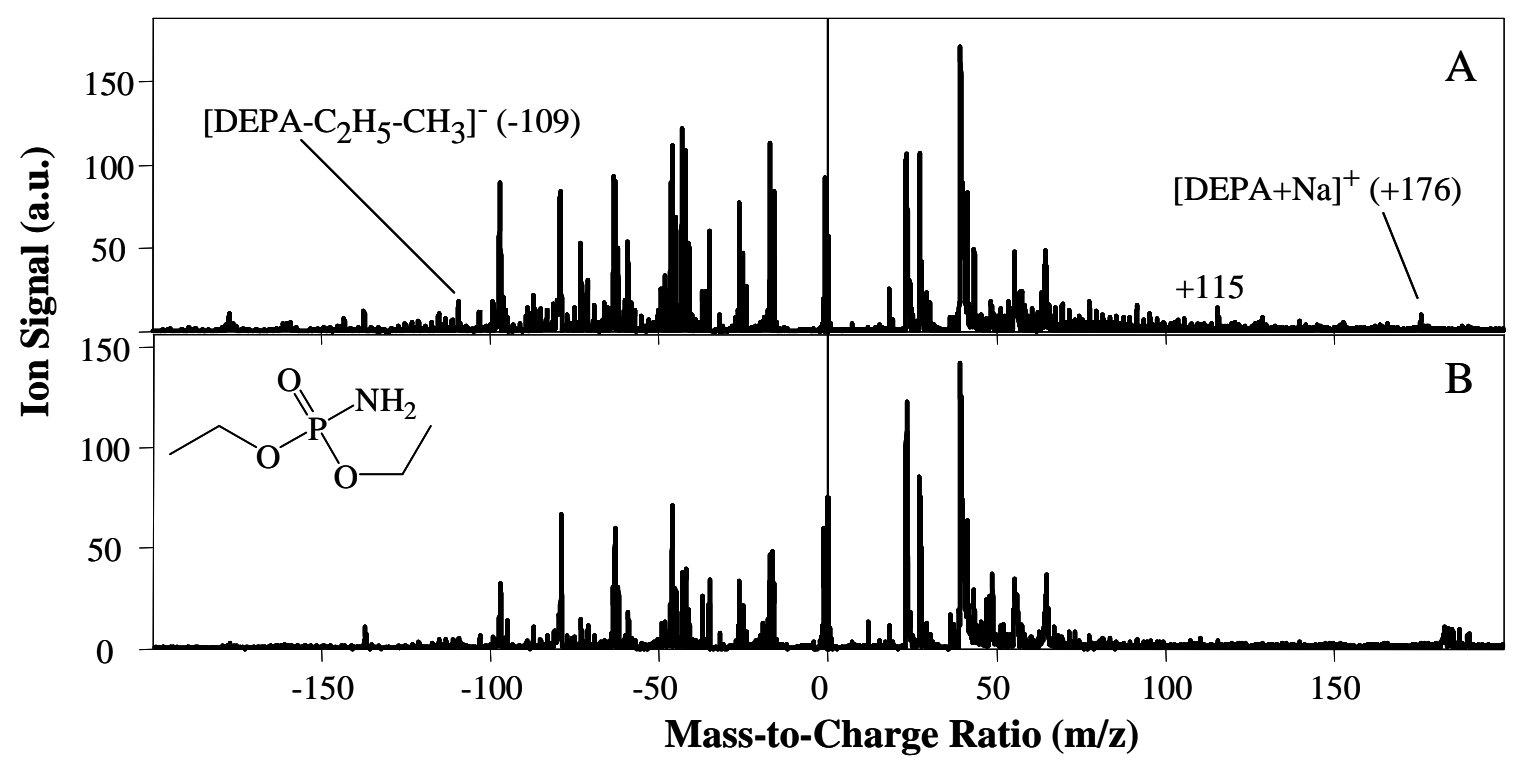

Figure 4-8: Single particle mass spectra of (A) DEPA-exposed titanium and (B) unexposed titanium at a laser fluence of $3.75 \mathrm{~nJ} / \mu^{2}$ (note differences in ion signal). Each spectrum is the average of the top 25 single particle spectra sorted by $\mathrm{m} / \mathrm{z}+176$ using computer software. The structure of DEPA is included as an inset in (B).

Although these peaks were not present in the overall average, the technique shows promise and should be further investigated for vapor-phase analysis.

\subsubsection{Analysis of Vapor Phase TEP}

Vapor phase TEP was studied as described in Method Two of Chapter Two using manganese powder. The manganese powder was exposed to TEP vapor for 40 minutes, and subsequently introduced into the SPAMS for analysis. 500 mass spectra were collected with a laser fluence of $3.67 \mathrm{~nJ} / \mu \mathrm{m}^{2}$. No significant difference was seen in the TEP-exposed manganese spectra. This method was therefore not pursued any further.

An additional method for sample introduction was investigated for the analysis of TEP. Since TEP was not capable of detection in the liquid phase, this method was 
developed to aid in transport of the particles. Method Three described in Chapter Two was used to analyze TEP using manganese powder. The liquid TEP and manganese powder were added directly to a plastic nebulizer and introduced to the SPAMS. 500 mass spectra were obtained with a laser fluence of $3.48 \mathrm{~nJ} / \mu \mathrm{m}^{2}$. The average spectra revealed peaks at m/z -153 and -94 , due to $\left[\text { TEP- } \mathrm{C}_{2} \mathrm{H}_{5}\right]^{-}$and $\left[\text {TEP- } 2\left(\mathrm{OC}_{2} \mathrm{H}_{5}\right)+2 \mathrm{H}\right]^{-}$, respectively, and an unknown peak at $\mathrm{m} / \mathrm{z}-113$. The average spectrum, and that of pure manganese, is shown in Figure 4-9.

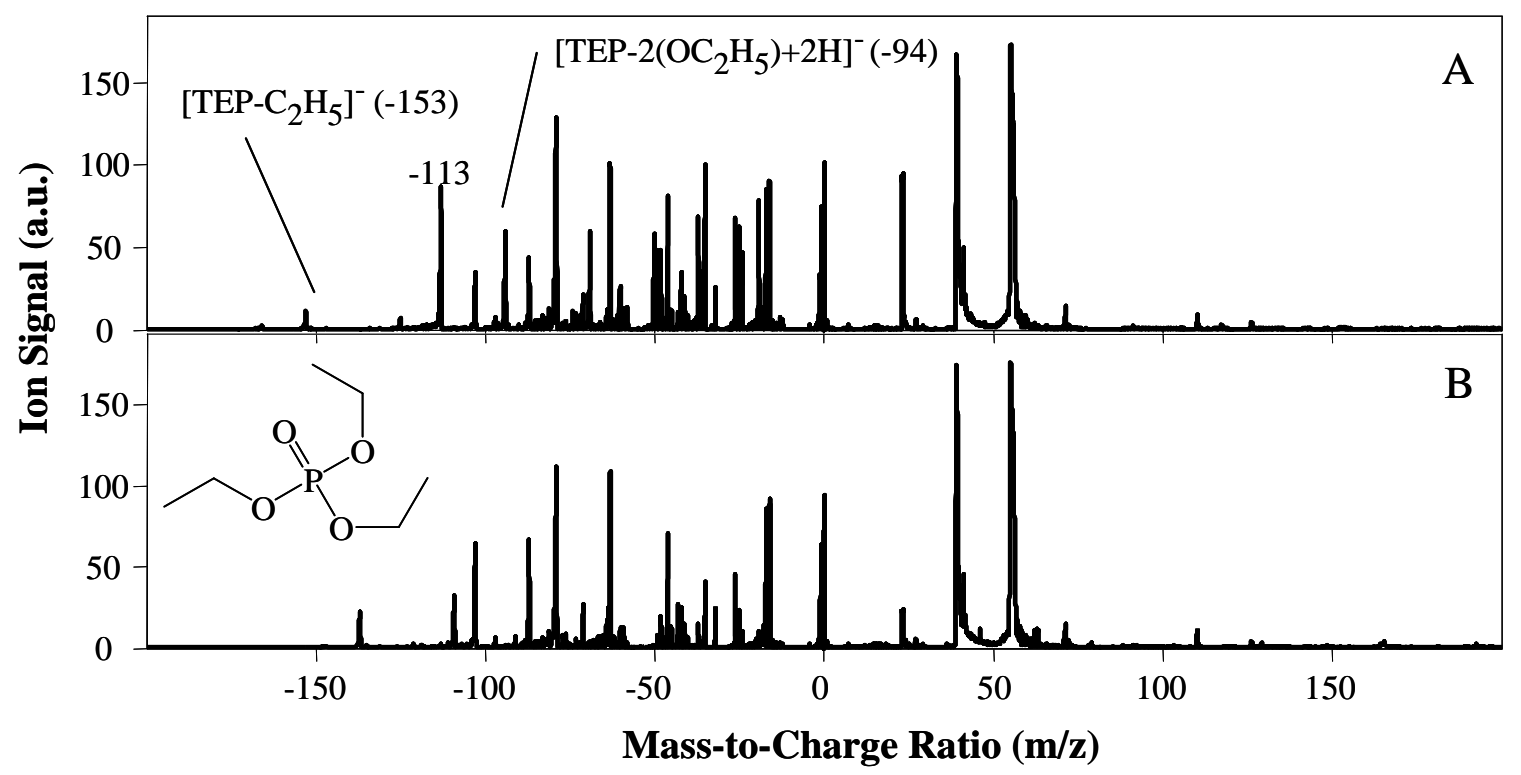

Figure 4-9: Single particle mass spectra of (A) TEP-exposed manganese and (B) unexposed manganese at a laser fluence of $3.48 \mathrm{~nJ} / \mu \mathrm{m}^{2}$. The structure of TEP is included as an inset in (B).

This result is significant because TEP could not be detected in the liquid phase; no particles were transported to the SPAMS. The use of the manganese powder as a support allowed TEP to be detected using the system. 
Tungsten powder was also tested for the adsorption of TEP vapors using Method Three. 500 mass spectra were obtained with a laser fluence of $3.46 \mathrm{~nJ} / \mu^{2}$ for the TEPexposed powder. The average spectra revealed peaks at $\mathrm{m} / \mathrm{z}-153,-125,-79$, and -63 , due to $\left.\left.\left[\mathrm{TEP}-\mathrm{C}_{2} \mathrm{H}_{5}\right]^{-}, \mathrm{TEP}^{-2}\left(\mathrm{C}_{2} \mathrm{H}_{5}\right)+\mathrm{H}\right]^{-}, \mathrm{P}(\mathrm{OH}) \mathrm{OCH}_{3}\right]^{-}$, and $\left[\mathrm{OC}_{2} \mathrm{H}_{5}+\mathrm{H}_{2} \mathrm{O}\right]^{-}$, respectively. Several smaller fragments were also present in the negative ion spectrum. A peak was seen at $\mathrm{m} / \mathrm{z}+182$, due to $[\mathrm{TEP}]^{+} ;^{56}$ although there was a peak at this mass in the background spectrum due to a tungsten isotope. The signal intensity of the peak in the TEP-exposed tungsten sample led to the conclusion that $[\mathrm{TEP}]^{+}$was present. Also, the isotopic distribution of tungsten in this mass range is extremely distorted in the TEPexposed sample as compared to the background, which also supports the contribution of TEP to this peak. The spectra were then sorted by $\mathrm{m} / \mathrm{z}+182$, and the average of the top 50 spectra of the TEP-exposed tungsten and the bare tungsten are shown in Figure 4-10. 


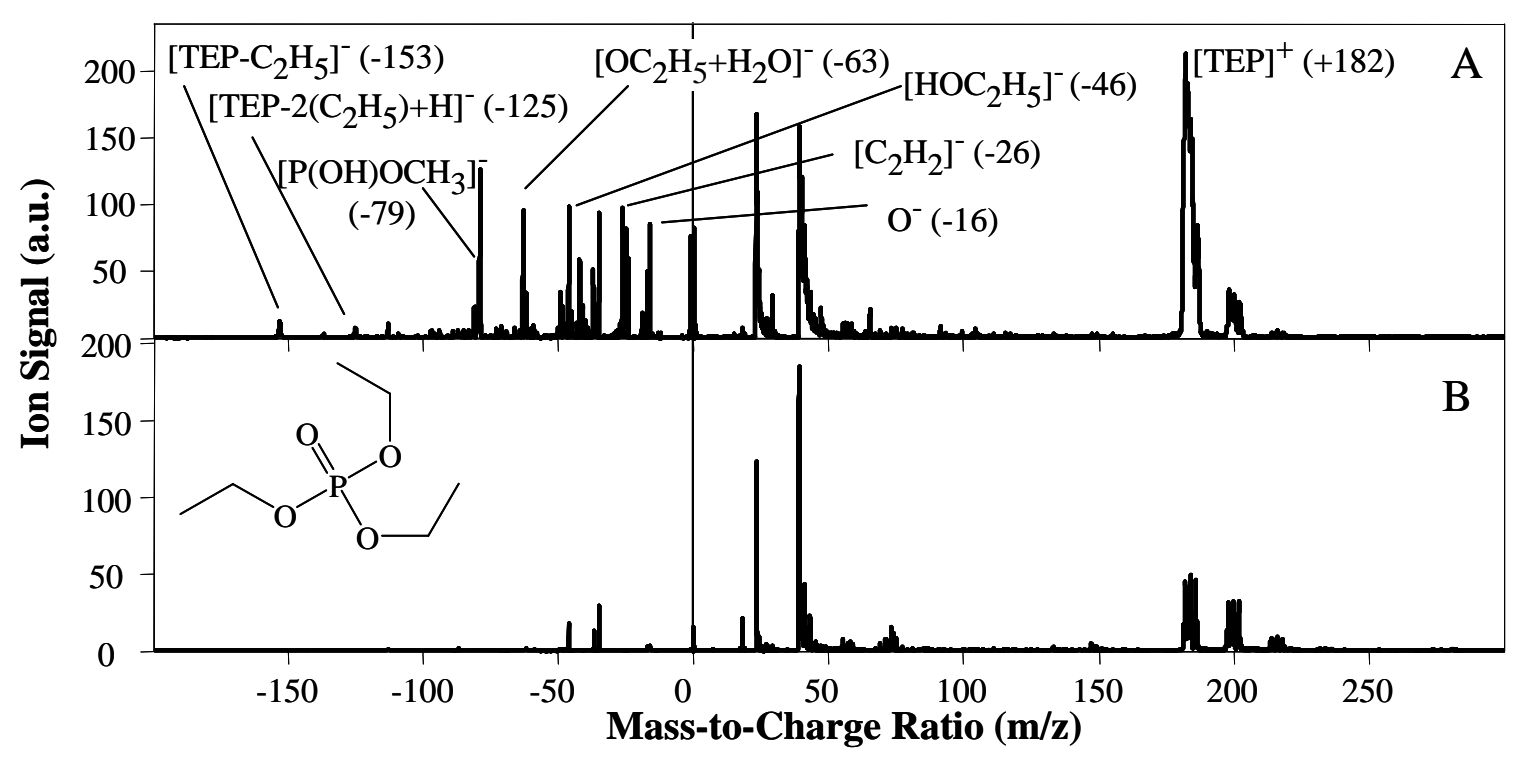

Figure 4-10: Single particle mass spectra of (A) TEP-exposed tungsten and (B) unexposed tungsten powder at a laser fluence of $3.46 \mathrm{~nJ} / \mu \mathrm{m}^{2}$. Each spectrum is the average of the top 50 single particle spectra sorted by $m / z+182$. The structure of TEP is included as an inset in (B).

The large increase in signal at $\mathrm{m} / \mathrm{z}+182$ in the presence of TEP makes tungsten an ideal solid support for TEP detection. The negative ion spectrum of tungsten contains very few peaks compared to that of manganese; many fragments of TEP can be clearly distinguished from the background in this area. The presence of the parent ion, in addition to the large number of identifiable fragments, allows the facile identification of TEP using tungsten.

\subsection{Summary}

CWA simulants were detected with the SPAMS system in both the liquid and vapor phases. Liquid samples of DMMP, DEEP, DEP, and DEPA were directly analyzed with various laser powers. DMMP, DEEP, and DEPA had several peaks in common due 
to their similar structures and thus similar fragmentation. Low laser fluences $(0.5-1 \mathrm{~nJ} /$ $\mu \mathrm{m}^{2}$ ) appeared to be the most useful for detecting the simulants. These laser energies allowed for fragments to be detected, as well as high mass ions such as dimers and adducts. TEP could not be analyzed as a liquid because of difficulties in transporting the particles to the SPAMS. The reason for this difficulty is unknown.

Vapor phase detection of CWA simulants was also investigated. Several solid supports were tested to determine the utility of the technique. Vapors of CWA simulants were adsorbed onto the solid particles, which were directly introduced to the SPAMS. DMMP was identified when adsorbed onto alumina by the presence of several fragment ions as well as a sodium adduct seen at m/z -147. However, DMMP analysis on tungsten powder seemed to be the most effective, where a significant signal from the parent ion was detected, allowing confirmation that DMMP was present. The most successful detection of DEEP using the solid supports was achieved using silica. Although the spectra had to be sorted based on a user-defined $\mathrm{m} / \mathrm{z}$, a contribution from the parent ion was seen. DEPA detection on titanium allow the identification of a sodium adduct at $\mathrm{m} / \mathrm{z}$ +176. Metals were also successful in aiding the analysis of TEP; the simulant could be transported to the instrument when a metal was present. Manganese and tungsten were both successful although tungsten was more promising due to the presence of the parent ion $(\mathrm{m} / \mathrm{z}+182)$. 


\section{Chapter 5: Conclusions and Future Work}

\subsection{Conclusions}

High explosives and CWAs present a threat to public safety, and are an analytical challenge in the terms of sampling and the need for fast analysis. The ideal detection system should be capable of detecting trace levels of the chemical threat from a safe distance (i.e. stand-off detection) and identifying the target compound quickly. SPAMS is capable of detecting single particles of target compounds; however, until now, the technique had never been specifically applied to the detection of high explosives and CWAs. In this study, the potential application of SPAMS to the detection of high explosives and CWA simulants was investigated.

The effect of laser fluence on the mass spectra of explosives obtained with SPAMS was investigated. At low laser fluence (approximately $0.6 \mathrm{~nJ} / \mu \mathrm{m}^{2}$ ), all explosives were detected and identified based on parent ions or adducts. At higher laser fluence, greater fragmentation was observed, which provides structural information, and can be used to confirm identifications. For screening applications, the instrument could be

operated at a low fluence such as $0.6 \mathrm{~nJ} / \mu \mathrm{m}^{2}$; if a target molecule was identified at this fluence, the laser fluence could then be tuned to a higher setting if further information on the explosive (e.g. fragmentation patterns) was desired.

Mass spectral data demonstrated in this work highlighted the specificity of SPAMS; parent ions of TNT (m/z -226) and PETN (m/z -317) were detected and, while no parent ion of RDX was detected, several adducts, such as $\left[\mathrm{RDX}+\mathrm{NO}_{3}\right]^{-}$, were seen which are characteristic of the explosive. The specificity of SPAMS was also highlighted in the detection of the individual explosive components in composite explosives: Comp B, 
Semtex 1A, and Semtex 1H. The ability of SPAMS to detect these explosives under the same operating conditions illustrates the broad application of the technique; three classes of explosives (nitroaromatics, nitramines, and nitrate esters) can be detected with one instrumental setting, both as neat compounds and in mixtures. The dual-polarity of the mass spectra obtained using SPAMS is also a significant advantage of the technique. It provides complementary sets of data from both the positive and negative ions generated from a single particle, maximizing the analytical capability of the instrument.

CWA detection was investigated to determine if SPAMS was capable of detecting CWAs in the liquid and vapor phases, as both forms of the agents are toxic. All of the CWA simulants were most easily identified at low laser fluences (approximately 0.6 $\mathrm{nJ} / \mu \mathrm{m}^{2}$ ) due to the presence of the parent ion or adducts. Similar to the explosives, higher laser fluences could then be used to obtain further fragmentation and hence, structural information of the simulant. DMMP, DEEP, and DEPA have similar organophosphate structures, and therefore shared some similar fragments and mass spectral peaks in the liquid phase analysis. However, identification of a particular compound was still possible due to the presence of characteristic ions. DEP was also successfully analyzed in the liquid phase with significant contribution from the protonated parent ion $(\mathrm{m} / \mathrm{z}+224)$ and high mass adducts. However, it was not possible to detect liquid TEP; particles were not efficiently transported into the SPAMS instrument and hence, mass spectra could not be collected. Vapor phase analysis of the CWAs was performed using several solid supports onto which the vapors were adsorbed, which were then analyzed. Successful detection of DMMP, DEEP, and DEPA was achieved using various materials. Alumina and silica powders allowed the detection of DMMP and 
DEEP vapor, respectively. Several metals were also successfully used for CWA simulant vapor detection: tungsten powder for DMMP and TEP, titanium for DEPA, and manganese for TEP. This is the first known use of the SPAMS for the detection of vapor-phase compounds.

A key highlight of this research was the discovery that TEP in the vapor phase could be detected by SPAMS using metal powders as the solid support. This is critical because the TEP was not detectable when aerosolized directly in the liquid phase. Significant peaks due to TEP were seen in the mass spectra, including the parent ion $(\mathrm{m} / \mathrm{z}$ $+182)$.

SPAMS is sensitive, specific, reliable, and reagent-free, and may provide a viable option for trace sample screening. The ability of the SPAMS system to determine the identity of a single particle is a valuable asset when the target analyte is dangerous in small quantities, or has no legal reason for being present in an environment. Since the presence of a particular compound can be identified from just one particle $(\sim 1 \mathrm{pg})$, SPAMS is an excellent system for differentiating target compounds from a background. The unique information in the spectra obtained from the compounds studied (e.g. parent ion and adduct peaks) demonstrates the high specificity of the technique as well as its application to a wide variety of compounds. Simultaneous acquisition of positive and negative ion spectra provides complementary information that is useful for spectral analysis. This work described a method of detecting biological, chemical, and explosive threats using one instrument with no modification, making it a prototype universal point detection system. 


\subsection{Future Work}

This work presented a new area of research that could be pursued. Several peaks in the mass spectra obtained remain unidentified. In the explosives study, some of these peaks are thought to be caused by the oils, plasticizers, or other additives present in the samples. In order to determine if this is the case, standards of common plasticizers or additives, such as di-n-octyl phthalate or butyl citrate, could be obtained, analyzed with the SPAMS, and the mass spectra compared with those of the explosive samples. Another possible source of the peaks could be due to contaminants present in the explosive samples themselves. The explosive sample could be purified and rerun on the SPAMS to determine if this was the case; however, since pure explosive compounds are not expected to be used in terrorist events, it is important to note that the explosive can still be identified even if contamination is present. Another possible experiment to identify the unknown peaks would be to perform MS/MS experiments on this ion. MS/MS capabilities are not currently possible using SPAMS and hence, a different mass analyzer, such as an ion trap or triple quadrupole, would be necessary. The MS/MS data obtained will show the further fragmentation of the selected ion, which may allow identification of the daughter ion. Similar experiments could be performed for the CWA simulants. The peak at m/z +117 in the mass spectra of DMMP, DEEP, and DEPA is an important peak to identify since it had a significant ion signal in all of the spectra. Since these compounds have similar structures, it is hypothesized that this peak is caused by a common fragment. This peak $\mathrm{m} / \mathrm{z}+117$ fragment could be isolated and fragmented to gain more information on its structure that would aid in its identification. 
The vapor analysis of the CWA simulants presented interesting preliminary results that should be further investigated. This study marks the first use of the SPAMS for the detection of vapor-phase compounds, so the preliminary success of the project should be exploited and expanded. Several support materials were tested; however, the specific explanation for why different supports allowed for the detection of different ions, parent and fragments, was not explored. Testing the amount of CWA simulant that is adsorbed onto each surface would provide information on the utility of each support in vapor analyses. Also, the way in which the presence of a solid support influences ionization should be investigated. The presence of the support can be likened to a simple form of matrix-assisted laser desorption ionization (MALDI), which would have implications beyond the analytes currently explored. Further experiments on the method in which the vapors are introduced to the solid supports would also be valuable. For an on-line detector, a simple method of vapor preconcentration and introduction would be necessary. Systems that could be tested include a chamber containing the support material through which a vapor analyte could be passed at a predetermined flow rate. The support material could then be introduced to the SPAMS after a set period of exposure. Alternatively, the vapor phase analyte could be created in a chamber and the solid support could be flowed through the chamber at a set rate and directly introduced to the SPAMS.

The ability of SPAMS to detect explosives and CWA simulants was demonstrated in this work. However, 'real-world' samples were not analyzed. The next step in making the SPAMS a viable detector for an end-user would be to analyze such samples. Sample introduction methods should be tested to ensure that the sampled particles are being 
transferred to the system. Cloth wipes similar to those used in IMS can be tested. Since the mass analyzer in SPAMS operates under vacuum there is low-level suction at the entrance to the instrument which could be used to pull particles off such a cloth. Shoes and clothing could also be tested to determine if particles transferred to this objects could be analyzed. 


\section{REFERENCES}

(1) Yinon, J.; Zitrin, S. Modern Methods and Applications in Analysis of Explosives; John Wiley \& Sons Ltd.: New York, 1993.

(2) Central Forensic Science Laboratory, Ministry of Home Affairs, Government of India, 2004.

(3) Hoffman, B. In U.S. Army War College Fifth Annual Strategy Conference; The Strategic Studies Institute: Carlisle Barracks, PA, 1994.

(4) Containing the Threat from Illegal Bombings: An Integrated National Strategy for Marking, Tagging, Rendering Inert, and Licensing Explosives and Their Precursors; The National Academies Press: Washington, D.C., 1998.

(5) Institute of Makers of Explosives: Washington, D.C., 2006.

(6) Opportunities to Improve Airport Passenger Screening with Mass Spectrometry; The National Academies Press: Washington, D.C., 2004.

(7) Existing and Potential Standoff Explosives Detection Techniques; The National Academies Press: Washington, D.C., 2004.

(8) Liu, H. B.; Chen, Y.; Bastiaans, G. J.; Zhang, X. C. Optics Express 2006, 14, 415423.

(9) Carter, J. C.; Angel, S. M.; Lawrence-Snyder, M.; Scaffidi, J.; Whipple, R. E.; Reynolds, J. G. Applied Spectroscopy 2005, 59, 769-775.

(10) Garroway, A. N.; Buess, M. L.; Yesinowski, J. P.; Miller, J. B.; Krauss, R. A., San Diego, CA, USA 1994; SPIE; 139-149.

(11) Anferov, V. P.; Mozjoukhine, G. V.; Fisher, R. Review of Scientific Instruments 2000, 71, 1656-1659.

(12) Moore, D. S. Review of Scientific Instruments 2004, 75, 2499-2512. 
(13) Bjella, K. L.; U.S. Army Engineer Research and Development Center: Hanover, 2005.

(14) Oehrle, S. A. Journal of Chromatography A 1996, 745, 233-237.

(15) Bailey, C. G.; Yan, C. Anal. Chem. 1998, 70, 3275-3279.

(16) Bailey, C. G.; Wallenborg, S. R. Electrophoresis 2000, 21, 3081-3087.

(17) Wallenborg, S. R.; Bailey, C. G. Anal. Chem. 2000, 72, 1872-1878.

(18) Anderson, G. P.; Moreira, S. C.; Charles, P. T.; Medintz, I. L.; Goldman, E. R.; Zeinali, M.; Taitt, C. R. Anal. Chem. 2006, 78, 2279-2285.

(19) Buryakov, I. A. Journal of Chromatography B 2004, 800, 75-82.

(20) Ewing, R. G.; Miller, C. J. Field Analytical Chemistry \& Technology 2001, 5, 215-221.

(21) Eiceman, G. A.; Stone, J. A. Analytical Chemistry 2004, ’, 391A-397A.

(22) Ewing, R. G.; Atkinson, D. A.; Eiceman, G. A.; Ewing, G. J. Talanta 2001, 54, 515-529.

(23) Tam, M.; Hill, H. H. Anal. Chem. 2004, 76, 2741-2747.

(24) Syage, J. A.; Hanold, K. A.; Hanning-Lee, M. A., Indian Wells, CA 2001; 1-8.

(25) Evans, C. S.; Sleeman, R.; Luke, J.; Keely, B. J. Rapid Communications in Mass Spectrometry 2002, 16, 1883-1891.

(26) Zhang, M.; Shi, Z.; Bai, Y.; Gao, Y.; Hu, R.; Zhao, F. Journal of the American Society for Mass Spectrometry 2006, 17, 189-193.

(27) Holmgren, E.; Carlsson, H.; Goede, P.; Crescenzi, C. Journal of Chromatography A 2005, 1099, 127-135. 
(28) Mullen, C.; Irwin, A.; Pond, B. V.; Huestis, D. L.; Coggiola, M. J.; Oser, H. Anal. Chem. 2006, 78, 3807-3814.

(29) Takats, Z.; Cotte-Rodriguez, I.; Talaty, N.; Chen, H.; Cooks, R. G. Chemical Communications 2005, 1950-1952.

(30) Perr, J. M.; Furton, K. G.; Almirall, J. R. Talanta 2005, 67, 430-436.

(31) Cotte-Rodriguez, I.; Takats, Z.; Talaty, N.; Chen, H.; Cooks, R. G. Anal. Chem. 2005, 77, 6755-6764.

(32) Cody, R. B.; Laramee, J. A.; Durst, H. D. Anal. Chem. 2005, 77, 2297-2302.

(33) Hankin, S. M.; Tasker, A. D.; Robson, L.; Ledingham, K. W. D.; Fang, X.; McKenna, P.; McCanny, T.; Singhal, R. P.; Kosmidis, C.; Tzallas, P.; Jaroszynski, D. A.; Jones, D. R.; Issac, R. C.; Jamison, S. Rapid Communications in Mass Spectrometry 2002, 16, 111-116.

Expray Explosive Detection Kit: http://www.plexsci.com/magnoliaPublic/index/products/kits/explosionkits/ex.htm 1 .

(35) All Clear; General Electric: http://www.ge.com/stories/en/20349.html, April 25, 2005.

IONSCAN@ SENTINEL II; Smiths Detection: http://trace.smithsdetection.com/products/Default.asp?Product=24, 2002.

(37) Wood, M.; Laloup, M.; Samyn, N.; del Mar Ramirez Fernandez, M.; de Bruijn, E. A.; Maes, R. A. A.; De Boeck, G. Journal of Chromatography A 2006, 1130, 3-15.

(38) Colorado, A.; Varian, Inc., 2004, pp 1-3.

(39) Gillen, G.; Mahoney, C.; Wight, S.; Lareau, R. Rapid Communications in Mass Spectrometry 2006, 20, 1949-1953.

(40) Convention on the Prohibition of the Development, Production, Stockpiling and Uuse of Chemical Weapons and their Destruction; Organisation for the 
Prohibition of Chemical Weapons, 2005: available at http://www.opcw.org/docs/cwc_eng.pdf.

(41) In NATO Handbook on the Medical Aspects of NBC Defensive Operations: AMedP-6(B); U.S. Department of Defense, Department of the Army, 1996.

(42) In Medical Management of Chemical Casualties Handbook, second ed.; Chemical Casualty Care Office: Aberdeen, MD, 1995.

(43) Newmark, J. Archives of Neurology 2004, 61, 649-652.

(44) Keyes, D. C.; Benitez, F. L.; Velez-Daubon, L. I. In University of Nebraska Continuing Medical Education, 2006.

(45) Augerson, W.; RAND Corporation: Washington, D.C., 2000.

(46) McGill, R. A.; Nguyen, V. K.; Chung, R.; Shaffer, R. E.; DiLella, D.; Stepnowski, J. L.; Mlsna, T. E.; Venezky, D. L.; Dominguez, D. Sensors and Actuators B: Chemical 2000, 65, 10-13.

(47) Laljer, C. E. MITRE Technical Paper 2000, 1-9.

(48) Naval Forces' Defense Capabilities Against Chemical and Biological Warfare Threats; The National Academies Press: Washinton, D.C., 2004.

(49) Seto, Y.; Kanamori-Kataoka, M.; Tsuge, K.; Ohsawa, I.; Matsushita, K.; Sekiguchi, H.; Itoi, T.; Iura, K.; Sano, Y.; Yamashiro, S. Sensors and Actuators B: Chemical 2005, 108, 193-197.

(50) Hill Jr., H. H.; Martin, S. J. Pure Applied Chemistry 2002, 74, 2281-2291.

(51) Mulchandani, A.; Mulchandani, P.; Chen, W.; Wang, J.; Chen, L. Anal. Chem. 1999, 71, 2246-2249.

(52) Mulchandani, P.; Chen, W.; Mulchandani, A. Environ. Sci. Technol. 2001, 35, 2562-2565. 
(53) Hooijschuur, E. W. J. Trends in Analytical Chemistry 2002, 21, 116-130.

(54) Hapsite Smart Chemical Identification System; Inficon: East Syracuse, 2004.

(55) Sekiguchi, H.; Matsushita, K.; Yamashiro, S.; Sano, Y.; Seto, Y.; Okuda, T.; Sato, A. Forensic Toxicology 2006, 24, 17-22.

(56) D'Agostino, P. A.; Hancock, J. R.; Chenier, C. L.; Lepage, C. R. J. Journal of Chromatography A 2006, 1110, 86-94.

(57) Steiner, W. E.; Clowers, B. H.; Matz, L. M.; Siems, W. F.; Hill Jr., H. H. Analytical Chemistry 2002, 74, 4343-4352.

(58) Steiner, W. E.; Clowers, B. H.; Haigh, P. E.; Hill Jr., H. H. Analytical Chemistry 2003, 75, 6068-6076.

(59) Steiner, W. E.; Klopsch, S. J.; English, W. A.; Clowers, B. H.; Hill Jr., H. H. Analytical Chemistry 2005, 77, 4792-4799.

(60) Noble, C. A.; Prather, K. A. Mass Spectrometry Reviews 2000, 19, 248-274.

(61) Davis, W. D. Environ. Sci. Technol. 1977, 11, 587-592.

(62) Sinha, M. P. Review of Scientific Instruments 1984, 55, 886-891.

(63) Gard, E.; Mayer, J. E.; Morrical, B. D.; Dienes, T.; Fergenson, D. P.; Prather, K. A. Anal. Chem. 1997, 69, 4083-4091.

(64) Steele, P. T.; Srivastava, A.; Pitesky, M. E.; Fergenson, D. P.; Tobias, H. J.; Gard, E. E.; Frank, M. Anal. Chem. 2005, 77, 7448-7454.

(65) Srivastava, A.; Pitesky, M. E.; Steele, P. T.; Tobias, H. J.; Fergenson, D. P.; Horn, J. M.; Russell, S. C.; Czerwieniec, G. A.; Lebrilla, C. B.; Gard, E. E.; Frank, M. Anal. Chem. 2005, 77, 3315-3323.

(66) Fergenson, D. P.; Pitesky, M. E.; Tobias, H. J.; Steele, P. T.; Czerwieniec, G. A.; Russell, S. C.; Lebrilla, C. B.; Horn, J. M.; Coffee, K. R.; Srivastava, A.; Pillai, S. 
P.; Shih, M.-T. P.; Hall, H. L.; Ramponi, A. J.; Chang, J. T.; Langlois, R. G.; Estacio, P. L.; Hadley, R. T.; Frank, M.; Gard, E. E. Anal. Chem. 2004, 76, 373378.

(67) Steele, P. T.; Tobias, H. J.; Fergenson, D. P.; Pitesky, M. E.; Horn, J. M.; Czerwieniec, G. A.; Russell, S. C.; Lebrilla, C. B.; Gard, E. E.; Frank, M. Anal. Chem. 2003, 75, 5480-5487.

(68) Czerwieniec, G. A.; Russell, S. C.; Tobias, H. J.; Pitesky, M. E.; Fergenson, D. P.; Steele, P.; Srivastava, A.; Horn, J. M.; Frank, M.; Gard, E. E.; Lebrilla, C. B. Anal. Chem. 2005, 77, 1081-1087.

(69) Tobias, H. J.; Pitesky, M. E.; Fergenson, D. P.; Steele, P. T.; Horn, J.; Frank, M.; Gard, E. E. Journal of Microbiological Methods 2006, In Press, Corrected Proof.

(70) Tobias, H. J.; Schafer, M. P.; Pitesky, M.; Fergenson, D. P.; Horn, J.; Frank, M.; Gard, E. E. Applied and Environmental Microbiology 2005, 71, 6086-6095.

(71) Russell, S. C.; Czerwieniec, G.; Lebrilla, C.; Steele, P.; Riot, V.; Coffee, K.; Frank, M.; Gard, E. E. Anal. Chem. 2005, 77, 4734-4741.

(72) May, K. R. Aerosol Science 1973, 4, 235-243.

(73) Collison Nebulizers; BGI Inc.: http://www.bgiusa.com/agc/collison.htm.

(74) Dockery, D. W.; Pope III, C. A. Annual Review of Public Health 1994, 15, 107132.

(75) de Hoffman, E.; Stroobant, V. Mass Spectrometry: Principles and Applications; John Wiley \& Sons, Ltd.: New York, 2002.

(76) Wiley, W. C.; McLaren, I. H. Review of Scientific Instruments 1955, 26, 11501157.

(77) Casetta, B.; Garofolo, F. Organic Mass Spectrometry 1994, 29, 517-525.

(78) Eiceman, G. A.; Krylov, E. V.; Krylova, N. S.; Nazarov, E. G.; Miller, R. A. Anal. Chem. 2004, 76, 4937-4944. 
(79) Hakansson, K.; Coorey, R. V.; Zubarev, R. A.; Talrose, V. L.; Hakansson, P. Journal of Mass Spectrometry 2000, 35, 337-346.

(80) Makas, A. L.; Troshkov, M. L.; Kudryavtsev, A. S.; Lunin, V. M. Journal of Chromatography B 2004, 800, 63-67.

(81) Marshall, A.; Clark, A.; Ledingham, K. W. D.; Sander, J.; Singhal, R. P.; Kosmidis, C.; Deas, R. M. Rapid Communications in Mass Spectrometry 1994, 8, 521-526.

(82) McLuckey, S. A.; Goeringer, D. E.; Asano, K. G.; Vaidyanathan, G.; Stephenson Jr., J. L. Rapid Communications in Mass Spectrometry 1996, 10, 287-298.

(83) Ostmark, H.; Bergman, H.; Ekvall, K. Journal of Analytical and Applied Pyrolysis 1992, 24, 163-178.

(84) Engelke, R.; Blais, N. C.; Sheffield, S. A.; Sander, R. K. J. Phys. Chem. A 2001, 105, 6955-6964.

(85) Mulligan, C. C.; Justes, D. R.; Noll, R. J.; Sanders, N. L.; Laughlin, B. C.; Cooks, R. G. The Analyst 2006, 131, 556-567.

(86) Tornes, J. A. Rapid Communications in Mass Spectrometry 1996, 10, 878-882.

(87) Spangler, G. E.; Vora, K. N.; Carrico, J. P. Journal of Physics E: Scientific Instruments 1986, 19, 191-198.

(88) Widmann, J. F.; Heusmann, C. M.; Davis, E. J. Colloid \& Polymer Science 1998, 276, 197-205.

(89) Material Safety Data Sheet: Dimethyl Methylphosphonate; Sigma-Aldrich: St. Louis, MO, 2006.

(90) Material Safety Data Sheet: Triethyl Phosphate; Sigma-Aldrich: St. Louis, MO, 2006.

(91) Material Safety Data Sheet: Diethyl Ethylphosphonate; Sigma-Aldrich: St. Louis, MO, 2006. 
(92) Material Safety Data Sheet: Diethyl Phthalate; Sigma-Aldrich: St. Louis, MO, 2006. 